\title{
Autoantibodies in disorders of the brain
}

Citation for published version (APA):

Zong, S. (2019). Autoantibodies in disorders of the brain: expanding the spectrum. [Doctoral Thesis, Maastricht University]. Maastricht University. https://doi.org/10.26481/dis.20191106sz

Document status and date:

Published: 06/11/2019

DOI:

$10.26481 /$ dis.20191106sz

Document Version:

Publisher's PDF, also known as Version of record

\section{Please check the document version of this publication:}

- A submitted manuscript is the version of the article upon submission and before peer-review. There can be important differences between the submitted version and the official published version of record.

People interested in the research are advised to contact the author for the final version of the publication, or visit the DOI to the publisher's website.

- The final author version and the galley proof are versions of the publication after peer review.

- The final published version features the final layout of the paper including the volume, issue and page numbers.

Link to publication

\footnotetext{
General rights rights.

- You may freely distribute the URL identifying the publication in the public portal. please follow below link for the End User Agreement:

www.umlib.nl/taverne-license

Take down policy

If you believe that this document breaches copyright please contact us at:

repository@maastrichtuniversity.nl

providing details and we will investigate your claim.
}

Copyright and moral rights for the publications made accessible in the public portal are retained by the authors and/or other copyright owners and it is a condition of accessing publications that users recognise and abide by the legal requirements associated with these

- Users may download and print one copy of any publication from the public portal for the purpose of private study or research.

- You may not further distribute the material or use it for any profit-making activity or commercial gain

If the publication is distributed under the terms of Article $25 \mathrm{fa}$ of the Dutch Copyright Act, indicated by the "Taverne" license above, 
Autoantibodies in disorders of the brain:

expanding the spectrum 
(C) Shenghua Zong, Maastricht 2019

All rights are reserved. For the chapters published, the copyright has been transferred to the respective publisher. No parts of this thesis maybe be reproduced, stored in a retrieval system or transmitted in any form or by any means, without prior permission from the author.

Cover design: Shenghua Zong and Ilse Modder

Printed by: Gildeprint, Enschede

ISBN: 978-94-6323-935-6 


\title{
Autoantibodies in disorders of the brain: expanding the spectrum
}

\author{
Dissertation \\ to obtain the degree of Doctor at the Maastrich University, \\ on the authority of the Rector Magnificus \\ Prof.dr. Rianne M. Letschert \\ in accordance with the decision of the Board of Deans,
}

to be defended in public on Wednesday $6^{\text {th }}$ of November 2019 at 12.00 hours

by

Shenghua Zong

宗盛华 


\section{Supervisors}

Prof. dr. P. Martinez

\section{Co-supervisor}

Dr. M. Losen

Dr. R. P.W. Rouhl

\section{Assessment Committee}

Prof. dr. K.R.J. Schruers (Chairman)

Dr. G. Kenis

Dr. S. Sobczak

Prof. dr. K. Vonck (4Brain Institute for Neuroscience, Ghent University Hospital)

Prof. dr. M. De Hert (Universitair Psychiatrisch Centrum KU Leuven) 


\section{Contents}

\section{Chapter 1}

General introduction

1

\section{Chapter 2}

Autoantibodies in neuropsychiatric disorders

\section{Chapter 3}

Neuronal surface autoantibodies in neuropsychiatric disorders: are there implications for depression?

\section{Chapter 4}

Novel neuronal surface autoantibodies in plasma of patients with depression and anxiety

\section{Chapter 5}

Low prevalence of autoantibodies related to neuronal and rheumatic autoimmune disease in sera of patients with psychotic disorders

\section{Chapter 6}

Autoantibodies to glutamic acid decarboxylase 65 (GAD65) and other neuronal antigens in a cohort suspected of GAD-related disorders: comparison of diagnostic methods and suggestions for clinical practice

\section{Chapter 7}

General discussion

\section{Appendix I}

Valorization (in biography).

\section{Appendix II}

Acknowledgements.

\section{Appendix III}

List of Publications

\section{Appendix IV}

Curriculum Vitae

\section{Appendix V}

Thesis defenses from MHeNS 



\section{Chapter 1}

General introduction 
Brain, as part of the central nervous system (CNS), is once thought to be an immune-privileged organ, which is now known to be incorrect. Actually, current evidence indicates a tight relation between the immune system and the brain [1]. This is not only supported by the fact that immune cells of the CNS have been found contributing to the maintenance of the normal neurogenesis but also the immune system can attack the brain and cause so-called autoimmune brain diseases, including autoimmune encephalitis, autoimmune-related epilepsy, CNS vasculitis, and neuromyelitis optica, etc $[2,3]$. The spectrum of autoimmune brain diseases is still growing nowadays. Although not all the exact pathogenic mechanisms in these diseases are clearly understood, autoantibodies to neuronal cell surface antigens are believed to be pathogenic in many cases.

\section{The spectrum of neuronal autoantibodies}

Autoantibodies to neuronal cells in the central nervous system (CNS) can be divided into two groups according to the location of their targeting antigens: 1) autoantibodies to intracellular neuronal proteins, such as $\mathrm{Hu}, \mathrm{Yo}, \mathrm{Ri}$ and 2) autoantibodies to neuronal surface proteins (NSAbs) [4]. The first group of autoantibodies are also known as classic paraneoplastic antibodies which are not pathogenic themselves but associated with a variety of neurological manifestations, occurring as a result of an underlying tumor, usually breast or lung cancer. While in the second group, autoantibodies are believed to play a pathogenic role in the associated neurological disorders with or without tumor. This research is rapidly expanding with new autoantibodies identified annually $[4,5]$. These NSAbs target neurotransmitter receptors, ion channels or associated proteins on the membrane of neuronal cells and most of their pathogenic effects have been demonstrated (the first reported time is indicated), including metabotropic glutamate receptor 1 (mGluR1) (2000) [6], N-Methyl-D-aspartate receptor (NMDAR) (2007) [5], $\alpha$-amino-3-hydroxy-5-methyl-4-isoxazolepropionic acid receptor (AMPAR) (2010) [7, 8], leucine-rich, glioma inactivated 1 (LGI1) and contactin-associated protein-like 2 (Caspr2) (2010) [9], GABAB receptor (GABABR) (2010) [10], metabotropic glutamate receptor 5 (mGluR5) (2011) [11], dipeptidyl aminopeptidase-like protein 6 (DPPX) (2013) [12-14], GABAA receptor (GABAAR) (2014) [15-17]. Besides, certain autoantibodies targeting intracellular antigens such as autoantibodies to glutamic acid decarboxylase (GADAbs) are usually not associated with tumors and their pathogenicity is questioned [18]. Nevertheless, these autoantibodies are associated with various neurological disorders including limbic encephalitis, neuromyotonia, Morvan's syndrome, epilepsy as well as a subgroup of first-episode psychosis [19-22]. Different autoantibodies may relate to distinct clinical syndromes and confer a broad clinical spectrum. Currently, our knowledge in this is still growing and it coincides with an increased interest in screening for NSAbs in psychiatric disorders.

\section{Neuronal autoantibodies and psychiatric disorders}

The etiology of psychiatric disorders is heterogeneous and still poorly understood. A set of biological changes and risk factors have been identified for the different diagnoses and immune dysregulation is one of them. The basic evidence is based on that psychiatric disorders occur more often amongst people suffering from autoimmune diseases than in healthy individuals $[23,24]$. It is not clear whether patients with autoimmune diseases have more mental complaints due to somatic discomforts or the dysregulated immune system directly targets the brain and causes mental disturbances. To study the latter situation, many researchers have 
focused on inflammation and cytokines. A few studies also show that certain autoantibodies targeting intracellular antigens, such as anti-nuclear antibodies, anti-ribosomal P proteins, and anti-thyroid peroxidase, are associated with psychiatric symptoms in systemic autoimmune disorders [25-27]. However, those autoantibodies to intracellular antigens are normally considered as an indication of immune dysregulation and have not been proved to play a causative role in the disease.

Another biological change shared among different neuropsychiatric disorders is the alteration of synaptic transmission or dysfunction of ion-channels, including hypofunction of NMDAR, dopamine receptor or voltage-gated potassium channel, are. In the past decades, studies have shown that those proteins are actually the target of the immune system in neurological disorders with psychiatric symptoms. Here anti-NMDAR encephalitis is used as a paradigm to show this connection between NSAbs and psychiatric disorders. In 2007, anti-NMDAR autoantibodies were initially detected in a group of patients with an ovarium teratoma with psychiatric symptoms followed by neurological manifestations including seizures, movement disorder, and dysfunction of the autonomous nervous system [5]. Thereafter, it has become clinical practice to investigate if patients might have NMDAR encephalitis in a subgroup of psychotic patients [28]. The concept that NSAbs can cause psychotic symptoms is based on the fact that two-thirds of anti-NMDAR encephalitis patients present initially with psychiatric manifestations before presenting with neurological complains and in 5\% of these cases, isolated psychotic episodes occur without simultaneous neurologic involvement [29, 30]. This is not surprising since the NMDAR is crucial for glutamate signaling, and the hypo-function of the system has been previously linked to schizophrenia [31]. To date, most NSAbs target receptors that play important roles in neural signal transduction. All in all, this leads to the hypothesis that a subgroup of patients with neuronal autoantibodies can present with only isolated psychiatric symptoms and thus mimic schizophrenia or psychosis (Figure 1) [32, 33]. Furthermore, the same hypothesis could also be applied to other psychiatric disorders, including mood disorders (bipolar, depression and anxiety), autism spectrum disorders, obsessive-compulsive disorders, and attention-deficit/hyperactivity disorders, which have not been well studied yet [34].

\section{Pitfalls of neuronal autoantibody detection}

Several studies have focused on the prevalence of neuronal autoantibodies in schizophrenia or first-episode psychosis with controversial results [35-39]. The main finding is that antiNMDAR autoantibodies are more common only in patients with first-episode psychosis, yet the exact prevalence is not consistent $[37,40]$. Three main points might have contributed to the different results in those studies: 1) differences in the biological fluid analyzed, serum or cerebrospinal fluid (CSF); 2) differences in the screening methods used: cell-based assay (CBA), rat brain tissue-based immunohistochemistry (IHC) and staining on live neurons. 3) The dilution of the tested sample ranged from 1 in 20 to 1 in 320.

Immunohistochemistry (IHC) was used in early studies to identify autoantibodies that gave neuropil staining on rat brain tissue [41, 42]. Then staining on live neurons was performed at the same time to confirm that those autoantibodies targeted membrane proteins. Later when the exact antigens were identified, CBA using fixed and permeabilized human embryonic kidney cells with transfected antigens were developed, which has become the standard detection method in the clinic. However, CBA only detects autoantibodies to known antigens 


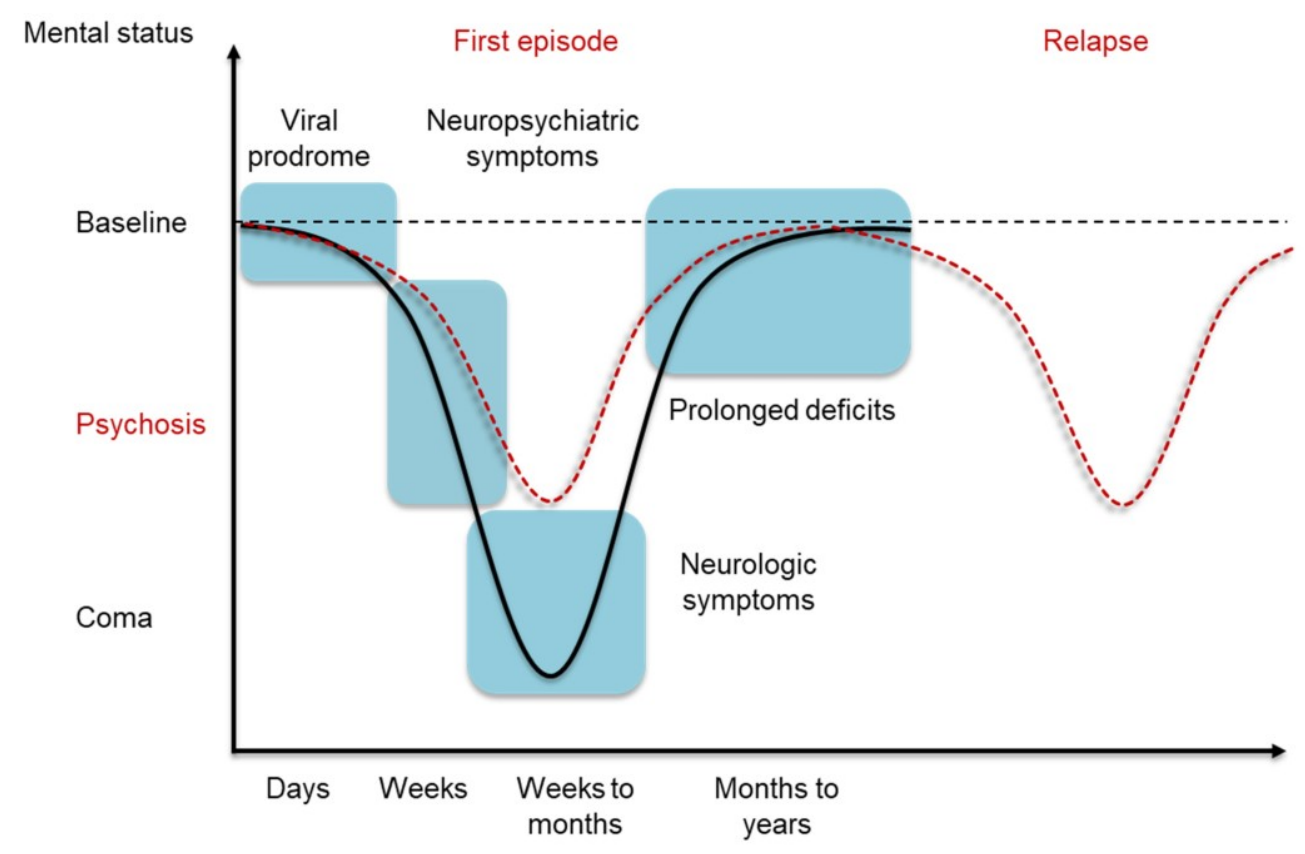

Figure 1. The typical clinical course of illness in NMDAR encephalitis (black trend line) and a hypothesis of autoimmune psychosis (red trend line). The clinical course of NMDAR encephalitis often starts with viral-like symptoms including lethargy, headache, upper respiratory symptoms, nausea, diarrhea, muscle pain, and fever. This stage can last several days. Then more severe psychotic symptoms will develop such as anxiety, paranoia (similar to first-episode psychosis), and short-term memory loss. Later, severe physical and behavioral changes take place including seizures, movement abnormalities, and hyperventilation. It takes time to return to their baseline function, with cognitive deficits and behavioral changes lasting from months to years. In a few cases, isolated psychotic symptoms without movement abnormalities have been reported. Even if in some cases the symptoms relapse, they might be misdiagnosed as psychotic disorders such as schizophrenia.

that are included in the assay. The fixation and permeabilization steps may also lead to falsenegative or false-positive results, as conformational surface antigens might be destroyed or modified, and some intracellular antigens would be exposed. In some laboratories, live CBA is used where the patient sample is incubated on transfected HEK cells before fixation to avoid conformational changes and to improve sensitivity. Due to the lack of a systematic comparison between IHC, live and fixed CBA in practice, it is not easy to interpret results from different laboratories when different methods were used. Our previous study showed that the exclusive use of a single method may yield clinically irrelevant, false-positive results, especially in highthroughput screening with low prior probability [43], which is the case in patients with psychiatric disorders.

Thus, in the investigation I conducted in neuropsychiatric disorders, I made use of multimethods including IHC, live and fixed CBA and staining on live neurons to better cover a broader range of known autoantibodies as well as lead the discovery of novel neuronal autoantibodies. 


\section{Aims and outline of this thesis:}

In this thesis, the aim is to summarize the current knowledge of autoantibodies in neuropsychiatric disorders, to search for known and novel pathogenic neuronal autoantibodies in a broader range of neuropsychiatric disorders, and to compare different neuronal autoantibodies detection methods.

Chapter 2 reviews evidence in the recent literature for the role of NSAbs as well as related systemic autoantibodies in five neuropsychiatric disorders. It evaluates the techniques used, discusses how results can be interpreted and identifies the research gaps.

Chapter3 reviews the recent evidence for the occurrence of NSAbs in mood disorders with a special focus on depression. It discusses how those NSAbs could potentially be related to neuropsychiatric disorders with a special focus on their putative pathogenic role in depression.

Chapter 4 assesses the prevalence of NSAbs in the plasma of patients with depression or anxiety by using IHC, CBA and staining on live neurons to analyze if they are more common in patients compared to controls. This is a large cohort-control study including 1739 depression or anxiety patients and 492 non-mental disorder controls.

Chapter 5 investigates the prevalence of neuronal and bystander autoantibodies in the sera of psychotic disorders. It is a large case-control study including 621 patients with psychotic disorders, 70 individuals with affective disorders, 41 with other mental disorders and 257 controls.

Chapter 6 compares different methods (ELISA, CBA, and IHC) for the detection of GADAbs. It is also investigated if other NSAbs rather than GAD-Abs are present in patients with suspected autoimmune brain diseases.

Chapter 7 summarizes the key findings of this thesis, discusses the limitations and outlines further research directions.

\section{References}

1. Carson, M.J., et al., CNS immune privilege: hiding in plain sight. Immunological reviews, 2006. 213: p. 48-65.

2. Ziv, Y., et al., Immune cells contribute to the maintenance of neurogenesis and spatial learning abilities in adulthood. Nature Neuroscience, 2006. 9(2): p. 268-275.

3. Lancaster, E. and J. Dalmau, Neuronal autoantigens-pathogenesis, associated disorders and antibody testing. Nature Reviews Neurology, 2012. 8: p. 380.

4. Dalmau;J. and M.R. Rosenfeld;. Overview of paraneoplastic syndromes of the nervous system. 2018 May 02, 2018 [cited 2019 20-05]; Available from: https://www.uptodate.com/contents/overview-of-paraneoplastic-syndromes-of-thenervous-system.

5. Dalmau, J., et al., Paraneoplastic anti-N-methyl-D-aspartate receptor encephalitis associated with ovarian teratoma. Annals of neurology, 2007. 61(1): p. 25-36.

6. Smitt, P.S., et al., Paraneoplastic Cerebellar Ataxia Due to Autoantibodies against a Glutamate Receptor. New England Journal of Medicine, 2000. 342(1): p. 21-27.

7. Bataller, L., et al., Reversible paraneoplastic limbic encephalitis associated with antibodies to the AMPA receptor. Neurology, 2010. 74(3): p. 265-267. 
8. Lai, M., et al., AMPA receptor antibodies in limbic encephalitis alter synaptic receptor location. Annals of neurology, 2009. 65(4): p. 424-434.

9. Irani, S.R., et al., Antibodies to Kv1 potassium channel-complex proteins leucine-rich, glioma inactivated 1 protein and contactin-associated protein-2 in limbic encephalitis, Morvan's syndrome and acquired neuromyotonia. Brain, 2010. 133(9): p. 2734-2748.

10. Lancaster, E., et al., Antibodies to the $G A B A(B)$ receptor in limbic encephalitis with seizures: case series and characterisation of the antigen. Lancet neurology, 2010. 9(1): p. 67-76.

11. Lancaster, E., et al., Antibodies to metabotropic glutamate receptor 5 in the Ophelia syndrome. Neurology, 2011. 77(18): p. 1698-1701.

12. Boronat, A., et al., Encephalitis and antibodies to DPPX, a subunit of Kv4.2 potassium channels. Annals of neurology, 2013. 73(1): p. 120-128.

13. Balint, B., et al., Progressive encephalomyelitis with rigidity and myoclonus $A$ new variant with DPPX antibodies. Neurology, 2014. 82(17): p. 1521-1528.

14. Tobin, W.O., et al., DPPX potassium channel antibody: Frequency, clinical accompaniments, and outcomes in 20 patients. Neurology, 2014. 83(20): p. 1797-1803.

15. Petit-Pedrol, M., et al., Encephalitis with refractory seizures, status epilepticus, and antibodies to the $G A B A(A)$ receptor: a case series, characterisation of the antigen, and analysis of the effects of antibodies. The Lancet. Neurology, 2014. 13(3): p. 276-286.

16. Ohkawa, T., et al., Identification and Characterization of GABA\&/t;sub\&gt;A\&/t;/sub\&gt; Receptor Autoantibodies in Autoimmune Encephalitis. The Journal of Neuroscience, 2014. 34(24): p. 8151.

17. Pettingill, P., et al., Antibodies to GABAA receptor $\alpha 1$ and $\gamma 2$ subunits Clinical and serologic characterization. Neurology, 2015. 84(12): p. 1233-1241.

18. Manto, M., H. Mitoma, and C.S. Hampe, Anti-GAD Antibodies and the Cerebellum: Where Do We Stand? The Cerebellum, 2018.

19. Vincent, A., et al., Autoantibodies associated with diseases of the CNS: new developments and future challenges. The Lancet Neurology, 2011. 10(8): p. 759-772.

20. Lennox, B.R., et al., Prevalence and clinical characteristics of serum neuronal cell surface antibodies in first-episode psychosis: a case-control study. The Lancet Psychiatry, 2016.

21. Pollak, T.A., et al., Prevalence of anti-N-methyl-d-aspartate (NMDA) receptor antibodies in patients with schizophrenia and related psychoses: a systematic review and meta-analysis. Psychological Medicine, 2014. 44(12): p. 2475-2487.

22. Dalmau, J., C. Geis, and F. Graus, Autoantibodies to Synaptic Receptors and Neuronal Cell Surface Proteins in Autoimmune Diseases of the Central Nervous System. Physiological reviews, 2017. 97(2): p. 839-887.

23. Chen, P., et al., Depression, another autoimmune disease from the view of autoantibodies. Med Hypotheses, 2009. 73(4): p. 508-9.

24. Shoenfeld, Y., To smell autoimmunity: Anti-P-ribosomal autoantibodies, depression, and the olfactory system. Journal of Autoimmunity, 2007. 28(2-3): p. 165-169.

25. Hirohata, S., et al., Association of cerebrospinal fluid anti-ribosomal p protein antibodies with diffuse psychiatric/neuropsychological syndromes in systemic lupus erythematosus. Arthritis Res Ther, 2007. 9(3): p. R44.

26. Arinuma, Y., T. Yanagida, and S. Hirohata, Association of cerebrospinal fluid anti-NR2 glutamate receptor antibodies with diffuse neuropsychiatric systemic lupus erythematosus. Arthritis \& Rheumatism, 2008. 58(4): p. 1130-1135. 
27. Englbrecht, M., J. Wendler, and R. Alten, Depressivität und Rheuma. Zeitschrift für Rheumatologie, 2014. 73(8): p. 714-720.

28. Kayser, M.S. and J. Dalmau, Anti-NMDA receptor encephalitis, autoimmunity, and psychosis. Schizophrenia research, 2016. 176(1): p. 36-40.

29. Herken, J. and H. Prüss, Red Flags: Clinical Signs for Identifying Autoimmune Encephalitis in Psychiatric Patients. Frontiers in psychiatry, 2017. 8: p. 25-25.

30. Kayser, M.S., et al., Frequency and Characteristics of Isolated Psychiatric Episodes in Anti-NMethyl-d-Aspartate Receptor EncephalitisPsychiatric Episodes in Anti-NMDAR EncephalitisPsychiatric Episodes in Anti-NMDAR Encephalitis. JAMA Neurology, 2013. 70(9): p. 1133-1139.

31. Lisman, J.E., et al., Circuit-based framework for understanding neurotransmitter and risk gene interactions in schizophrenia. Trends in neurosciences, 2008. 31(5): p. 234-242.

32. Masdeu, J.C., J. Dalmau, and K.F. Berman, NMDA Receptor Internalization by Autoantibodies: A Reversible Mechanism Underlying Psychosis? Trends in Neurosciences, 2016. 39(5): p. $300-$ 310.

33. Coutinho, E., P. Harrison, and A. Vincent, Do Neuronal Autoantibodies Cause Psychosis? A Neuroimmunological Perspective. Biological Psychiatry, 2014. 75(4): p. 269-275.

34. Hoffmann, C., et al., Autoantibodies in Neuropsychiatric Disorders. Antibodies, 2016. 5(2): p. 9.

35. Zandi, M.S., et al., Disease-relevant autoantibodies in first episode schizophrenia. Journal of Neurology, 2011. 258(4): p. 686-688.

36. Pathmanandavel, K., et al., Antibodies to Surface Dopamine-2 Receptor and N-Methyl-DAspartate Receptor in the First Episode of Acute Psychosis in Children. Biological Psychiatry, 2015. 77(6): p. 537-547.

37. Lennox, B.R., et al., Prevalence and clinical characteristics of serum neuronal cell surface antibodies in first-episode psychosis: a case-control study. The Lancet Psychiatry, 2017. 4(1): p. $42-48$.

38. Leypoldt, F., et al., Serum neuronal cell-surface antibodies in first-episode psychosis. The Lancet Psychiatry, 2017. 4(3): p. 186-187.

39. Hammer, C., et al., Neuropsychiatric disease relevance of circulating anti-NMDA receptor autoantibodies depends on blood-brain barrier integrity. Molecular Psychiatry, 2013. 19: p. 1143.

40. Pollak, T.A., et al., Prevalence of anti-N-methyl-d-aspartate (NMDA) receptor antibodies in patients with schizophrenia and related psychoses: a systematic review and meta-analysis. Psychological Medicine, 2013. 44(12): p. 2475-2487.

41. Vitaliani, R., et al., Paraneoplastic encephalitis, psychiatric symptoms, and hypoventilation in ovarian teratoma. Annals of neurology, 2005. 58(4): p. 594-604.

42. Ances, B.M., et al., Treatment-responsive limbic encephalitis identified by neuropil antibodies: MRI and PET correlates. Brain : a journal of neurology, 2005. 128(Pt 8): p. 1764-1777.

43. de Witte, L.D., et al., Absence of N-Methyl-D-Aspartate Receptor IgG Autoantibodies in Schizophrenia: The Importance of Cross-Validation StudiesN-Methyl-D-Aspartate Receptor IgG Autoantibodies in SchizophreniaLetters. JAMA Psychiatry, 2015. 72(7): p. 731-733. 


\section{Chapter 2}

\section{Autoantibodies in neuropsychiatric disorders}

\section{Corresponding publication:}

Carolin Hoffmann, Shenghua Zong*, Marina Mané-Damas*, Peter Molenaar, Mario Losen and Pilar Martinez-Martinez. Antibodies. 2016; 5(2).

* authors contributed equally to this manuscript. 


\begin{abstract}
:
Little is known about the etiology of neuropsychiatric disorders. The identification of autoantibodies targeting the $N$-methyl-D-aspartate receptor (NMDA-R), which causes neurological and psychiatric symptoms, has reinvigorated the hypothesis that other patient subgroups may also suffer from an underlying autoimmune condition. In recent years, a wide range of neuropsychiatric diseases and autoantibodies targeting ion-channels or neuronal receptors including NMDA-R, voltage-gated potassium channel complex (VGKC complex), $\alpha$-amino-3-hydroxy-5-methyl-4-isoxazolepropionic acid receptor (AMPA-R), $\gamma$-aminobutyric acid receptor (GABA-R) and dopamine receptor (DR) were studied and conflicting reports have been published regarding the seroprevalence of these autoantibodies. A clear causative role of autoantibodies on psychiatric symptoms has as yet only been shown for the NMDA-R. Several other autoantibodies have been related to the presence of certain symptoms and antibody effector mechanisms have been proposed. However, extensive clinical studies with large multicenter efforts to standardize diagnostic procedures for autoimmune etiology and animal studies are needed to confirm the pathogenicity of these autoantibodies. In this review, we discuss the current knowledge of neuronal autoantibodies in the major neuropsychiatric disorders: psychotic, major depression, autism spectrum, obsessive-compulsive and attentiondeficit/hyperactivity disorders.
\end{abstract}




\section{Introduction}

Schizophrenia, major depressive disorder (MDD), and bipolar disorder (BD) were classically seen as psychiatric disorders or mental illness, which classifies a disturbance of the "mind". This classification developed within the paradigm of dualism in which mind and body are separated [1]. As such, psychiatric disorders were distinguished from the neurological diseases which have a demonstrable pathology. With today's understanding of both fields, the distinction is only based on symptomatology because both classifications have detectable biological causes. Due to these developments in psychiatry, the subspecialty of neuropsychiatry is growing. Accordingly, in neuropsychiatric disorders, both psychiatric symptoms (affecting emotions, thoughts, and behaviors) and neurological symptoms (movement disorders, epileptic seizures, and cognitive impairment) can be identified. The occurrence of one of these symptoms does not necessarily yet leads to the diagnosis of a certain psychiatric or neurological disease; an isolated epileptic attack is not epilepsy and an isolated psychotic episode is not schizophrenia. Only when symptoms are persisting over a certain time, this diagnosis will be made. Notwithstanding that the knowledge of biological psychiatry is advancing, the diagnosis of these syndromes is still based on behavioral phenotypes following the classification from the Diagnostic and Statistical Manual of Mental Disorders (DSM, currently version 5) and the International Statistical Classification of Diseases and Related Health Problems (ICD, currently version 10). These diagnoses are still not trivial because the rating of psychiatric symptoms is challenging (although important efforts have been made to objectivize the diagnosis [2]) and many neuropsychiatric disorders have overlapping symptoms. Consequently, classification guidelines keep changing during the years.

The etiology of neuropsychiatric disorders is very diverse and still poorly understood but a set of biological changes and risk factors have been identified for the different diagnoses. Some of these disease mechanisms are overlapping between different neuropsychiatric disorders, with the major biological changes being the alteration of synaptic transmission, including hypofunction of dopamine receptor (DR) and $N$-methyl-D-aspartate receptor (NMDA-R) and, also, dysfunction of the voltage-gated potassium channel (VGKC) [3-5]. Inflammation is associated with neuropsychiatric etiology, probably caused by infections or autoimmune diseases. In recent years, the discovery of certain autoantibodies targeting the central nervous system (CNS) such as $\alpha$-amino-3-hydroxy-5-methyl-4-isoxazolepropionic acid receptor (AMPA-R), $\gamma$-aminobutyric acid (GABA-R), and the metabotropic glutamate receptors (mGluR) could be an important breakthrough in neuropsychiatry. Autoantibodies targeting mainly neuronal membrane proteins have now been revealed to potentially alter memory, behavior, and cognition or cause psychosis, seizures, and abnormal movements [6,7]. These autoimmune encephalopathies also have an implication in psychiatry as some of these autoantibodies (such as anti-NMDA-R) are seen in patients with psychotic symptoms that have not previously been considered to have an autoimmune origin [8]. Thus, psychotic disorders and autoimmune encephalitis have overlapping symptoms. During the last years, effort has been made to better understand the autoimmune mechanisms that can induce neuropsychiatric disorders. Here we review antibody-mediated autoimmunity against neuronal (membrane) proteins in five major neuropsychiatric disorders: psychotic, major depressive (MDD), autism spectrum (ASD), obsessive-compulsive (OCD) and attention-deficit/hyperactivity (ADHD) disorder. Table 1 summarizes the characteristics, prevalence, and etiology of these disorders. 


\section{Indications for Autoimmune Mechanisms in Neuropsychiatric Disorders}

Table 1. Description of the characteristics, prevalence, and etiology of mental disorders.

\begin{tabular}{|c|c|c|c|}
\hline Disorder & Characteristics & Prevalence & Etiology \\
\hline Psychotic disorders & $\begin{array}{l}\text { Delusions, hallucinations, disorganized } \\
\text { speech and behavior, and other } \\
\text { symptoms. Social or occupational } \\
\text { dysfunction. }\end{array}$ & $\begin{array}{l}\text { Estimates of the } \\
\text { prevalence vary greatly. } \\
\text { The median European } \\
\text { prevalence is } \sim 5.3 \% \text {, with } \\
\text { an interquartile range of } \\
1.9 \%-14.4 \% \text { [9]. }\end{array}$ & $\begin{array}{l}\text { Environmental } \\
\text { and genetic } \\
\text { factors; about } \\
80 \% \text { of } \\
\text { heritability [10- } \\
\text { 13]. }\end{array}$ \\
\hline $\begin{array}{l}\text { Major depressive disorder } \\
\text { (MDD) }\end{array}$ & $\begin{array}{l}\text { Feelings of persistent sadness and } \\
\text { anhedonia that affect thoughts and } \\
\text { behavior. Leading to physical problems. } \\
\text { A major cause of morbidity worldwide } \\
\text { [14]. }\end{array}$ & $\begin{array}{l}\text { Prevalence is up to } 15 \% \text { of } \\
\text { the population. }\end{array}$ & $\begin{array}{l}\text { Environmental } \\
\text { and genetic } \\
\text { factors; possibly } \\
\text { autoantibody } \\
\text { involvement [15- } \\
\text { 19]. }\end{array}$ \\
\hline $\begin{array}{l}\text { Autism spectrum disorder } \\
\text { (ASD) }\end{array}$ & $\begin{array}{l}\text { Social communication deficit, restricted } \\
\text { interest, repetitive behaviors with high } \\
\text { sensitivity to changes in the } \\
\text { environment. } \\
\text { Difficulty to establish human affective } \\
\text { and interpersonal relationships [20]. }\end{array}$ & $\begin{array}{l}\text { Prevalence of } 1.47 \% \text { in } \\
2010 \text { [21], increased over } \\
\text { time, males being } 5 \text { times } \\
\text { more affected than } \\
\text { females [22]. }\end{array}$ & $\begin{array}{l}\text { Environmental } \\
\text { and genetic } \\
\text { factors; } \sim 90 \% \\
\text { heritability [23]. }\end{array}$ \\
\hline $\begin{array}{l}\text { Attention-deficit/hyperactivity } \\
\text { disorder (ADHD) }\end{array}$ & $\begin{array}{l}\text { Inattention, hyperactivity, and } \\
\text { impulsivity like excessive talking, } \\
\text { fidgeting, or an inability to remain seated } \\
\text { in appropriate situations. Incapability to } \\
\text { focus and organize tasks and activities. }\end{array}$ & $\begin{array}{l}\text { Most prevalent chronic } \\
\text { neurodevelopmental } \\
\text { disorder in school-age } \\
\text { children, affecting } 2-18 \% \\
{[24,25] \text { and being more }} \\
\text { frequent in males than in } \\
\text { females. }\end{array}$ & $\begin{array}{l}\text { Strong genetic } \\
\text { link as well as } \\
\text { environmental } \\
\text { factors [25]; } \\
\text { heritability } 76 \% \\
\text { [26]; post- } \\
\text { infectious } \\
\text { autoimmunity } \\
\text { [27]. }\end{array}$ \\
\hline $\begin{array}{l}\text { Obsessive-Compulsive } \\
\text { disorder (OCD) }\end{array}$ & $\begin{array}{l}\text { Anxiety, recurrent unwanted thoughts } \\
\text { (obsessions) and repetitive behaviors } \\
\text { (compulsions). }\end{array}$ & $\begin{array}{l}\text { Affects } 1 \%-3 \% \text { of the } \\
\text { worldwide population } \\
{[28-30] .}\end{array}$ & $\begin{array}{l}\text { Genetic and } \\
\text { environmental } \\
\text { factors } \\
\text { heritability of } \\
\sim 50 \% \text { in children } \\
{[32]} \\
\text { infectious } \\
\text { autoimmunity } \\
{[33,34] .}\end{array}$ \\
\hline
\end{tabular}

Genetic studies of large sample sizes have revealed several gene variants that increase the risk of neuropsychiatric disorders, including genes encoding for neurotransmitter receptors and ion channels. In the Psychiatric Genomics Consortium, single nucleotide polymorphisms (SNPs) in two L-type voltage-gated calcium channel subunits, voltage-gated calcium channel subunit alpha1 $\mathrm{C}$ (CACNA1C) and calcium voltage-gated channel auxiliary subunit beta2 (CACNB2), 
were identified as common risk factor among all studied diagnosis including ASD, ADHD, BD, MDD and schizophrenia [35].

In addition, variants from the human leukocyte antigen (HLA) region (major histocompatibility complex; MHC molecules) which are involved in antigen presentation have not only been associated with the risk of developing autoimmune diseases, but also with the risk of developing several neuropsychiatric disorders. A C4B null allele, a deficient form of the HLA C4B gene (no C4B protein produced), was reported to be more frequent in ASD, ADHD, and dyslexia [12]. Another locus called the HLA DRB1 was implicated in schizophrenia and ASD as well as autoimmunity [36,37]. Taken together these findings suggest that neuroinflammation and autoimmunity may play a role in neuropsychiatric disorders [13].

Autoantibodies in neuropsychiatric disorders cause mainly a loss rather than a changed pattern of channel activity, possibly associated with neuroinflammation and neurodegeneration [3840]. To demonstrate autoimmune pathogenicity according to Witebsky's postulates, four conditions have to be met: (1) the autoantibody must be present with the clinical manifestation and detectable in the blood and/or affected tissue; (2) autoantibodies should target a receptor, ion channel, or other protein expressed on the membrane surface; (3) antibody transfer can replicate the disease in an animal experimental model or in humans (maternal transfer); and (4) elimination or suppression of the autoimmune response by therapy can prevent disease progression or improves the clinical manifestations.

\section{Ion Channels and Receptor Functions}

Autoantibodies in neuropsychiatric disorders commonly target neuronal ion channels or associated proteins. For an in-depth understanding of how autoantibodies against these molecules cause disease, it is necessary to comprehend the functions of neuronal ion channels and receptors, which largely determine the inter-neuronal communication and properties of neurons. These channels are facilitating the depolarization, hyperpolarization and also repolarization of neurons and thus are essential to the signal transmission and functioning of the brain [41]. The basis of the transmission of electric currents is the membrane potential, which is the difference in electrical charge between the inside and outside of neurons. This difference is produced by ion pumps that create high extracellular $\mathrm{Na}^{+}, \mathrm{Cl}^{-}$and $\mathrm{Ca}^{2+}$ concentrations and high $\mathrm{K}^{+}$inside of the neuron. During an action potential, depolarization induces a rapid influx of $\mathrm{Na}^{+}$followed by a slightly slower opening of $\mathrm{K}^{+}$channels that induce repolarization and thereby enable a relatively fast subsequent activation of the neuron. Within the nervous system, different neurons possess a unique mixture of a wide variety of ion channels, which characterize their electrophysiological properties. The different types of synapses are largely defined by the neurotransmitter that is used for signal transduction, which are acetylcholine (ACh), noradrenaline (NA), dopamine, glutamate (Glu), serotonin (5HT), $\gamma$ aminobutyric acid (GABA, inhibitory), glycine (Gly, inhibitory), nitric oxide and a series of peptide neurotransmitters including endorphin.

Neurotransmitters can activate these receptors by either inducing a direct opening of an ion channel (ionotropic receptor) or altering the concentration of intracellular metabolites via GTP binding proteins (metabotropic receptors). Due to their mode of action, ionotropic receptors, such as the NMDA-R, promote rapid signal transduction and are responsible for the majority of neuronal communication in the CNS and peripheral nervous system (PNS). On the other hand, metabotropic receptors, including the metabotropic Glu receptors (mGluRs) and the D2 
dopamine receptor (D2DR), act via second messengers and therefore have a slower effect but also a longer duration of action and can lead to long-term changes such as synaptogenesis.

Conceptually, it makes sense that binding of autoantibodies to these receptors which have the potency to interfere with the action of these fundamental signaling processes can induce severe neurological and psychiatric symptoms. This is further supported by the fact that substances with an inhibitory effect on neurotransmitter receptors, such as ketamine, acting on NMDA-R or lysergic acid diethylamide on 5HT receptors (5HT-R) are potent hallucinogens.

\section{The Role of Blood-Brain Barrier Integrity on Autoantibody Effects}

Despite tight immune surveillance of the CNS, antibodies cross in low numbers through the blood-brain barrier (BBB). Once they reach the cerebrospinal fluid (CSF), the turn-over is about four times per day. This dynamic equilibrium results in immunoglobulin $\mathrm{G}$ ( $\mathrm{IgG}$ ) levels in the brain that amount to about $1 \%$ of the plasma levels, and in about $10 \%$ of the total protein in the CSF $[38,42,43]$. In autoimmune encephalitis, it is known that several autoantibodies cross the BBB and can be detected in the CSF. However, the mechanism of how antibodies cross to the CSF is not very well understood. The permeability of the BBB is altered upon damage and inflammation of the brain. Additionally, an impaired function of apolipoprotein $\mathrm{E}$ (ApoE) has been shown to reduce the barrier function of tight junctions [44]. This knowledge was used to study whether an impaired $\mathrm{BBB}$ would change the effect of peripherally administered human NMDA-R antibodies in a mouse model. Hammer et al. claim that only in ApoE knock out mice but not in wild type mice, human NMDA-R antibodies cause psychosisrelated behavioral perturbation [45]. The same study also relates the effects of the autoantibodies to the patients' history of birth complications or neurotrauma indicating possible BBB insufficiency. This hypothesis is further supported by the findings that an increased prevalence of psychiatric comorbidity in diseases is associated with BBB dysfunction, including systemic lupus erythematosus (SLE) [46-48], stroke [49-52], epilepsy $[53,54]$ and autoimmune encephalitis $[45,55]$. An increased albumin ratio in CSF to serum in patients with MDD and schizophrenia further suggests increased BBB permeability [56]. On the other hand, circulating $\mathrm{B}$ cells cross the BBB during normal immune surveillance [57] which might include antibody-producing cells. CD138+ plasma cells were found in postmortem and biopsy tissue of NMDA-R encephalitis patients [58]. Intrathecal antibody production was also described in Sydenham chorea (SC) patients with anti-lysoganglioside GM1-specific IgG [56] and in a case with autoantibodies against the GluN1 subunit (also known as NR1) of the NMDA-R where the patient did not respond to plasmapheresis treatment, while plasma antibody levels dropped but CSF levels remained high [59]. Some groups report that in patients with encephalitis autoantibodies against NMDA-R, AMPA-R, metabotropic or B class of the GABA-R (GABAB-R), dipeptidyl-peptidase-like protein-6 (DPPX), mGluR1 or mGluR5 can always be found in the CSF whereas other autoantibodies, such as autoantibodies to leucine-rich glioma inactivated-1 (LGI1), to contactin associated protein-2 (CASPR2), to glycine receptor (GlyR) and to the ionotropic or A class of the GABA-R (GABAA-R) may, in rare instances, be identified only in serum [7]. If no autoantibodies can be detected in the CSF, it is unclear how they can have central effects and thus if they are pathogenic. However, if the autoantibodies are present but immuno-absorbed by the antigen in the brain, they might not be detectable in the CSF [60]. 
In addition, $\mathrm{T}$ cells might have a role in BBB integrity and thus antibody penetration. Recently, Dileepan and colleagues described that T-helper 17 cells activation caused by group A Streptococcus infection disrupt the integrity of the BBB, and facilitate circulating autoantibodies to enter the brain [61].

\section{Transfer of Autoantibodies via the Placenta}

Transfer of maternal IgG antibodies to the fetus is a protective mechanism during the period in which the infant has an undeveloped humoral immune response [62]. IgG antibodies are the only Ig isotype that crosses the placenta and they do so via neonatal Fc receptors (FcRn) on syncytiotrophoblast cells. The amount of IgGs passing to the fetus is altered dependent on e.g. maternal levels of specific antibodies, the period of gestation, placental integrity, and type of antigen. If the mother has IgG autoantibodies in the blood, these will also be transferred to the neonate where they can induce pathogenic effects. Additionally, it has been seen in a rat model that in the fetus, the IgG penetration to the brain is higher than in the adult [63], indicating that these autoantibodies might reach and bind neuronal receptors in the fetus. Such an example is autoantibodies targeting the acetylcholine receptor (AChR) located at the neuromuscular junction (NMJ) which is composed of five subunits. Receptors are either of the embryonic form, composed of $\alpha 1, \beta 1, \gamma$ and $\delta$ subunits, or of the adult form composed of $\alpha 1, \beta 1, \delta$ and $\varepsilon$ subunits. Mothers carrying autoantibodies specifically against the gamma subunit (AChR $\gamma)$ are frequently asymptomatic [64,65]. Maternal antibodies of this sort can impair skeletal muscle development and cause fixed joint contractures and other deformities called arthrogryposis multiplex congenita. In other neurodevelopmental disorders such as autism [66-68] and dyslexia [69], a role of maternal autoantibodies has been suggested (see the section on ASD later). In SLE, a pathogenic transfer of maternal antibodies has been described [70] and maternal antibodies have been hypothesized to cause long-term cognitive changes since children born to mothers with SLE display a high incidence of learning disorders [71-73]. In a mouse model with high maternal autoantibody levels targeting double-stranded DNA (dsDNA) and cross-reacting with GluN2a/2b subunits of NMDA-R, cognitive impairments in adult offspring have been detected due to histological abnormalities in the fetal brain [74]. Taken together, these studies suggest that in utero exposure to neurotoxic/inflammatory autoantibodies generates developmental abnormalities with long-term consequences. In some cases, the effects of neonatal autoantibody exposure might only present later in life and potentially only with certain environmental exposures which make it very difficult to study these disease mechanisms. In case that the presence of maternal autoantibodies can be detected, these complications are treatable during pregnancy with intravenous IgG (IVIg) that competes with the endogenous autoantibodies, saturate FcRn and increase IgG turnover [75].

\section{Autoantibody Effector Mechanisms}

Autoimmune diseases are induced by complex immune dysfunctions of T-cells, B-cells, and other immune cells, but can be simply classified as T-cell or antibody-mediated. It is still largely unknown which mechanisms are involved in autoimmune neuropsychiatric disorders; however, most studies point towards an antibody-mediated pathology. We will, therefore, focus here on the IgG antibody-mediated disease mechanisms, which can be summarized as follows:

(a) Complement deposition and inflammation is a common mechanism in autoimmune diseases. The complement system is part of the innate immune system and can be activated by 
antibody-antigen complexes, which leads to the activation of complement proteins amplifying its effector mechanisms [39,76]. Effects of complement are (i) opsonization and engulfment by phagocytes with receptors for complement; (ii) chemo-attraction and activation of phagocytes and (iii) formation of the so-called membrane attack complex in cell membranes leading to lysis, extensive tissue damage and loss of tissue architecture, including receptors and ion channels.

For example, complement activation is important in Rasmussen's encephalitis, where autoantibodies anti-GluR3 subunit of the AMPA-R have been detected [77]. Peripherally, antiAChR autoantibodies (of IgG1 and IgG3 isotype) from myasthenia gravis (MG) patients $[78,79]$ activate the classical complement pathway. This causes complement deposition in the NMJ, where the antigen is located, resulting in morphological damage and loss of the AChR in the postsynaptic membrane [39].

(b) Stimulation or inhibition of receptor function can be induced upon binding of the autoantibody without further activation of the immune system. Examples for this mechanism are autoantibodies targeting the folate receptor (FR) which have a very high binding affinity and thereby block binding and uptake of folic acid [80]. This inhibits the transport of folic acid into the CSF and causes cerebral folate deficiency leading to infantile-onset neuropsychiatric symptoms including psychomotor retardation, cerebellar ataxia, dyskinesias and in some cases, seizures. The autoantibodies found in SC patients alter the D2DR function by reducing adenylate cyclase levels at a comparable level to the inhibitory effect by dopamine [81]. By targeting the receptor the autoantibodies can also interfere with the intracellular signaling pathways activated by the calcium/calmodulin-dependent (CaM) kinase II, an enzyme involved in cognition and neurotransmitter synthesis and release [82-84]. The activation of this enzyme has been correlated with an increase of dopamine release in the brain [85].

(c) Antigen internalization (or antigenic modulation) is a mechanism in which binding of autoantibodies induces internalization and commonly degradation of the antigen. The two arms of the antibody can bind each separately to an antigen leading to clustering or cross-linking of the antigens in the membrane. Antibodies against the NMDA-R are thought to cause crosslinking and selective internalization of receptors as shown in cultured neurons [86,87]. Reduction in DR levels has also been observed in the presence of SC patient autoantibodies [81]. In the PNS, specifically in MG, anti-AChR autoantibodies accelerate the internalization of the receptor $[88,89]$, a mechanism that can be blocked by overexpression of the AChR anchoring protein, rapsyn, in an experimental passive transfer MG model, showing the important role of anchoring proteins in the resistance to the autoantibody attack [90].

(d) Loss or block of receptor associated proteins can also significantly alter the function of ion channels. One of the known antigens associated with the VGKC is LGI1 [91,92]. LGI1 autoantibodies can cause a disruption of the ligand-receptor interaction of LGI1 with scaffolding proteins ADAM22 or ADAM23, which is interfering with the trans-synaptic complex that includes presynaptic Kv1.1 potassium channels and post-synaptic AMPA-R $[93,94]$. It has also been observed in the PNS that the AChR internalization and complement damage produces a loss of scaffolding proteins associated with the receptor like musclespecific kinase (MuSK), rapsyn, docking protein 7 (Dok-7), LDL Receptor Related Protein 4 (Lrp4) or agrin, altering the endplate organization and, in some cases, aggravating the symptoms and delaying the repairing mechanisms [39]. 


\section{The relevance of Intracellular Antigens as Target of Autoimmunity}

Considering the pathologic mechanisms described above, autoantibodies are unlikely to be pathogenic if they target intracellular antigens such as $\mathrm{Hu}$, Yo or $\mathrm{Ri}$, as commonly seen in paraneoplastic syndromes [95]. Instead, diseases with intracellular antigens are thought to be T-cell mediated [96] and are not within the scope of this review. The pathogenicity of a few autoantibodies targeting intracellular antigens e.g. amphiphysin, glutamic acid decarboxylase (GAD), ribosome P proteins (Rib-P) and anti-dsDNA, is still controversial. Amphiphysin is a synaptic vesicle protein which might be exposed to autoantibodies in the membrane during synaptic vesicle uptake [7] and has been described as an antigen affected by autoantibodies in Stiff Person syndrome. Amphiphysin autoantibodies induced structural disorganization in GABAergic synapses and changed presynaptic vesicle pools [97]. In addition, autoantibodies to GAD, the enzyme synthesizing the inhibitory neurotransmitter GABA, are related to many neurological disorders e.g. Stiff Person Syndrome, cerebellar ataxia, limbic encephalitis (LE), epilepsy and oculomotor dysfunction [98]. Gresa-Arribas and collaborators observed that antiGAD autoantibodies are not internalized by neuronal cell cultures, indicating that the antibodies are unlikely to interact with GAD on live neurons [99]. Epitope specificity overlaps between different syndromes with GAD autoantibodies and thus cannot explain the differences in symptoms $[98,99]$.

If the anti-GAD autoantibody is the causative factor, other antibody properties or interacting factors such as environmental factors must also play a role. The study of these autoantibodies is of clinical relevance as a potential diagnostic marker, because GAD autoantibodies in classical paraneoplastic syndrome are indicative for identification of tumors and often coincide with other autoantibodies that target neuronal antigens such as GABA-R [100,101] and GlyR $[102,103]$. Studies in rats showed that injection of IgG from patients with GAD autoantibodies and neurological symptoms lead to motor dysfunction and impaired NMDA-R signaling but not when injecting IgG from GAD positive diabetes patients without neurological presentation [104], which was interpreted as the pathogenic role of autoantibodies related to neurological symptoms. Other authors claim that these changes were evoked by accompanying other autoantibodies [101]. Interestingly, the repertoire of antibodies to different immunodominant regions in the GAD antigen is wider in the CNS than systemically [99].

Autoantibodies against Rib-P have been proposed to be involved in the neuropathogenic in psychiatric SLE, e.g., anti-Rib-P autoantibody titers were correlated to depression in the onset of SLE [105]. A murine model illustrates the ability of anti-Rib-P autoantibodies to induce depressive-like symptoms [106,107]. Moreover, Matus et al. showed that these antibodies could cross-react with a novel neuronal surface protein causing $\mathrm{Ca}^{2+}$ influx and apoptosis. However, there exists in the literature some controversy in the association of anti-Rib-P with CNS involvement and neuropsychiatric manifestations in SLE $[108,109]$, which may be due to the great variation in detection assays concerning the purity of the anti-Rib-P autoantibodies, the use of synthetic peptides, or parts/complete antigen as well as the carrier proteins used. Anti-dsDNA autoantibodies have been proposed to cross-react with the GluN2 subunit of the NMDA-R and are responsible for excitatory, non-inflammatory cell death and altered neuronal function [110].

In Table 2 the presence of autoantibodies in neuropsychiatric diseases targeting membrane and intracellular proteins is summarized; the latter will be discussed in the following section. 
Table 2. Autoantibodies in neurologic diseases with psychiatric symptoms.

\begin{tabular}{|c|c|c|c|c|c|c|c|}
\hline $\begin{array}{l}\text { Antigen } \\
\text { Target }\end{array}$ & $\begin{array}{l}\text { Subunit/ } \\
\text { Associated } \\
\text { Protein }\end{array}$ & Related Disease & $\begin{array}{l}\mathrm{n}+/ \mathrm{n} \\
\text { Patient }\end{array}$ & $\begin{array}{l}\mathbf{n}+/ \mathbf{n} \\
\text { Control }\end{array}$ & $\begin{array}{l}\text { Age } \\
\text { Range* }\end{array}$ & $\begin{array}{l}\text { Ig } \\
\text { Type }\end{array}$ & Ref. \\
\hline \multicolumn{8}{|c|}{ Autoantibodies to neuronal surface antigens ** } \\
\hline $\begin{array}{l}\text { VGKC } \\
\text { complex }\end{array}$ & n.s. ${ }^{* * *}$ & Limbic encephalitis & $4 / 15$ & n.t. ${ }^{* * *}$ & $47-69$ & $\operatorname{IgG}$ & [113] \\
\hline \multirow{11}{*}{ NMDA-R } & \multirow{7}{*}{ GluN1 } & \multirow{4}{*}{$\begin{array}{l}\text { NMDA-R encephalitis with } \\
\text { psychiatric symptoms }\end{array}$} & $50 / 485$ & n.t & $17-44$ & $\mathrm{IgG}$ & [114] \\
\hline & & & $100 / 100$ & n.t & $5-76$ & IgG & [115] \\
\hline & & & $250 / 250$ & $0 / 100$ & $\mathrm{n} / \mathrm{a}$ & IgG & [116] \\
\hline & & & $6 / 505$ & n.t & $18-35$ & IgG & [117] \\
\hline & & $\begin{array}{l}\text { NMDA-R encephalitis (isolated } \\
\text { psychiatric episodes) }\end{array}$ & $571 / 571$ & n.t & $12-62$ & $\operatorname{IgG}$ & [8] \\
\hline & & $\begin{array}{l}\text { NMDA-R encephalitis } \\
\text { (schizophrenia, and autism) }\end{array}$ & $1 / 1$ & n.t & 9 & $\operatorname{IgG}$ & [118] \\
\hline & & $\begin{array}{l}\text { Autoimmune encephalitis in } \\
\text { postpartum psychosis }\end{array}$ & $2 / 96$ & $0 / 64$ & 25,31 & $\operatorname{IgG}$ & [119] \\
\hline & \multirow{3}{*}{ GluN2a/2b } & $\begin{array}{l}\text { Progressive cognitive dysfunction } \\
\text { of unclear etiology }\end{array}$ & $7 / 24$ & n.t & $49-81$ & $\operatorname{Ig} \mathrm{A}$ & [120] \\
\hline & & Herpes simplex encephalitis & $\begin{array}{l}5 / 44 \\
9 / 44\end{array}$ & n.t & $24-79$ & $\begin{array}{l}\operatorname{IgG} \\
\operatorname{IgM} \\
\operatorname{Ig} \mathrm{A} \\
\end{array}$ & [121] \\
\hline & & Limbic encephalitis, narcolepsy & $3 / 5,3 / 5$ & n.t & $\begin{array}{l}18-59 \\
24-61\end{array}$ & $\operatorname{IgG}$ & [122] \\
\hline & $\begin{array}{l}\text { GluN1/ } \\
\text { GluN2a/2b }\end{array}$ & $\begin{array}{l}\text { NMDA-R encephalitis associate } \\
\text { with ovarian teratoma }\end{array}$ & $12 / 12$ & $0 / 200$ & $14-44$ & $\operatorname{IgG}$ & [123] \\
\hline AMPA-R & GluA1, GluA2 & Limbic encephalitis & $22 / 62$ & n.t & $23-81$ & $\mathrm{n} / \mathrm{a}$ & [124] \\
\hline \multirow{3}{*}{ GABA-R } & Type B & $\begin{array}{l}\text { Encephalitis with opsoclonus, } \\
\text { Ataxia, Chorea and Seizures }\end{array}$ & $1 / 1$ & n.t & 3 & $\operatorname{IgG}$ & [125] \\
\hline & $\alpha 1 / \beta 3$ subunits & $\begin{array}{l}\text { Encephalitis with refractory } \\
\text { seizures, status epilepticus, }\end{array}$ & $6 / 140$ & $0 / 75$ & $\mathrm{n} / \mathrm{a}$ & $\operatorname{IgG}$ & [125] \\
\hline & $\alpha 1 / \beta 3$ subunits & Encephalitis with thymoma & $1 / 1$ & n.t & 45 & $\mathrm{IgG}$ & [126] \\
\hline GlyR & $\alpha 1$ & $\begin{array}{l}\text { Progressive encephalomyelitis with } \\
\text { rigidity and myoclonus (PERM) }\end{array}$ & $52 / 779$ & n.t & $1-75$ & $\operatorname{IgG}$ & [102] \\
\hline mGluR & mGluR5 & $\begin{array}{l}\text { Encephalitis (Hodgkin lymphoma, } \\
\text { Ophelia syndrome) }\end{array}$ & $2 / 2$ & n.t & 15,46 & $\operatorname{IgG}$ & [127] \\
\hline Kv4.2 & DPPX & $\begin{array}{l}\text { Encephalitis (subacute onset of } \\
\text { neuropsychiatric symptoms) }\end{array}$ & $4 / 4$ & $0 / 210$ & $45-76$ & $\operatorname{IgG}$ & [128] \\
\hline D2DR & D2 & $\begin{array}{l}\text { Basal ganglia encephalitis **, } \\
\text { Sydenham's chorea **, Tourette's } \\
\text { syndrome }{ }^{* *}\end{array}$ & $\begin{array}{l}12 / 17 \\
10 / 30 \\
4 / 44\end{array}$ & $0 / 67$ & $\begin{array}{l}1-15 \\
2-17 \\
2-13\end{array}$ & $\operatorname{IgG}$ & [129] \\
\hline $\begin{array}{l}\text { Folate } \\
\text { receptor }\end{array}$ & - & $\begin{array}{lll}\begin{array}{l}\text { Cerebral } \\
\text { syndrome }\end{array} & \text { folate } & \text { deficiency } \\
\end{array}$ & $25 / 28$ & $0 / 28$ & $2.5-19.3$ & $\mathrm{n} / \mathrm{a}$ & [130] \\
\hline \multicolumn{8}{|c|}{ Autoantibodies to (neuronal) intracellular antigens ** } \\
\hline Rib-P & P1, P2, P3 & SLE with Depression & $22 / 100$ & n.t & $23-36$ & IgG & [105] \\
\hline GAD & n.s. & $\begin{array}{l}\text { Non-paraneoplastic } \\
\text { encephalitis }\end{array}$ & $2 / 2$ & n.t & 20,47 & $\operatorname{IgG}$ & [131] \\
\hline
\end{tabular}

* Age range of the positive subjects; ${ }^{* *}$ Anti-basal ganglia antibodies (ABGA) can bind to either neuronal surface or intracellular antigens and are related to basal ganglia encephalitis, Sydenham's chorea, Tourette's syndrome, OCD and ADHD. For details see OCD and ADHD sections; ${ }^{* * *}$ n.s. $=$ not specified;. n.t. $=$ not tested; VGKC complex = voltage gated potassium channel complex; NMDA-R: $N$ Methyl-D-Asparte receptor; AMPA-R $=\alpha$-amino-3-hydroxy-5-methyl-4-isoxazolepropionic acid receptor; GABA-R = $\nu$-aminobutyric acid; GlyR = glycine receptor; $\mathrm{mGluR}=$ metabotropic glutamate receptor; Kv4.2 = Potassium channel, voltage dependent, Kv4.2; DPPX = Dipeptidyl-Peptidase-Like Protein-6; $\mathrm{DRD} 2$ = dopamine-2 receptor; $\mathrm{Rib}-\mathrm{P}=$ ribosome $\mathrm{P}$ protein; $\mathrm{SLE}=$ Systemic lupus erythematosus; GAD = glutamic acid decarboxylase. 
Table 3 gives an overview of autoantibodies targeting membrane proteins and intracellular antigens only in psychiatric disorders.

\section{Autoimmune Encephalitis}

Encephalitis is an inflammation of the brain characterized by memory alterations, behavioral and cognitive changes, and seizures, where immune-mediated mechanisms have been related [111]. Paraneoplastic events are very common in encephalitis patients and antibodies to intracellular onconeuronal antigens and cytotoxicity mechanisms have been described [112]. In Table 2, the autoantibodies involved in neurological diseases with psychiatric symptoms are summarized.

A few years ago, NMDA-R autoantibodies were described for the first time in a group of encephalitis patients with ovarian teratoma with the peculiar fact that they suffered psychotic symptoms. Autoantibodies were identified in serum and CSF using a cell-based assay (CBA) (HEK293 cells expressing single subunits or dimers of the GluN1 and GluN2a/2b) and rat brain immunohistochemistry (IHC) [123]. Importantly, about $80 \%$ of these patients had full or substantial recovery after treatment with immunotherapy and removal of the tumor if present, which indicates that the antibody is an important, if not, the only cause of symptoms. This further implies that subgroups of patients with neuropsychiatric disorders are treatable with immunotherapy. These findings were confirmed in other encephalitis cohorts $[122,132]$ and in individual patients [133] with a case example of a young lethargic encephalitis patient, who had high NMDA-R autoantibodies (higher in CSF than in serum) and responded well to immunosuppressive therapy [134]. For NMDA-R autoantibodies, higher sensitivity and specificity was found in studies using CSF [116,118,134]. In contrast, using a fluorescent immunoprecipitation assay anti-GluN1, IgG autoantibodies were found in higher levels in serum than in CSF in $10 \%$ of cases [114]. The GluN1 subunit of the receptor was identified as the main antigenic epitope in the classic full spectrum NMDA-R encephalitis cases $[117,135]$, specifically a small region in the amino-terminal domain [136]. Upon binding, the autoantibodies are thought to cause cross-linking and selective internalization of NMDA-R as shown in cultured neurons [86]. It has also been proposed that in the extrasynaptic compartment, autoantibodies significantly reduce the surface diffusion of NMDA-R, likely facilitating their internalization and degradation [87]. An important contribution to verify the effect of these autoantibodies was recently given by Planagumà and colleagues who showed that passive transfer of NMDA-R autoantibodies by continuous intraventricular infusion of CSF from patients with NMDA-R encephalitis causes memory and behavioral deficits in mice. The passive transfer model was also able to reproduce the downregulation of total and synaptic NMDA-R density observed in the disease in humans. After discontinuing the patient CSF infusion, the NMDA-R clusters in the hippocampus, and the total NMDA-R protein amount was recovered gradually, supporting the reversible effect of these autoantibodies $[137,138]$. Patients with autoantibodies against the VGKC complex have been reported in many neurological disorders (including LE, epilepsy, neuromyotonia) as immunotherapy-responsive [139]. Radioimmunoassay (RIA) and IHC techniques were used to test VGKC reactivity in serum and CSF. Higher percentages $(17 \%-26 \%)$ of autoantibodies that were thought to be antiVGKC were found in LE patients $[113,140,141]$. The autoantibodies were actually targeting proteins that were in complex with the ion channel. In the following study, LGI1 was identified as the real antigen in VGKC positive patients by CBA. CASPR2 which forms part of the scaffold required to anchor the VGKC [142] was also described as an antigen [93,143]. 
Other neuronal surface antigens have been identified in LE patients such as autoantibodies to AMPA-R with concomitant psychotic symptoms and good response to immunotherapy [124]. The main epitopes are in the AMPA-R subunits GluR2 (6/12) followed by the GluR1 (3/10) and a GluR1/GluR2 conformational epitope (1/10) [124]. No autoantibodies against the GluR3 subunit were found. The autoantibodies bound in $91 \%$ of the cases to GluR2 in cluster with GluR3, produced a reduction in the number of GluR2 subunit in the AMPA-R clusters at the synapsis. GABAB-R autoantibodies have been recently related to an aggressive course of autoimmune encephalitis in a young patient [125]. In contrast, GABAA-R autoantibodies have been found in severe forms of encephalitis [125] e.g., in combination with anti-LGI1 in a patient presenting a subacute onset of memory loss, confabulation, and behavioral changes [126]. The D2DR has been first identified in 12 out of 17 basal ganglia encephalitis patients, an autoimmune disorder characterized by movement and psychiatric symptoms. In this study, 3 out of $12 \mathrm{IgG}$ positive patients presented paranoia, psychosis, and hallucinations. These autoantibodies have also been described in other neuropsychiatric disorders [129].

Table 3. Autoantibodies related to psychiatric disorders.

\begin{tabular}{|c|c|c|c|c|c|c|c|}
\hline $\begin{array}{l}\text { Antigen } \\
\text { Target }\end{array}$ & $\begin{array}{l}\text { Subunit/ } \\
\text { Associated } \\
\text { Protein }\end{array}$ & Related Disorders (D) & $\begin{array}{l}\mathrm{n}+/ \mathbf{n} \\
\text { Patient }\end{array}$ & $\begin{array}{l}\mathrm{n}+/ \mathbf{n} \\
\text { Control }\end{array}$ & $\begin{array}{l}\text { Ig } \\
\text { Type }\end{array}$ & $\begin{array}{l}\text { Age } \\
\text { Range* }\end{array}$ & Ref. \\
\hline \multicolumn{8}{|c|}{ Autoantibodies to neuronal surface antigens ${ }^{* *}$} \\
\hline \multirow{2}{*}{$\begin{array}{l}\text { VGKC } \\
\text { complex }\end{array}$} & $\begin{array}{l}\text { LGI1, } \\
\text { CASPR2 }\end{array}$ & Psychotic D & $3 / 125$ & $\mathrm{n} / \mathrm{t}^{* * *}$ & IgG & $\mathrm{n} / \mathrm{a}^{* * *}$ & [144] \\
\hline & n.s. ${ }^{* * *}$ & Psychotic D (schizophrenia) & $1 / 46$ & $\mathrm{n} / \mathrm{t}$ & IgG & $22(\mathrm{pp})$ & [145] \\
\hline \multirow{5}{*}{ NMDA-R } & \multirow{3}{*}{ GluN1 } & \multirow{3}{*}{ Psychotic D and major depressive D. (n.s.) } & $81 / 1688$ & $74 / 1703$ & IgM & \multirow{3}{*}{$26-56(p)$} & \multirow{3}{*}{ [146] } \\
\hline & & & $92 / 1688$ & $76 / 1703$ & $\operatorname{Ig} \mathrm{A}$ & & \\
\hline & & & $14 / 1688$ & $20 / 1703$ & IgG & & \\
\hline & \multirow{2}{*}{ GluN2a/2b } & Psychotic D (schizophrenia) & $4 / 51$ & $\mathrm{n} / \mathrm{t}$ & IgG & $\begin{array}{l}26-53 \\
(\mathrm{pp})\end{array}$ & [122] \\
\hline & & Psychotic D (schizophrenia) & $3 / 46$ & $\mathrm{n} / \mathrm{t}$ & IgG & $\begin{array}{l}19-28 \\
(\mathrm{pp})\end{array}$ & [145] \\
\hline \multirow{2}{*}{$\begin{array}{l}\text { Muscarinic } \\
\text { AChR }\end{array}$} & \multirow{2}{*}{ M1,M2 } & Schizophrenia & $(\mathrm{n} / \mathrm{a}) / 21$ & $(\mathrm{n} / \mathrm{a}) / 25$ & IgG & $25-56(p)$ & [147] \\
\hline & & Psychotic D, bipolar and depressive D & $42 / 122$ & $0 / 52$ & $\mathrm{n} / \mathrm{a}$ & $24-63(\mathrm{p})$ & [148] \\
\hline $\begin{array}{l}\text { Nicotinic } \\
\text { AChR }\end{array}$ & $\alpha 7$ & Schizophrenia & $5 / 21$ & $0 / 17$ & IgG & $\begin{array}{l}46-61 \\
(\mathrm{pp})\end{array}$ & [149] \\
\hline D2DR & D2 & Bipolar and major depressive $\mathrm{D}$ & $6 / 122$ & $0 / 52$ & $\mathrm{n} / \mathrm{a}$ & $30-63(\mathrm{p})$ & [148] \\
\hline \multirow{2}{*}{$\begin{array}{l}\text { Opioid } \\
\text { receptor }\end{array}$} & \multirow[t]{2}{*}{ OPRM1 } & $\begin{array}{l}\text { Psychotic D, bipolar and major depressive } \\
\text { D }\end{array}$ & $16 / 122$ & $0 / 52$ & $\mathrm{n} / \mathrm{a}$ & $30-63(\mathrm{p})$ & [148] \\
\hline & & Major depressive $\mathrm{D}$ & $2 / 27$ & $\mathrm{n} / \mathrm{a}$ & IgG & $\mathrm{n} / \mathrm{a}$ & [150] \\
\hline \multirow{2}{*}{$\begin{array}{l}\mathrm{HT} \\
\text { receptor }\end{array}$} & \multirow{2}{*}{ HTR1A } & Psychotic D, Major depressive D & $9 / 63$ & $0 / 52$ & $\mathrm{n} / \mathrm{a}$ & $30-63(\mathrm{p})$ & [148] \\
\hline & & Autism spectrum D (Autism) & $\mathrm{n} / \mathrm{a}$ & $\mathrm{n} / \mathrm{a}$ & $\mathrm{n} / \mathrm{a}$ & $<10(\mathrm{pp})$ & [151] \\
\hline FR & - & Autism spectrum D (Autism) & $70 / 93$ & $\mathrm{n} / \mathrm{t}$ & $\mathrm{n} / \mathrm{a}$ & $3-18(\mathrm{t})$ & [152] \\
\hline DAT & - & Attention-deficit/hyperactivity & $\mathrm{n} / \mathrm{a} / 46$ & $\mathrm{n} / \mathrm{a} / 15$ & IgG & $4-16(t)$ & [153] \\
\hline \multicolumn{8}{|c|}{ Autoantibodies to (neuronal) intracellular antigens ${ }^{* *}$} \\
\hline \multirow[b]{2}{*}{ GAD } & \multirow[b]{2}{*}{ GAD 65} & Psychotic D (Schizophrenia) & $1 / 1$ & $\mathrm{n} / \mathrm{t}$ & $\mathrm{n} / \mathrm{a}$ & $19(\mathrm{pp})$ & [154] \\
\hline & & $\begin{array}{l}\text { Autism spectrum D (Autism), Attention- } \\
\text { deficit/hyperactivity D }\end{array}$ & $\begin{array}{l}3 / 20 \\
4 / 15\end{array}$ & $0 / 14$ & IgG & $8-11(\mathrm{pp})$ & [155] \\
\hline
\end{tabular}

* Age range: (pp) the age range belongs to the patients tested positive in the assay, (p) the age range belongs to the total patients cohort tested in the assay, $(t)$ the age range belongs to all the subjects (including controls and patients) tested in the assay; ** Anti-basal ganglia antibodies (ABGA) can bind to either neuronal surface or intracellular antigens and are related to OCD, ADHD. For details see paragraph on OCD and ADHD; ${ }^{* * *}$ n.s. = not specified; $\mathrm{n} / \mathrm{a}=$ not available. $\mathrm{n} / \mathrm{t}=$ not tested; VGKC complex = voltage-gated potassium channel complex; Ig = immunoglobulin G; NMDA-R: N-Methyl-DAsparte receptor; $A C h R=$ acetylcholine receptor; $D R D 2=$ dopamine-2 receptor; OPRM1 = opioid receptor, mu 1; $5 \mathrm{H}=$ serotonin; $\mathrm{HTR} 1 \mathrm{~A}=5$-Hydroxytryptamine (Serotonin) Receptor $1 \mathrm{~A} ; \mathrm{FR}=$ Folate receptor; DAT = Dopamine transporter; GAD= glutamic acid decarboxylase. 


\section{Psychotic Disorders}

Psychotic disorders are difficult to conceptualize and thus many misconceptions still exist on what psychosis and schizophrenia are. These disorders share common symptoms that can be divided into five main categories: (i) psychosis (encompassing delusions and hallucinationsalso called the positive-symptom dimension); (ii) alterations in drive and volition (the negativesymptom dimension); (iii) alterations in neuro-cognition (cognitive-symptom dimension); and (iv and v) affective dysregulation (giving rise to depressive and manic (bipolar) symptoms) [11]. The different diagnoses will be dependent on the duration and intensity of these different symptoms. Schizophrenia is the most common diagnosis within the psychotic disorders and applies to a syndrome characterized by long duration, bizarre delusions, negative symptoms, and few affective symptoms (non-affective psychosis). Other diagnoses of psychotic depression or bipolar disorder (affective psychosis) represent patients who present with a psychotic disorder with fewer negative symptoms, but with higher levels of affective (depression and mania) symptoms previous to psychosis.

The immunological involvement in psychotic disorders was already hypothesized in 1930 when some immunological signs were detected in patients with schizophrenia [156]. In Table 3 , the studies involving autoantibodies in psychiatric disorders are described in detail, including an overview of the specific role of the neuronal antigens in these pathologies.

As it has been already described, NMDA-R encephalitis presents usually with an early psychotic phase and subsequent seizures, movement disorders and autonomous dysfunction, but about $4 \%$ of patients develop only isolated psychotic episodes [8,157]. NMDA-R autoantibodies have been detected in schizophrenia [122] and in some case reports, such as a patient with the pure typical psychotic syndrome who recovers after immunotherapy [145] and patients with a first psychotic episode post-partum [119]. Some children also show isolated psychiatric symptoms, such as a case of a 9-year-old individual diagnosed with early schizophrenia, who presented high autoantibody titers in CSF compared with serum and responded well to immunosuppressive therapy [118]. These cases are not typical because, other than in adult cases of NMDA-R encephalitis, symptoms in early life are mainly neurologic rather than psychiatric [158].

After the antigenic epitope was defined, the immunoglobulin isotype frequency was studied in a schizophrenia cohort [159]. IgGs against the GluN1a subunit were described in two first episode catatonic schizophrenic patients (probably misdiagnosed NMDA-R encephalitis), while two other paranoid schizophrenia patients presented IgGs against GluN1a/2b, in lower titers, which declined during remission also shown in other studies [115,141,145]. Curiously, only the two patients with anti-GluN1 IgG autoantibodies presented IgG positive titers in CSF, a controversial result based on the $3.2 \%$ reactivity to neuronal surface antigens in CSF found in a psychotic disorder cohort (0.8\% to NMDA-R and $2.4 \%$ to VGKC complex) [144]. Another study showed GluN1 IgG autoantibodies in 5 out of 43 children with the first episode of acute psychosis, screened by a more objective variety of the CBA using flow cytometry [160]. This subunit was also recognized by $\operatorname{IgA}$ or $\operatorname{IgM}[160]$ but not specifically related to schizophrenia since they were also present in other pathologies and in control individuals $[121,159]$. IgA autoantibodies to NMDA-R (but not IgG) were described in a cognitive dysfunction cohort where they are thought to induce decreased NMDA-R expression and NMDA-R mediated currents in neuronal cell cultures [120].

The frequency of autoantibodies to NMDA-R and VGKC complex in different studies ranged from $0 \%$ to $10 \%$ in cohorts of first-episode psychosis or schizophrenia 
$[38,122,144,159,161,162]$. Nevertheless, the results are controversial, since a number of other studies did not find autoantibodies in neuropsychiatric cohorts [146,159,162,163] or not specific to the disease $[45,122]$. New and more objective techniques, like flow cytometry CBA, are being introduced to the research routine $[129,160]$, but a standardized procedure to screen patients for neuronal surface antigens needs to be defined to reduce results variability.

No serum autoantibodies against GluR1/GluR2 subunits from the AMPA-R were detected in a schizophrenia cohort (also not in other neuropsychiatric disorders and controls) [159]. On the other hand, the presence of autoantibodies to any class of the GABA-R has not been studied in psychotic disorders to our knowledge. The D2DR autoantibodies have been described in a cohort of first-episode acute psychosis children ( 3 out of 43 IgG and 1 out of 43 IgM subtypes) [160].

Autoantibodies against muscarinic AChR (mAChR), specifically against the mAChR in the cerebral cortex, have been identified in a small percentage of schizophrenia patients [147,164]. Similarly, autoantibodies against the $\alpha 7$ adult subunit of the nicotinic AChR (nAChR) were found in five out of 21 (23\%) schizophrenia patients [149].

Autoantibodies to GAD have been studied in a schizophrenia cohort where no autoantibodies were found in any of the 180 CSF samples [144]. Only a single case has been reported, where a schizophrenic patient presented elevated serum titers against GAD [154].

Psychiatric manifestations consist of a broad spectrum of symptoms that can occur during the course of different disorders that do not only include classical psychiatric disorders. We expect that some patients diagnosed with psychotic disorders like schizophrenia will in the future fall under the diagnosis of autoimmune encephalitis, yet in most cases, the causative role of these autoantibodies remains to be proven. Due to the heterogeneous phenotype of mental disorders, it is important to maintain diagnostic guidelines as homogeneous, standardized and as international as possible.

\section{Major Depressive Disorders (MDD)}

Depression is a major cause of morbidity worldwide [14]. The prevalence is up to $15 \%$ of the population in industrialized nations and by 2030 it is projected by the World Health Organization to be the leading cause of disease burden globally [165]. MDD is characterized by a state of low mood and anhedonia, affecting the person's thoughts, behavior, feelings, and sense of well-being [166,167]. Patients may also present with diverse symptoms including lethargy, insomnia, social withdrawal and sexual dysfunction among a range of others.

In MDD variations in ion channel and neurotransmitter receptor function are associated with the risk to develop the disorder. Serotonergic neurotransmission plays an important role in the etiology of depression [168]. The serotonin transporter (SERT) is the only known high-affinity transporter that primary regulates 5HT levels in the brain and is considered a key target for widely used antidepressant drugs [17]. So alterations in SERT levels have been implicated in behavioral and neuropsychiatric disorders including MDD [17,18,169]. Genetic studies also support that polymorphisms within genes that encode for receptors or proteins involved in the serotonergic and dopaminergic systems including SERT, 1A serotonin receptor 5HT-1A, dopamine transporter (DAT) and D4 DR are associated to the risk of MDD [19].

Autoantibodies targeting neurotransmitter receptors or other neuronal antigens have been reported in association with MDD [15,16]. Roy et al. were the first to report high reactivity of anti-opioid receptor (OPRM1) IgG autoantibodies in 3 out of 27 patients with MDD [170]. In a later study by the same group, patient serum IgGs were isolated by affinity chromatography 
and analyzed for reactivity on rat brain tissue [150]. The results suggested that autoantibodies to neuronal receptors might contribute to psychiatric impairment. Susumu et al. replicated this study examining the presence of autoantibodies against not only OPRM1 but also 5HT-1A or 5-hydroxytryptamine receptor 1A (HTR-1A), DRD2 as well as muscarinic cholinergic receptor 1 (CHRM1) [148]. Serum IgG from patients suffering from a range of neuropsychiatric disorders, including mood disorders, was analyzed by RIA. Autoantibodies against CHRM1, in particular, were significantly higher in neuropsychiatric patients than in healthy controls. However, there was no significant difference between different neuropsychiatric disorders nor any obvious correlation was found between the titer of the antibody and psychiatric symptoms [148]. The data on autoantibodies in MDD may suggest autoimmune abnormalities within the brain, however, it is still unclear if they play a pathological role or they are merely bystanders. Anti-NMDA-R antibodies have also been found in patients with MDD [110,171]. In contrast to anti-GluN1 autoantibodies present in autoimmune encephalitis, Larissa et al. proposed that anti-GluN2a antibodies are associated with the depressive mood in SLE patients [171]. As described before, anti-GluN2 autoantibodies are thought to be a subset of anti-dsDNA antibodies, which could cause apoptosis of neurons in vivo and in vitro [110,172].

\section{Autism Spectrum Disorder (ASD)}

At the beginning of the 20th century, Dr. Asperger described the term "autistic", referring to patients who from the beginning of their lives have difficulties to establish human affective and interpersonal relationships [20]. Nowadays, the last edition of the Diagnostic and Statistical Manual of Mental Disorders (DSM-V) includes four separate disorders under the term Autism Spectrum disorder (ASD): autistic disorder, Asperger's disorder, childhood disintegrative disorder and the catch-all diagnosis of pervasive developmental disorder not otherwise specified. The symptomatology described in these disorders is characterized by social communication deficit and restricted interest/repetitive behaviors with high sensitivity to changes in their environment, which can be developed in different degrees of severity.

Autoimmune diseases such as rheumatoid arthritis, SLE and type 1 diabetes are strongly associated with ASD family members and ASD patients [173,174]. In a subgroup of ASD patients' maternal autoantibody transfer may play a role in the disease. The autoantibodies are targeting the GluN2 subunits, which are enriched in female fetuses and make them more vulnerable and severely affected in the fetal state than their male siblings [175]. The infusion of serum or IgGs from mothers with ASD children in pregnant mice [176-178] or non-human primates $[68,179]$ reproduced the ASD-like pathology. Subsequently, neuron-reactive maternal antibodies were studied [180-183] and a pair of 37/73 and 39/73 $\mathrm{kDa}$ of fetal brain proteins have been specifically described as maternal antibody targets in mothers with ASD children $[180,181]$. In contrast, autoantibodies targeting these antigens were not detected in ASD patients [184]. Recently, seven proteins expressed in the developing brain, which are not neuronal receptors but are intracellular, extracellular and/or secreted, have been identified as fetal brain targets and they are currently used as biomarkers to predict ASD risk [185].

As discussed above, most ASD related autoantibodies that are known are transferred from the mother, yet some studies have also identified autoantibodies produced by ASD patients. These are anti-5HT receptor IgG autoantibodies $[151,186]$, and also autoantibodies targeting nonidentified antigens in the basal ganglia, prefrontal and temporal cortex, cingulate gyrus, and cerebellum $[187,188]$ specifically against the Purkinje cells $[155,189]$. IgGs and IgMs against brain endothelial cells were increased in ASD patients measured by (enzyme-linked 
immunosorbent assay) ELISA [190]. These findings were confirmed in another study by reactivity on brain endothelial cells where IgG autoantibodies were increased in ASD patients $(50 \%)$ whereas none of the healthy children showed positive autoantibody staining and children without neurological illnesses to a lower degree (2 out of 21) [191]. A 45/62 kDa cerebellar protein was identified as a possible autoantigen by Western blot using rhesus macaque cerebellum homogenate. The presence of the autoantibodies correlated with a lower adaptive and cognitive function and aberrant behavior in children [192]. A $52 \mathrm{kDa}$ protein located in cerebellar Golgi cells was identified in $21 \%$ of the ASD patients analyzed [193]. Later on, the same sera cohort was studied by IHC using the rostrocaudal extent of the macaque brain. A specific subgroup of GABAergic interneurons located in the V1 layer was identified as the specific target [194]. Controversially, another study suggested that this staining might be unspecific because immunoreactivity was detected using the serum of both healthy controls and ASD patients with the intriguing fact that the IgG seropositive ASD patients presented more severe behavior and emotional problems compared to the IgG seronegative ones [195]. Folate receptor autoantibodies have been detected by RIA in $75.3 \%$ of ASD patients [152]. Treatment with folic acid (leucovorin) has been shown to significantly improve the ASD symptoms in at least 1 out of 3 of the individuals with ASD. The role of parental autoantibodies remains unclear since the presence of FR autoantibodies in ASD children is not always related to the presence of the autoantibodies in the parents [196].

\section{Obsessive-Compulsive Disorder (OCD) and Attention-Deficit/Hyperactivity Disorder (ADHD)}

The mental disorders explained below are two of the most common neuropsychiatric diseases in early life patients. OCD patients develop pathological hoarding behaviors characterized by obsessions (recurrent intrusive thought) and/or compulsions or tics (repetitive or serotyped behaviors) like recurrent skin-piking resulting in skin lesions. ADHD is the most prevalent chronic neurodevelopmental disorder in school-age children, affecting 5\%-8\% [197,198] and being more frequent in boys than in girls. In two-thirds of these cases, the disease coexists with other conditions like tics or Tourette syndrome. It is characterized by hyperactivity, impulsiveness and long-lasting inattention.

The relationship between post-streptococcal infections immunity and OCD and ADHD has been widely studied. Obsessions and compulsions were observed in post-streptococcal infection and pediatric autoimmune neuropsychiatric disorders, then commonly referred to as pediatric autoimmune neuropsychiatric disorders associated with streptococcal infections (PANDAS) [199-201]. An animal model was established to study if these antibodies cause neuropsychiatric symptoms [202]. Plasma exchange affects the disease and removal of the autoantibodies could cause an improvement of symptoms in OCD and tic disorders in childhood [203]. In recent years, more studies revealed that anti-basal ganglia antibodies (ABGA) actually could target neuronal surface antigens. Kirvan et al. found that autoantibodies in PANDAS could bind to neuronal surface and caudate-putamen, which could activate CaM kinase II and cause behavioral disorders [83,204]. Brimberg et al first reported that autoantibodies could bind to DRD1 and DRD2 after the immunization with a streptococcal antigen which leads to neuropsychiatric symptoms in the rat animal model [205]. Lately, Lotan and colleagues reported that rats exposed to group A streptococcal antigens developed compulsive-like behavior. Serum IgG from group A streptococcal-exposed rats reacted with DRD 1 and DRD2 and 5HT-2A and 5HT-2C serotonin receptors in vitro (determined by ELISA 
and Western blot). In vivo, IgG deposits in the striatum of infused rats colocalized with specific brain proteins such as DR and SERT (by IHC), suggesting that the autoantibodies are the cause of the compulsive-like and motor dysfunction behavior observed in the animals [206]. Autoimmunity is, arising from an abnormal immune response, probably due to the high mimicry found between pathogens and neuronal surface epitopes involved in the dopaminergic and the serotonergic system. These findings link post-infectious autoimmunity to the onset of both OCD and ADHD. Giana et al. found elevated IgG autoantibody titers against DAT in the serum of ADHD children by ELISA $(n=61)$ [153], which again suggests that the dysregulation in the levels of dopamine neurotransmitter may be caused by autoantibodies in these disorders.

\section{Conclusions/ Future Directions}

NMDA-R autoantibodies can cause neuropsychiatric symptoms which can range from purely psychiatric to encephalitis with neurological symptoms. Due to the overlap in symptoms with psychotic disorders, some patients might be misdiagnosed as first-episode psychosis or even schizophrenia. We see the need for systematic screening of neuronal autoantibodies in psychotic patients, especially in the early phase of the disease to improve the diagnosis of autoimmune psychotic disorders. Preferably, hereby not only serum but also CSF would be screened because antibody titers might be low in the blood and only detectable in CSF (e.g. due to intrathecal antibody synthesis). The diagnosis of autoimmune neuropsychiatric diseases could be challenging for many clinicians and the acceptance and implementation of these diagnostic procedures differ widely between countries. The communication between the disciplines of neurology and psychiatry is of high importance in these cases because not only antibody testing but also neurological testing might improve the diagnosis of these patients. Mild neurological symptoms are frequent in patients with psychotic symptoms [207] but could be missed because they are (a) difficult to examine in the presence of acute psychiatric symptoms; (b) less attention is paid on these examinations and (c) neurological symptoms are attributed to the side effect of psychopharmacological therapy. Psychiatrists thus need to be aware of this new diagnosis in a subset of psychotic patients and education has to be provided to also perform neurological examinations or form a multidisciplinary team with neurologists (also for CSF sampling).

Still, the prevalence of these autoantibodies in cohorts of schizophrenia, bipolar disorder or other mental illnesses is not determined due to high variation in the current research results. The variable results in the field might be caused by small sample sizes, the heterogeneity in patient cohorts, the unclear distinction between the different mental disorders (especially in psychotic disorders), stage of the disease and also by methodological differences. The most commonly used diagnostic methods are the CBA and IHC on rat brain. Nevertheless, these methods are still relatively new with room for improvement. Adequate training is necessary to interpret the results and to avoid false conclusions as they have been reported before [163,208]. The IHC is limited by high background with serum stainings. The other neuronal autoantibodies described here are still lacking the final proof to confirm that they are causing a neuropsychiatric autoimmune disease. Indications for autoimmunity are that several of these autoantibodies targeting VGKC complex, mAChR and DRD2 receptor are present with the clinical manifestation of psychotic disorders including MDD, that they are detectable in the blood and CSF and also that they target a receptor, ion channel, or other protein expressed on the cell surface which is related to symptoms. To confirm the pathogenic role of isolated autoantibodies according to Witebsky's postulates, (monoclonal) antibody transfer should be 
shown to replicate the disease in an animal experimental model or in humans (maternal transfer) and that elimination or suppression of the autoimmune response by therapy can prevent disease progression or reduces the clinical manifestations. To this end, larger systematic, multicenter clinical studies are necessary to reveal the prevalence of different neuronal autoantibodies in neuropsychiatric disorders and whether these patients react to immunotherapy. Additionally, it is especially important to not only analyze sera but also CSF (see above) [116]. Table 4 highlights the relevance of the discussed autoantibodies in neuropsychiatric diseases and summarizes what remains unknown. Presumably, a number of antigens involved in neuropsychiatric disorders are still not well understood demanding further work to identify novel autoantibody targets and help to better diagnose autoimmune patients' subgroups and understand disease mechanisms.

Table 4. Evidence of autoantibody-mediated mechanisms in neuropsychiatric disorders.

\begin{tabular}{|c|c|c|c|c|c|c|c|c|c|}
\hline \multirow[t]{2}{*}{ Disorders } & \multirow{2}{*}{$\begin{array}{l}\text { Targets of the } \\
\text { Autoantibodies } \\
\text { NMDA }\end{array}$} & \multicolumn{2}{|c|}{ Prevalence * } & \multicolumn{2}{|c|}{ in Vitro * } & \multicolumn{2}{|c|}{ in Vivo * } & \multicolumn{2}{|c|}{ Immunotherapy * } \\
\hline & & $+/-$ & {$[122,145,146]$} & + & {$[86,114,120]$} & + & [137] & + & [145] \\
\hline \multirow{8}{*}{ Psychotic } & VGKC complex & $+/-$ & {$[144,145]$} & + & [93] & $\mathrm{n} / \mathrm{a}^{* *}$ & & + & {$[145]$} \\
\hline & AMPA-R & - & {$[144,159]$} & + & {$[209,210]$} & + & [211] & $\mathrm{n} / \mathrm{a}$ & \\
\hline & D2DR & + & {$[148,160]$} & + & [129] & $\mathrm{n} / \mathrm{a}$ & & $\mathrm{n} / \mathrm{a}$ & \\
\hline & HTR-1A & + & [148] & $\mathrm{n} / \mathrm{a}$ & & $\mathrm{n} / \mathrm{a}$ & & $\mathrm{n} / \mathrm{a}$ & \\
\hline & mAChR & + & {$[147,148]$} & + & {$[147,164]$} & $\mathrm{n} / \mathrm{a}$ & & $\mathrm{n} / \mathrm{a}$ & \\
\hline & $\mathrm{nAChR}$ & + & [149] & $\mathrm{n} / \mathrm{a}$ & & $\mathrm{n} / \mathrm{a}$ & & $\mathrm{n} / \mathrm{a}$ & \\
\hline & GAD & $+/-$ & {$[144,154]$} & - & [99] & $\mathrm{n} / \mathrm{a}$ & & + & [154] \\
\hline & FR & + & {$[202,212]$} & $\mathrm{n} / \mathrm{a}$ & & $\mathrm{n} / \mathrm{a}$ & & $\mathrm{n} / \mathrm{a}$ & \\
\hline \multirow{6}{*}{$\begin{array}{l}\text { Major } \\
\text { depressive }\end{array}$} & OPRM1 & + & {$[148,150]$} & $\mathrm{n} / \mathrm{a}$ & & $\mathrm{n} / \mathrm{a}$ & & $\mathrm{n} / \mathrm{a}$ & \\
\hline & D2DR & + & [148] & $\mathrm{n} / \mathrm{a}$ & & $\mathrm{n} / \mathrm{a}$ & & $\mathrm{n} / \mathrm{a}$ & \\
\hline & HTR-1A & + & [148] & $\mathrm{n} / \mathrm{a}$ & & $\mathrm{n} / \mathrm{a}$ & & $\mathrm{n} / \mathrm{a}$ & \\
\hline & mAChR & + & [148] & $\mathrm{n} / \mathrm{a}$ & & $\mathrm{n} / \mathrm{a}$ & & $\mathrm{n} / \mathrm{a}$ & \\
\hline & NMDA-R & + & [146] & + & [86] & + & [137] & $\mathrm{n} / \mathrm{a}$ & \\
\hline & Rib-p & $\mathrm{n} / \mathrm{a}$ & & + & [213] & + & [106] & $\mathrm{n} / \mathrm{a}$ & \\
\hline \multirow{3}{*}{ Autism } & HTR-1A & + & [151] & $\mathrm{n} / \mathrm{a}$ & & $\mathrm{n} / \mathrm{a}$ & & $\mathrm{n} / \mathrm{a}$ & \\
\hline & FR & + & [152] & $\mathrm{n} / \mathrm{a}$ & & $\mathrm{n} / \mathrm{a}$ & & $\mathrm{n} / \mathrm{a}$ & \\
\hline & GAD & + & [155] & $\mathrm{n} / \mathrm{a}$ & & $\mathrm{n} / \mathrm{a}$ & & $\mathrm{n} / \mathrm{a}$ & \\
\hline \multirow{2}{*}{$\begin{array}{l}\text { Obsessive- } \\
\text { compulsive }\end{array}$} & Basal ganglia & $+/-$ & {$[34,214,215]$} & + & [204] & + & {$[202,206]$} & + & [203] \\
\hline & D2DR & $\mathrm{n} / \mathrm{a}$ & & + & [216] & + & [205] & $\mathrm{n} / \mathrm{a}$ & \\
\hline \multirow{2}{*}{$\begin{array}{l}\text { Attention deficit } \\
\text { hyperactivity }\end{array}$} & Basal ganglia & $+/-$ & {$[217,218]$} & + & [204] & $\mathrm{n} / \mathrm{a}$ & & $\mathrm{n} / \mathrm{a}$ & \\
\hline & GAD & $+/-$ & {$[155,219]$} & $\mathrm{n} / \mathrm{a}$ & & $\mathrm{n} / \mathrm{a}$ & & $\mathrm{n} / \mathrm{a}$ & \\
\hline
\end{tabular}

* All autoantibodies mentioned above have been reported in biological fluids in human subjects with neuropsychiatric disorders. Data shown here does not include autoimmune encephalitis. The pathological role of the autoantibodies has not been demonstrated for all cases; Coding is done as follows: Column for prevalence (Pre): Antibody is more frequent in the specific patients' cohorts than in healthy individuals $(+)$, not $(-)$, or not available (n/a); in vitro: Autoantibody shows toxicity to cells in vitro or could change the antigen function $(+)$, not $(-)$, or not available (n/a); in vivo: Animal studies show the autoantibody could cause neuropsychiatric behavior $(+)$, not $(-)$, or not available $(\mathrm{n} / \mathrm{a})$; Immunotherapy: Patients would benefit from immunotherapy $(+)$; if immunotherapy was not beneficial $(-)$, if data not available $(\mathrm{n} / \mathrm{a}) ;{ }^{* *} \mathrm{n} / \mathrm{a}=$ not available; NMDA-R $=N$-Methyl-D-Asparte receptor; VGKC complex $=$ voltage gated potassium channel complex; AMPA- $R=\alpha$-amino-3-hydroxy5-methyl-4-isoxazolepropionic acid receptor; DRD2 = dopamine-2 receptor; HTR1A = 5Hydroxytryptamine (Serotonin) Receptor $1 A ; A C h R=$ acetylcholine receptor; $G A D=$ glutamic acid decarboxylase; FR = Folate receptor; OPRM1= opioid receptor, $\mathrm{mu} 1$.

To take home...

- Neuronal surface autoantibodies cause neuropsychiatric symptoms in a subgroup of the patients. 
- Antibody screening and neurological examinations should be implemented to improve the diagnosis of autoimmune psychotic disorders.

- Limited sample sizes, differences in patient cohorts and stage of the disease but also methodological differences generate high variation in current results.

- Common techniques, more sensitive and reproducible, are required to standardize the diagnostic tools for the different neuronal antigens across-laboratories.

- It is important to implement CSF analysis in neuropsychiatric disorder diagnosis routine since some autoantibodies are only detectable in CSF.

- More animal studies are needed to unravel the pathogenic effect of the autoantibodies in the CNS.

Acknowledgements: The authors thank the Netherlands Organization for Scientific Research "Graduate School of Translational Neuroscience Program" (022005019), the Brain Foundation of the Netherlands (KS2012(1)-157) and the ZonMW NWO Program Translationeel onderzoek (40-41200-98-9257); as well as the Veni Fellowship of the Netherlands Organization for Scientific Research (916.10.148), a fellowship of the Brain Foundation of the Netherlands (FS2008(1)-28), the Prinses Beatrix Fonds (Project WAR08-12) and the China Scholarship Council (201507720015). The authors also thank Inga Koneczny for reading the manuscript and providing helpful comments.

Author Contributions: Carolin Hoffmann, Shenghua Zong, and Marina Mané-Damas contributed equally in the design and in the writing of the paper; Peter Molenaar and Mario Losen helped with the correction of the review; Pilar Martinez supervised the design and helped to write the review.

\section{Abbreviations}

The following abbreviations are used in this manuscript:

$\begin{array}{ll}\text { 5HT } & \text { serotonin } \\ \text { 5HT-R } & \text { serotonin receptor } \\ \text { ABGA } & \text { Anti-basal ganglia antibodies } \\ \text { ACh } & \text { acetylcholine } \\ \text { AChR } & \text { acetylcholine receptor } \\ \text { AChR } \gamma & \text { gamma subunit of the peripheral neuronal ACh receptor } \\ \text { ADHD } & \text { attention-deficit/hyperactivity disorder } \\ \text { AMPA-R } & \alpha \text {-amino-3-hydroxy-5-methyl-4-isoxazolepropionic acid receptor } \\ \text { ApoE } & \text { apolipoprotein E } \\ \text { ASD } & \text { Autism Spectrum disorder } \\ \text { BBB } & \text { blood-brain barrier } \\ \text { BD } & \text { bipolar disorder } \\ \text { CASPR2 } & \text { contactin associated protein-2 } \\ \text { CBA } & \text { cell based assay } \\ \text { CHRM1 } & \text { muscarinic cholinergic receptor 1 } \\ \text { CNS } & \text { central nervous system } \\ \text { CSF } & \text { cerebrospinal fluid } \\ \text { D } & \text { Disorder }\end{array}$




\begin{tabular}{|c|c|}
\hline DAT & dopamine transporter \\
\hline DPPX & Dipeptidyl-Peptidase-Like Protein-6 \\
\hline DRD2 & dopamine-2 receptor \\
\hline dsDNA & double stranded DNA \\
\hline FcRn & neonatal $\mathrm{Fc}$ receptors \\
\hline FR & folate receptor \\
\hline GABA & $\gamma$-aminobutyric acid \\
\hline GABAA-R & A class of the GABA-R \\
\hline GABAB-R & B class of the GABA-R \\
\hline GABA-R & $\gamma$-aminobutyric acid receptor \\
\hline GAD & glutamic acid decarboxylase \\
\hline Glu & glutamate \\
\hline Gly & glycine \\
\hline GlyR & glycine receptor \\
\hline HLA & human leukocyte antigen \\
\hline HTR-1A & 5-hydroxytryptamine receptor $1 \mathrm{~A}$ \\
\hline $\operatorname{IgG}$ & immunoglobulin G \\
\hline $\mathrm{IHC}$ & immunohistochemistry \\
\hline LE & limbic encephalitis \\
\hline LGI1 & leucine-rich glioma inactivated-1 \\
\hline $\mathrm{mAChR}$ & muscarinic AChR \\
\hline MDD & major depressive disorder \\
\hline MG & myasthenia gravis \\
\hline mGluR & metabotropic glutamate receptor \\
\hline MHC & major histocompatibility complex \\
\hline nAChR & nicotinic $\mathrm{AChR}$ \\
\hline NMDA-R & $N$-Methyl-D-Asparte receptor \\
\hline NMJ & neuromuscular junction \\
\hline $\mathrm{OCD}$ & Obsessive-Compulsive disorder \\
\hline PNS & peripheral nervous system \\
\hline RIA & radioimmunoassay \\
\hline Rib-P & ribosome $\mathrm{P}$ protein \\
\hline SERT & serotonin transporter \\
\hline $\mathrm{SC}$ & Sydenham chorea \\
\hline SLE & systemic lupus erythematous \\
\hline
\end{tabular}

VGKC complex voltage gated potassium channel complex

\section{References}

1. Descartes, R. Meditations on first philosophy. In The Philosophical Writings of René Descartes; Cambridge University Press: Cambridge, UK, 1984; Volume 2, pp. 1-62.

2. Myin-Germeys, I.; Oorschot, M.; Collip, D.; Lataster, J.; Delespaul, P.; van Os, J. Experience sampling research in psychopathology: Opening the black box of daily life. Psychol. Med. 2009, 39, 1533-1547. 
3. Stephan, K.E.; Baldeweg, T.; Friston, K.J. Synaptic plasticity and dysconnection in schizophrenia. Biol. Psychiatry 2006, 59, 929-939.

4. Corti, C.; Xuereb, J.H.; Crepaldi, L.; Corsi, M.; Michielin, F.; Ferraguti, F. Altered levels of glutamatergic receptors and $\mathrm{Na}^{+} / \mathrm{K}^{+}$atpase-alpha1 in the prefrontal cortex of subjects with schizophrenia. Schizophr. Res. 2011, 128, 7-14.

5. Vukadinovic, Z.; Rosenzweig, I. Abnormalities in thalamic neurophysiology in schizophrenia: Could psychosis be a result of potassium channel dysfunction? Neurosci. Biobehav. Rev. 2012, 36, 960-968.

6. Moscato, E.H.; Jain, A.; Peng, X.; Hughes, E.G.; Dalmau, J.; Balice-Gordon, R.J. Mechanisms underlying autoimmune synaptic encephalitis leading to disorders of memory, behavior and cognition: Insights from molecular, cellular and synaptic studies. Eur. J. Neurosci. 2010, 32, 298309.

7. Leypoldt, F.; Armangue, T.; Dalmau, J. Autoimmune encephalopathies. Ann. N. Y. Acad. Sci. 2015, 1338, 94-114.

8. Kayser, M.S.; Titulaer, M.J.; Gresa-Arribas, N.; Dalmau, J. Frequency and characteristics of isolated psychiatric episodes in anti- $N$-methyl-D-aspartate receptor encephalitis. JAMA Neurol. 2013, 70 , 1133-1139.

9. Van Os, J.; Linscott, R.J.; Myin-Germeys, I.; Delespaul, P.; Krabbendam, L. A systematic review and meta-analysis of the psychosis continuum: Evidence for a psychosis proneness-persistenceimpairment model of psychotic disorder. Psychol. Med. 2009, 39, 179-195.

10. Nothen, M.M.; Nieratschker, V.; Cichon, S.; Rietschel, M. New findings in the genetics of major psychoses. Dialog. Clin. Neurosci. 2010, 12, 85-93.

11. Van Os, J.; Kapur, S. Schizophrenia. Lancet 2009, 374, 635-645.

12. Warren, R.P.; Singh, V.K.; Averett, R.E.; Odell, J.D.; Maciulis, A.; Burger, R.A.; Daniels, W.W.; Warren, W.L. Immunogenetic studies in autism and related disorders. Mol. Chem. Neuropathol. 1996, 28, 77-81.

13. Crespi, B.J.; Thiselton, D.L. Comparative immunogenetics of autism and schizophrenia. Genes Brain Behav. 2011, 10, 689-701.

14. Brundtland, G.H. Mental health: New understanding, new hope. JAMA J. Am. Med. Assoc. 2001, 286, 2391-2391.

15. Iseme, R.A.; McEvoy, M.; Kelly, B.; Agnew, L.; Attia, J.; Walker, F.R. Autoantibodies and depression: Evidence for a causal link? Neurosci. Biobehav. Rev. 2014, 40, 62-79.

16. Postal, M.; Appenzeller, S. The importance of cytokines and autoantibodies in depression. Autoimmun. Rev. 2015, 14, 30-35.

17. Torres, G.E.; Gainetdinov, R.R.; Caron, M.G. Plasma membrane monoamine transporters: Structure, regulation and function. Nat. Rev. Neurosci. 2003, 4, 13-25.

18. Camardese, G.; De Risio, L.; Di Nicola, M.; Pucci, L.; Cocciolillo, F.; Bria, P.; Giordano, A.; Janiri, L.; Di Giuda, D. Changes of dopamine transporter availability in depressed patients with and without

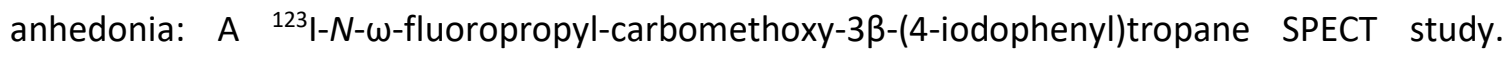
Neuropsychobiology 2014, 70, 235-243.

19. Gatt, J.M.; Burton, K.L.; Williams, L.M.; Schofield, P.R. Specific and common genes implicated across major mental disorders: A review of meta-analysis studies. J. Psychiatr. Res. 2015, 60, 113.

20. Ashok, A.H.; Baugh, J.; Yeragani, V.K. Paul eugen bleuler and the origin of the term schizophrenia (schizopreniegruppe). Indian J. Psychiatry 2012, 54, 95-96. 
21. Developmental Disabilities Monitoring Network Surveillance Year 2010 Principal Investigators; Centers for Disease Control and Prevention (CDC). Prevalence of autism spectrum disorder among children aged 8 years-Autism and developmental disabilities monitoring network, 11 sites, United States, 2010. Morb. Mortal. Wkly. Rep. 2014, 63, 1-21.

22. Forrester, J.V.; Xu, H.; Lambe, T.; Cornall, R. Immune privilege or privileged immunity? Mucosal Immunol. 2008, 1, 372-381.

23. Bailey, A.; Le Couteur, A.; Gottesman, I.; Bolton, P.; Simonoff, E.; Yuzda, E.; Rutter, M. Autism as a strongly genetic disorder: Evidence from a british twin study. Psychol. Med. 1995, 25, 63-77.

24. Faraone, S.V.; Sergeant, J.; Gillberg, C.; Biederman, J. The worldwide prevalence of ADHD: Is it an american condition? World Psychiatry Off. J. World Psychiatr. Assoc. 2003, 2, 104-113.

25. Rowland, A.S.; Lesesne, C.A.; Abramowitz, A.J. The epidemiology of attentiondeficit/hyperactivity disorder (ADHD): A public health view. Mental Retard. Dev. Disabil. Res. Rev. 2002, 8, 162-170.

26. Faraone, S.V.; Perlis, R.H.; Doyle, A.E.; Smoller, J.W.; Goralnick, J.J.; Holmgren, M.A.; Sklar, P. Molecular genetics of attention-deficit/hyperactivity disorder. Biol. Psychiatry 2005, 57, 13131323.

27. Toto, M.; Margari, F.; Simone, M.; Craig, F.; Petruzzelli, M.G.; Tafuri, S.; Margari, L. Antibasal ganglia antibodies and antistreptolysin o in noncomorbid ADHD. J. Atten. Disord. 2015, 19, 965970.

28. Mancebo, M.C.; Greenberg, B.; Grant, J.E.; Pinto, A.; Eisen, J.L.; Dyck, I.; Rasmussen, S.A. Correlates of occupational disability in a clinical sample of obsessive-compulsive disorder. Compr. Psychiatry 2008, 49, 43-50.

29. Eisen, J.L.; Mancebo, M.A.; Pinto, A.; Coles, M.E.; Pagano, M.E.; Stout, R.; Rasmussen, S.A. Impact of obsessive-compulsive disorder on quality of life. Compr. Psychiatry 2006, 47, 270-275.

30. Ruscio, A.M.; Stein, D.J.; Chiu, W.T.; Kessler, R.C. The epidemiology of obsessive-compulsive disorder in the national comorbidity survey replication. Mol. Psychiatry 2010, 15, 53-63.

31. Hoekstra, P.J.; Minderaa, R.B. Tic disorders and obsessive-compulsive disorder: Is autoimmunity involved? Int. Rev. Psychiatry 2005, 17, 497-502.

32. Pauls, D.L.; Abramovitch, A.; Rauch, S.L.; Geller, D.A. Obsessive-compulsive disorder: An integrative genetic and neurobiological perspective. Nat. Rev. Neurosci. 2014, 15, 410-424.

33. Pavone, P.; Bianchini, R.; Parano, E.; Incorpora, G.; Rizzo, R.; Mazzone, L.; Trifiletti, R.R. Anti-brain antibodies in pandas versus uncomplicated streptococcal infection. Pediatr. Neurol. 2004, 30 , 107-110.

34. Dale, R.C.; Heyman, I.; Giovannoni, G.; Church, A.W. Incidence of anti-brain antibodies in children with obsessive-compulsive disorder. Br. J. Psychiatry J. Ment. Sci.2005, 187, 314-319.

35. Cross-Disorder Group of the Psychiatric Genomics Consortium. Identification of risk loci with shared effects on five major psychiatric disorders: A genome-wide analysis. Lancet 2013, 381, 1371-1379.

36. Alonsoa, V.R.; de Jesus, F.R.J.; Garcia, Y.R.; Granados, J.; Sanchez, T.; Mena-Hernandez, L.;

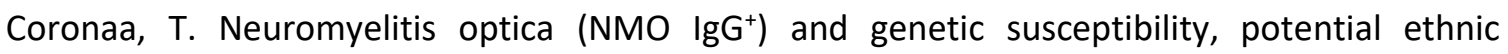
influences. Central Nervous Syst. Agents Med. Chem. 2016, 16, 1-4.

37. Kim, K.; Bang, S.Y.; Yoo, D.H.; Cho, S.K.; Choi, C.B.; Sung, Y.K.; Kim, T.H.; Jun, J.B.; Kang, Y.M.; Suh, C.H.; et al. Imputing variants in HLA-DR beta genes reveals that HLA-DRB1 is solely associated with rheumatoid arthritis and systemic lupus erythematosus. PLOS ONE 2016, 11, doi:10.1371/journal.pone.0150283. 
38. Martinez-Martinez, P.; Molenaar, P.; Losen, M.; Stevens, J.; De Baets, M.; Szoke, A.; Honnorat, J.; Tamouza, R.; Leboyer, M.; van Os, J.; et al. Autoantibodies to neurotransmitter receptors and ion channels: From neuromuscular to neuropsychiatric disorders. Front. Genet. 2013, 4, doi:10.3389/fgene.2013.00181.

39. Gomez, A.M.; Van Den Broeck, J.; Vrolix, K.; Janssen, S.P.; Lemmens, M.A.; Van Der Esch, E.; Duimel, H.; Frederik, P.; Molenaar, P.C.; Martinez-Martinez, P.; et al. Antibody effector mechanisms in myasthenia gravis-pathogenesis at the neuromuscular junction. Autoimmunity 2010, 43, 353-370.

40. Lennon, V.A.; Wingerchuk, D.M.; Kryzer, T.J.; Pittock, S.J.; Lucchinetti, C.F.; Fujihara, K.; Nakashima, I.; Weinshenker, B.G. A serum autoantibody marker of neuromyelitis optica: Distinction from multiple sclerosis. Lancet 2004, 364, 2106-2112.

41. Squire, L.; Berg, D.; Bloom, F.; du Lac, S.; Ghosh, A.; Spitzer, N. Fundamental Neuroscience, 4th ed.; Academic Press: Waltham, MA, USA, 2012.

42. Cutler, R.W.; Watters, G.V.; Hammerstad, J.P. The origin and turnover rates of cerebrospinal fluid albumin and gamma-globulin in man. J. Neurol. Sci. 1970, 10, 259-268.

43. Poduslo, J.F.; Curran, G.L.; Berg, C.T. Macromolecular permeability across the blood-nerve and blood-brain barriers. Proc. Natl. Acad. Sci. USA 1994, 91, 5705-5709.

44. Nishitsuji, K.; Hosono, T.; Nakamura, T.; Bu, G.; Michikawa, M. Apolipoprotein E regulates the integrity of tight junctions in an isoform-dependent manner in an in vitro blood-brain barrier model. J. Biol. Chem. 2011, 286, 17536-17542.

45. Hammer, C.; Stepniak, B.; Schneider, A.; Papiol, S.; Tantra, M.; Begemann, M.; Siren, A.L.; Pardo, L.A.; Sperling, S.; Mohd Jofrry, S.; et al. Neuropsychiatric disease relevance of circulating antiNMDA receptor autoantibodies depends on blood-brain barrier integrity. Mol. Psychiatry 2014, 19, 1143-1149.

46. Postal, M.; Costallat, L.T.; Appenzeller, S. Neuropsychiatric manifestations in systemic lupus erythematosus: Epidemiology, pathophysiology and management. CNS Drugs 2011, 25, 721-736.

47. Mahajan, S.D.; Parikh, N.U.; Woodruff, T.M.; Jarvis, J.N.; Lopez, M.; Hennon, T.; Cunningham, P.; Quigg, R.J.; Schwartz, S.A.; Alexander, J.J. C5a alters blood-brain barrier integrity in a human in vitro model of systemic lupus erythematosus. Immunology 2015, 146, 130-143.

48. Hirohata, S.; Arinuma, Y.; Yanagida, T.; Yoshio, T. Blood-brain barrier damages and intrathecal synthesis of anti- $N$-methyl-D-aspartate receptor NR2 antibodies in diffuse psychiatric/neuropsychological syndromes in systemic lupus erythematosus. Arthritis Res. Ther. 2014, 16, doi:10.1186/ar4518.

49. Hackett, M.L.; Yapa, C.; Parag, V.; Anderson, C.S. Frequency of depression after stroke: A systematic review of observational studies. Stroke J. Cereb. Circ. 2005, 36, 1330-1340.

50. Yang, J.; d'Esterre, C.; Ceruti, S.; Roversi, G.; Saletti, A.; Fainardi, E.; Lee, T.Y. Temporal changes in blood-brain barrier permeability and cerebral perfusion in lacunar/subcortical ischemic stroke. BMC Neurol. 2015, 15, doi:10.1186/s12883-015-0468-0.

51. Pinheiro, M.A.L.; Kooij, G.; Mizee, M.R.; Kamermans, A.; Enzmann, G.; Lyck, R.; Schwaninger, M.; Engelhardt, B.; de Vries, H.E. Immune cell trafficking across the barriers of the central nervous system in multiple sclerosis and stroke. Biochim. Biophys. Acta 2015, 1862, 461-471.

52. Prakash, R.; Carmichael, S.T. Blood-brain barrier breakdown and neovascularization processes after stroke and traumatic brain injury. Curr. Opin. Neurol. 2015, 28, 556-564.

53. Lin, J.J.; Mula, M.; Hermann, B.P. Uncovering the neurobehavioural comorbidities of epilepsy over the lifespan. Lancet 2012, 380, 1180-1192. 
54. Sahin, D.; Ilbay, G.; Ates, N. Changes in the blood-brain barrier permeability and in the brain tissue trace element concentrations after single and repeated pentylenetetrazole-induced seizures in rats. Pharmacol. Res. 2003, 48, 69-73.

55. Boettger, M.K.; Weishaupt, A.; Geis, C.; Toyka, K.V.; Sommer, C. Mild experimental autoimmune encephalitis as a tool to induce blood-brain barrier dysfunction. J. Neural Transm. 2010, 117, 165169.

56. Shalev, H.; Serlin, Y.; Friedman, A. Breaching the blood-brain barrier as a gate to psychiatric disorder. Cardiovasc. Psychiatry Neurol. 2009, 2009, doi:10.1155/2009/278531.

57. Alter, A.; Duddy, M.; Hebert, S.; Biernacki, K.; Prat, A.; Antel, J.P.; Yong, V.W.; Nuttall, R.K.; Pennington, C.J.; Edwards, D.R.; et al. Determinants of human b cell migration across brain endothelial cells. J. Immunol. 2003, 170, 4497-4505.

58. Martinez-Hernandez, E.; Horvath, J.; Shiloh-Malawsky, Y.; Sangha, N.; Martinez-Lage, M.; Dalmau, J. Analysis of complement and plasma cells in the brain of patients with anti-NMDAR encephalitis. Neurology 2011, 77, 589-593.

59. Smitt, P.S.; Kinoshita, A.; De Leeuw, B.; Moll, W.; Coesmans, M.; Jaarsma, D.; Henzen-Logmans, S.; Vecht, C.; De Zeeuw, C.; Sekiyama, N.; et al. Paraneoplastic cerebellar ataxia due to autoantibodies against a glutamate receptor. N. Engl. J. Med. 2000, 342, 21-27.

60. Castillo-Gomez, E.; Kastner, A.; Steiner, J.; Schneider, A.; Hettling, B.; Poggi, G.; Ostehr, K.; Uhr, M.; Asif, A.R.; Matzke, M.; et al. The brain as immunoprecipitator of serum autoantibodies against N-Methyl-D-aspartate receptor subunit NR1. Ann. Neurol. 2016, 79, 144-151.

61. Dileepan, T.; Smith, E.D.; Knowland, D.; Hsu, M.; Platt, M.; Bittner-Eddy, P.; Cohen, B.; Southern, P.; Latimer, E.; Harley, E.; et al. Group A Streptococcus intranasal infection promotes CNS infiltration by streptococcal-specific Th17 cells. J. Clin. Investig. 2015, 126, 303-317.

62. Palmeira, P.; Quinello, C.; Silveira-Lessa, A.L.; Zago, C.A.; Carneiro-Sampaio, M. IgG placental transfer in healthy and pathological pregnancies. Clin. Dev. Immunol. 2012, 2012, doi:10.1155/2012/985646.

63. Hulsebosch, C.E.; Fabian, R.H. Penetration of IgGs into the neuraxis of the neonatal rat. Neurosci. Lett. 1989, 98, 13-18.

64. Riemersma, S.; Vincent, A.; Beeson, D.; Newland, C.; Hawke, S.; Vernet-der Garabedian, B.; Eymard, B.; Newsom-Davis, J. Association of arthrogryposis multiplex congenita with maternal antibodies inhibiting fetal acetylcholine receptor function. J. Clin. Investig. 1996, 98, 2358-2363.

65. Jacobson, L.; Polizzi, A.; Morriss-Kay, G.; Vincent, A. Plasma from human mothers of fetuses with severe arthrogryposis multiplex congenita causes deformities in mice. J. Clin. Investig. 1999, 103, 1031-1038.

66. Warren, R.P.; Cole, P.; Odell, J.D.; Pingree, C.B.; Warren, W.L.; White, E.; Yonk, J.; Singh, V.K. Detection of maternal antibodies in infantile autism. J. Am. Acad. Child Adolesc. Psychiatry 1990, 29, 873-877.

67. Dalton, P.; Deacon, R.; Blamire, A.; Pike, M.; McKinlay, I.; Stein, J.; Styles, P.; Vincent, A. Maternal neuronal antibodies associated with autism and a language disorder. Ann. Neurol. 2003, 53, 533537.

68. Martin, L.A.; Ashwood, P.; Braunschweig, D.; Cabanlit, M.; Van de Water, J.; Amaral, D.G. Stereotypies and hyperactivity in rhesus monkeys exposed to Ig $\mathrm{G}$ from mothers of children with autism. Brain Behav. Immunity 2008, 22, 806-816.

69. Vincent, A.; Deacon, R.; Dalton, P.; Salmond, C.; Blamire, A.M.; Pendlebury, S.; Johansen-Berg, H.; Rajogopalan, B.; Styles, P.; Stein, J. Maternal antibody-mediated dyslexia? Evidence for a 
pathogenic serum factor in a mother of two dyslexic children shown by transfer to mice using behavioural studies and magnetic resonance spectroscopy. J. Neuroimmunol. 2002, 130, 243247.

70. Kobayashi, R.; Mii, S.; Nakano, T.; Harada, H.; Eto, H. Neonatal lupus erythematosus in japan: A review of the literature. Autoimmun. Rev. 2009, 8, 462-466.

71. McAllister, D.L.; Kaplan, B.J.; Edworthy, S.M.; Martin, L.; Crawford, S.G.; Ramsey-Goldman, R.; Manzi, S.; Fries, J.F.; Sibley, J. The influence of systemic lupus erythematosus on fetal development: Cognitive, behavioral, and health trends. J. Int. Neuropsychol. Soc. 1997, 3, 370376.

72. Neri, F.; Chimini, L.; Bonomi, F.; Filippini, E.; Motta, M.; Faden, D.; Lojacono, A.; Rebaioli, C.B.; Frassi, M.; Danieli, E.; et al. Neuropsychological development of children born to patients with systemic lupus erythematosus. Lupus 2004, 13, 805-811.

73. Ross, G.; Sammaritano, L.; Nass, R.; Lockshin, M. Effects of mothers' autoimmune disease during pregnancy on learning disabilities and hand preference in their children. Arch. Pediatr. Adolesc. Med. 2003, 157, 397-402.

74. Lee, J.Y.; Huerta, P.T.; Zhang, J.; Kowal, C.; Bertini, E.; Volpe, B.T.; Diamond, B. Neurotoxic autoantibodies mediate congenital cortical impairment of offspring in maternal lupus. Nat. Med. 2009, 15, 91-96.

75. Yu, Z.; Lennon, V.A. Mechanism of intravenous immune globulin therapy in antibody-mediated autoimmune diseases. N. Engl. J. Med. 1999, 340, 227-228.

76. Martin, F.; Chan, A.C. Pathogenic roles of b cells in human autoimmunity; insights from the clinic. Immunity 2004, 20, 517-527.

77. Whitney, K.D.; McNamara, J.O. GluR3 autoantibodies destroy neural cells in a complementdependent manner modulated by complement regulatory proteins. J. Neurosci. Off. J. Soc. Neurosci. 2000, 20, 7307-7316.

78. Rodgaard, A.; Nielsen, F.C.; Djurup, R.; Somnier, F.; Gammeltoft, S. Acetylcholine receptor antibody in myasthenia gravis: Predominance of IgG subclasses 1 and 3. Clin. Exp. Immunol. 1987, $67,82-88$.

79. Vincent, A.; Newsom-Davis, J. Acetylcholine receptor antibody characteristics in myasthenia gravis. I. Patients with generalized myasthenia or disease restricted to ocular muscles. Clin. Exp. Immunol. 1982, 49, 257-265.

80. Ramaekers, V.T.; Rothenberg, S.P.; Sequeira, J.M.; Opladen, T.; Blau, N.; Quadros, E.V.; Selhub, J. Autoantibodies to folate receptors in the cerebral folate deficiency syndrome. N. Engl. J. Med. 2005, 352, 1985-1991.

81. Cox, C.J.; Sharma, M.; Leckman, J.F.; Zuccolo, J.; Zuccolo, A.; Kovoor, A.; Swedo, S.E.; Cunningham, M.W. Brain human monoclonal autoantibody from sydenham chorea targets dopaminergic neurons in transgenic mice and signals dopamine D2 receptor: Implications in human disease. J. Immunol. 2013, 191, 5524-5541.

82. Kotani, M.; Kawashima, I.; Ozawa, H.; Ogura, K.; Ishizuka, I.; Terashima, T.; Tai, T. Immunohistochemical localization of minor gangliosides in the rat central nervous system. Glycobiology 1994, 4, 855-865.

83. Kirvan, C.A.; Swedo, S.E.; Heuser, J.S.; Cunningham, M.W. Mimicry and autoantibody-mediated neuronal cell signaling in sydenham chorea. Nat. Med. 2003, 9, 914-920.

84. Ishida, A.; Fujisawa, H. Stabilization of calmodulin-dependent protein kinase II through the autoinhibitory domain. J. Biol. Chem. 1995, 270, 2163-2170. 
85. Kantor, L.; Hewlett, G.H.; Gnegy, M.E. Enhanced amphetamine- and K'-mediated dopamine release in rat striatum after repeated amphetamine: Differential requirements for $\mathrm{Ca}^{2+}$ - and calmodulin-dependent phosphorylation and synaptic vesicles. J. Neurosci. Off. J. Soc. Neurosci. 1999, 19, 3801-3808.

86. Hughes, E.G.; Peng, X.; Gleichman, A.J.; Lai, M.; Zhou, L.; Tsou, R.; Parsons, T.D.; Lynch, D.R.; Dalmau, J.; Balice-Gordon, R.J. Cellular and synaptic mechanisms of anti-NMDA receptor encephalitis. J. Neurosci. Off. J. Soc. Neurosci. 2010, 30, 5866-5875.

87. Mikasova, L.; De Rossi, P.; Bouchet, D.; Georges, F.; Rogemond, V.; Didelot, A.; Meissirel, C.; Honnorat, J.; Groc, L. Disrupted surface cross-talk between NMDA and Ephrin-B2 receptors in anti-NMDA encephalitis. Brain J. Neurol. 2012, 135, 1606-1621.

88. Drachman, D.B.; Angus, C.W.; Adams, R.N.; Michelson, J.D.; Hoffman, G.J. Myasthenic antibodies cross-link acetylcholine receptors to accelerate degradation. N. Engl. J. Med. 1978, 298, 11161122.

89. Heinemann, S.; Bevan, S.; Kullberg, R.; Lindstrom, J.; Rice, J. Modulation of acetylcholine receptor by antibody against the receptor. Proc. Natl. Acad. Sci. USA 1977, 74, 3090-3094.

90. Losen, M.; Stassen, M.H.; Martinez-Martinez, P.; Machiels, B.M.; Duimel, H.; Frederik, P.; Veldman, H.; Wokke, J.H.; Spaans, F.; Vincent, A.; et al. Increased expression of rapsyn in muscles prevents acetylcholine receptor loss in experimental autoimmune myasthenia gravis. Brain $\mathrm{J}$. Neurol. 2005, 128, 2327-2337.

91. Vincent, A.; Buckley, C.; Schott, J.M.; Baker, I.; Dewar, B.K.; Detert, N.; Clover, L.; Parkinson, A.; Bien, C.G.; Omer, S.; et al. Potassium channel antibody-associated encephalopathy: A potentially immunotherapy-responsive form of limbic encephalitis. Brain J. Neurol. 2004, 127, 701-712.

92. Sunwoo, J.S.; Lee, S.T.; Byun, J.I.; Moon, J.; Shin, J.W.; Jeong, D.E.; Lee, G.H.; Jeong, S.H.; Shin, Y.W.; Jung, K.H.; et al. Clinical manifestations of patients with CASPR2 antibodies. J. Neuroimmunol. 2015, 281, 17-22.

93. Lai, M.; Huijbers, M.G.; Lancaster, E.; Graus, F.; Bataller, L.; Balice-Gordon, R.; Cowell, J.K.; Dalmau, J. Investigation of IGII as the antigen in limbic encephalitis previously attributed to potassium channels: A case series. Lancet Neurol. 2010, 9, 776-785.

94. Ohkawa, T.; Fukata, Y.; Yamasaki, M.; Miyazaki, T.; Yokoi, N.; Takashima, H.; Watanabe, M.; Watanabe, O.; Fukata, M. Autoantibodies to epilepsy-related IGI1 in limbic encephalitis neutralize IGI1-ADAM22 interaction and reduce synaptic AMPA receptors. J. Neurosci. Off. J. Soc. Neurosci. 2013, 33, 18161-18174.

95. Blaes, F.; Tschernatsch, M. Paraneoplastic neurological disorders. Expert Rev. Neurother. 2010, 10, 1559-1568.

96. Liblau, R.S.; Gonzalez-Dunia, D.; Wiendl, H.; Zipp, F. Neurons as targets for $t$ cells in the nervous system. Trends Neurosci. 2013, 36, 315-324.

97. Werner, C.; Pauli, M.; Doose, S.; Weishaupt, A.; Haselmann, H.; Grunewald, B.; Sauer, M.; Heckmann, M.; Toyka, K.V.; Asan, E.; et al. Human autoantibodies to amphiphysin induce defective presynaptic vesicle dynamics and composition. Brain J. Neurol. 2015, 139, 365-379.

98. Fouka, P.; Alexopoulos, H.; Akrivou, S.; Trohatou, O.; Politis, P.K.; Dalakas, M.C. GAD65 epitope mapping and search for novel autoantibodies in GAD-associated neurological disorders. $J$. Neuroimmunol. 2015, 281, 73-77.

99. Gresa-Arribas, N.; Arino, H.; Martinez-Hernandez, E.; Petit-Pedrol, M.; Sabater, L.; Saiz, A.; Dalmau, J.; Graus, F. Antibodies to inhibitory synaptic proteins in neurological syndromes 
associated with glutamic acid decarboxylase autoimmunity. PLOS ONE 2015, 10, doi:10.1371/journal.pone.0121364.

100. Arino, H.; Hoftberger, R.; Gresa-Arribas, N.; Martinez-Hernandez, E.; Armangue, T.; Kruer, M.C.; Arpa, J.; Domingo, J.; Rojc, B.; Bataller, L.; et al. Paraneoplastic neurological syndromes and glutamic acid decarboxylase antibodies. JAMA Neurol. 2015, 72, 874-881.

101. Bien, C.G. Association of paraneoplastic neurological disorders with glutamic acid decarboxylase antibodies. JAMA Neurol. 2015, 72, 861-862.

102. Carvajal-Gonzalez, A.; Leite, M.I.; Waters, P.; Woodhall, M.; Coutinho, E.; Balint, B.; Lang, B.; Pettingill, P.; Carr, A.; Sheerin, U.M.; et al. Glycine receptor antibodies in PERM and related syndromes: Characteristics, clinical features and outcomes. Brain J. Neurol. 2014, 137, 21782192.

103. lizuka, T.; Leite, M.I.; Lang, B.; Waters, P.; Urano, Y.; Miyakawa, S.; Hamada, J.; Sakai, F.; Mochizuki, H.; Vincent, A. Glycine receptor antibodies are detected in progressive encephalomyelitis with rigidity and myoclonus (PERM) but not in saccadic oscillations. J. Neurol. 2012, 259, 1566-1573.

104. Manto, M.U.; Laute, M.A.; Aguera, M.; Rogemond, V.; Pandolfo, M.; Honnorat, J. Effects of antiglutamic acid decarboxylase antibodies associated with neurological diseases. Ann. Neurol. 2007, $61,544-551$.

105. Karimifar, M.; Sharifi, I.; Shafiey, K. Anti-ribosomal p antibodies related to depression in early clinical course of systemic lupus erythematosus. J. Res. Med. Sci. Off. J. Isfahan Univ. Med. Sci. 2013, 18, 860-864.

106. Katzav, A.; Solodeev, I.; Brodsky, O.; Chapman, J.; Pick, C.G.; Blank, M.; Zhang, W.; Reichlin, M.; Shoenfeld, Y. Induction of autoimmune depression in mice by anti-ribosomal $p$ antibodies via the limbic system. Arthritis Rheum. 2007, 56, 938-948.

107. Shoenfeld, Y. To smell autoimmunity: Anti-p-ribosomal autoantibodies, depression, and the olfactory system. J. Autoimmun. 2007, 28, 165-169.

108. Nojima, Y.; Minota, S.; Yamada, A.; Takaku, F.; Aotsuka, S.; Yokohari, R. Correlation of antibodies to ribosomal $\mathrm{p}$ protein with psychosis in patients with systemic lupus erythematosus. Ann. Rheum. Dis. 1992, 51, 1053-1055.

109. Schneebaum, A.B.; Singleton, J.D.; West, S.G.; Blodgett, J.K.; Allen, L.G.; C. Cheronis, J.; Kotzin, B.L. Association of psychiatric manifestations with antibodies to ribosomal P proteins in systemic lupus erythematosus. Am. J. Med. 1991, 90, 54-62.

110. Watson, P.; Storbeck, J.; Mattis, P.; Mackay, M. Cognitive and emotional abnormalities in systemic lupus erythematosus: Evidence for amygdala dysfunction. Neuropsychol. Rev. 2012, 22, 252-270.

111. Gultekin, S.H.; Rosenfeld, M.R.; Voltz, R.; Eichen, J.; Posner, J.B.; Dalmau, J. Paraneoplastic limbic encephalitis: Neurological symptoms, immunological findings and tumour association in 50 patients. Brain J. Neurol. 2000, 123, 1481-1494.

112. Darnell, R.B.; Posner, J.B. A new cause of limbic encephalopathy. Brain J. Neurol. 2005, 128, 17451746.

113. Pozo-Rosich, P.; Clover, L.; Saiz, A.; Vincent, A.; Graus, F. Voltage-gated potassium channel antibodies in limbic encephalitis. Ann. Neurol. 2003, 54, 530-533.

114. Irani, S.R.; Bera, K.; Waters, P.; Zuliani, L.; Maxwell, S.; Zandi, M.S.; Friese, M.A.; Galea, I.; Kullmann, D.M.; Beeson, D.; et al. N-methyl-D-aspartate antibody encephalitis: Temporal progression of clinical and paraclinical observations in a predominantly non-paraneoplastic disorder of both sexes. Brain J. Neurol. 2010, 133, 1655-1667. 
115. Dalmau, J.; Gleichman, A.J.; Hughes, E.G.; Rossi, J.E.; Peng, X.; Lai, M.; Dessain, S.K.; Rosenfeld, M.R.; Balice-Gordon, R.; Lynch, D.R. Anti-NMDA-receptor encephalitis: Case series and analysis of the effects of antibodies. Lancet Neurol. 2008, 7, 1091-1098.

116. Gresa-Arribas, N.; Titulaer, M.J.; Torrents, A.; Aguilar, E.; McCracken, L.; Leypoldt, F.; Gleichman, A.J.; Balice-Gordon, R.; Rosenfeld, M.R.; Lynch, D.; et al. Antibody titres at diagnosis and during follow-up of anti-NMDA receptor encephalitis: A retrospective study. Lancet Neurol. 2014, 13, 167-177.

117. Pruss, H.; Dalmau, J.; Harms, L.; Holtje, M.; Ahnert-Hilger, G.; Borowski, K.; Stoecker, W.; Wandinger, K.P. Retrospective analysis of NMDA receptor antibodies in encephalitis of unknown origin. Neurology 2010, 75, 1735-1739.

118. Creten, C.; van der Zwaan, S.; Blankespoor, R.J.; Maatkamp, A.; Nicolai, J.; van Os, J.; Schieveld, J.N. Late onset autism and anti-NMDA-receptor encephalitis. Lancet 2011, 378, doi:10.1016/S0140-6736(11)60548-5.

119. Bergink, V.; Armangue, T.; Titulaer, M.J.; Markx, S.; Dalmau, J.; Kushner, S.A. Autoimmune encephalitis in postpartum psychosis. Am. J. Psychiatry 2015, 172, 901-908.

120. Pruss, H.; Holtje, M.; Maier, N.; Gomez, A.; Buchert, R.; Harms, L.; Ahnert-Hilger, G.; Schmitz, D.; Terborg, C.; Kopp, U.; et al. Iga NMDA receptor antibodies are markers of synaptic immunity in slow cognitive impairment. Neurology 2012, 78, 1743-1753.

121. Pruss, H.; Finke, C.; Holtje, M.; Hofmann, J.; Klingbeil, C.; Probst, C.; Borowski, K.; Ahnert-Hilger, G.; Harms, L.; Schwab, J.M.; et al. $\mathrm{N}$-methyl-D-aspartate receptor antibodies in herpes simplex encephalitis. Ann. Neurol. 2012, 72, 902-911.

122. Tsutsui, K.; Kanbayashi, T.; Tanaka, K.; Boku, S.; Ito, W.; Tokunaga, J.; Mori, A.; Hishikawa, Y.; Shimizu, T.; Nishino, S. Anti-NMDA-receptor antibody detected in encephalitis, schizophrenia, and narcolepsy with psychotic features. BMC Psychiatry 2012, $12,37$.

123. Dalmau, J.; Tuzun, E.; Wu, H.Y.; Masjuan, J.; Rossi, J.E.; Voloschin, A.; Baehring, J.M.; Shimazaki, H.; Koide, R.; King, D.; et al. Paraneoplastic anti- $N$-methyl-D-aspartate receptor encephalitis associated with ovarian teratoma. Ann. Neurol. 2007, 61, 25-36.

124. Hoftberger, R.; van Sonderen, A.; Leypoldt, F.; Houghton, D.; Geschwind, M.; Gelfand, J.; Paredes, M.; Sabater, L.; Saiz, A.; Titulaer, M.J.; et al. Encephalitis and AMPA receptor antibodies: Novel findings in a case series of 22 patients. Neurology 2015, 84, 2403-2412.

125. Petit-Pedrol, M.; Armangue, T.; Peng, X.; Bataller, L.; Cellucci, T.; Davis, R.; McCracken, L.; Martinez-Hernandez, E.; Mason, W.P.; Kruer, M.C.; et al. Encephalitis with refractory seizures, status epilepticus, and antibodies to the GABAA receptor: A case series, characterisation of the antigen, and analysis of the effects of antibodies. Lancet Neurol. 2014, 13, 276-286.

126. Simabukuro, M.M.; Petit-Pedrol, M.; Castro, L.H.; Nitrini, R.; Lucato, L.; Zambon, A.A.; Silva, L.G.; Fortes, G.C.; Soares Neto, H.R.; Dalmau, J.O. GABAA receptor and IGI1 antibody encephalitis in a patient with thymoma. Neurol. Neuroimmunol. Neuroinflamm. 2015, 2, doi:10.1212/NXI.0000000000000073.

127. Lancaster, E.; Martinez-Hernandez, E.; Titulaer, M.J.; Boulos, M.; Weaver, S.; Antoine, J.C.; Liebers, E.; Kornblum, C.; Bien, C.G.; Honnorat, J.; et al. Antibodies to metabotropic glutamate receptor 5 in the ophelia syndrome. Neurology 2011, 77, 1698-1701.

128. Boronat, A.; Gelfand, J.M.; Gresa-Arribas, N.; Jeong, H.Y.; Walsh, M.; Roberts, K.; MartinezHernandez, E.; Rosenfeld, M.R.; Balice-Gordon, R.; Graus, F.; et al. Encephalitis and antibodies to dipeptidyl-peptidase-like protein-6, a subunit of Kv4.2 potassium channels. Ann. Neurol. 2013, 73, 120-128. 
129. Dale, R.C.; Merheb, V.; Pillai, S.; Wang, D.; Cantrill, L.; Murphy, T.K.; Ben-Pazi, H.; Varadkar, S.; Aumann, T.D.; Horne, M.K.; et al. Antibodies to surface dopamine-2 receptor in autoimmune movement and psychiatric disorders. Brain J. Neurol. 2012, 135, 3453-3468.

130. Vo, H.D.; Sequeira, J.M.; Quadros, E.V.; Schwarz, S.M.; Perenyi, A.R. The role of folate receptor autoantibodies in preterm birth. Nutrition 2015, 31, 1224-1227.

131. Matà, S.; Muscas, G.C.; Naldi, I.; Rosati, E.; Paladini, S.; Cruciatti, B.; Bisulli, F.; Paganini, M.; Mazzi, G.; Sorbi, S.; et al. Non-paraneoplastic limbic encephalitis associated with anti-glutamic acid decarboxylase antibodies. J. Neuroimmunol. 2008, 199, 155-159.

132. lizuka, T.; Sakai, F.; Ide, T.; Monzen, T.; Yoshii, S.; ligaya, M.; Suzuki, K.; Lynch, D.R.; Suzuki, N.; Hata, T.; et al. Anti-NMDA receptor encephalitis in japan: Long-term outcome without tumor removal. Neurology 2008, 70, 504-511.

133. Sansing, L.H.; Tuzun, E.; Ko, M.W.; Baccon, J.; Lynch, D.R.; Dalmau, J. A patient with encephalitis associated with NMDA receptor antibodies. Nat. Clin. Pract. Neurol. 2007, 3, 291-296.

134. Dale, R.C.; Irani, S.R.; Brilot, F.; Pillai, S.; Webster, R.; Gill, D.; Lang, B.; Vincent, A. N-methyl-Daspartate receptor antibodies in pediatric dyskinetic encephalitis lethargica. Ann. Neurol. 2009, 66, 704-709.

135. Florance, N.R.; Davis, R.L.; Lam, C.; Szperka, C.; Zhou, L.; Ahmad, S.; Campen, C.J.; Moss, H.; Peter, N.; Gleichman, A.J.; et al. Anti-N-methyl-D-aspartate receptor (NMDAR) encephalitis in children and adolescents. Ann. Neurol. 2009, 66, 11-18.

136. Gleichman, A.J.; Spruce, L.A.; Dalmau, J.; Seeholzer, S.H.; Lynch, D.R. Anti-NMDA receptor encephalitis antibody binding is dependent on amino acid identity of a small region within the GluN1 amino terminal domain. J. Neurosci. Off. J. Soc. Neurosc. 2012, 32, 11082-11094.

137. Planaguma, J.; Leypoldt, F.; Mannara, F.; Gutierrez-Cuesta, J.; Martin-Garcia, E.; Aguilar, E.; Titulaer, M.J.; Petit-Pedrol, M.; Jain, A.; Balice-Gordon, R.; et al. Human N-methyl-D-aspartate receptor antibodies alter memory and behaviour in mice. Brain J. Neurol. 2015, 138, 94-109.

138. Wright, S.; Hashemi, K.; Stasiak, L.; Bartram, J.; Lang, B.; Vincent, A.; Upton, A.L. Epileptogenic effects of NMDAR antibodies in a passive transfer mouse model. Brain J. Neurol. 2015, 138, 31593167.

139. Vincent, A.; Bien, C.G.; Irani, S.R.; Waters, P. Autoantibodies associated with diseases of the CNS: New developments and future challenges. Lancet Neurol. 2011, 10, 759-772.

140. Bataller, L.; Kleopa, K.A.; Wu, G.F.; Rossi, J.E.; Rosenfeld, M.R.; Dalmau, J. Autoimmune limbic encephalitis in 39 patients: Immunophenotypes and outcomes. J. Neurol. Neurosurg. Psychiatry 2007, 78, 381-385.

141. Graus, F.; Saiz, A.; Lai, M.; Bruna, J.; Lopez, F.; Sabater, L.; Blanco, Y.; Rey, M.J.; Ribalta, T.; Dalmau, J. Neuronal surface antigen antibodies in limbic encephalitis: Clinical-immunologic associations. Neurology 2008, 71, 930-936.

142. Poliak, S.; Salomon, D.; Elhanany, H.; Sabanay, H.; Kiernan, B.; Pevny, L.; Stewart, C.L.; Xu, X.; Chiu, S.Y.; Shrager, P.; et al. Juxtaparanodal clustering of Shaker-like $\mathrm{K}^{+}$channels in myelinated axons depends on CASPR2 and TAG-1. J. Cell Biol. 2003, 162, 1149-1160.

143. Becker, E.B.; Zuliani, L.; Pettingill, R.; Lang, B.; Waters, P.; Dulneva, A.; Sobott, F.; Wardle, M.; Graus, F.; Bataller, L.; et al. Contactin-associated protein-2 antibodies in non-paraneoplastic cerebellar ataxia. J. Neurol. Neurosurg. Psychiatry 2012, 83, 437-440.

144. Endres, D.; Perlov, E.; Baumgartner, A.; Hottenrott, T.; Dersch, R.; Stich, O.; van Elst, L.T. Immunological findings in psychotic syndromes: A tertiary care hospital's CSF sample of 180 patients. Front. Hum. Neurosci. 2015, 9, doi:10.3389/fnhum.2015.00476. 
145. Zandi, M.S.; Irani, S.R.; Lang, B.; Waters, P.; Jones, P.B.; McKenna, P.; Coles, A.J.; Vincent, A.; Lennox, B.R. Disease-relevant autoantibodies in first episode schizophrenia. J. Neurol. 2011, 258, 686-688.

146. Dahm, L.; Ott, C.; Steiner, J.; Stepniak, B.; Teegen, B.; Saschenbrecker, S.; Hammer, C.; Borowski, K.; Begemann, M.; Lemke, S.; et al. Seroprevalence of autoantibodies against brain antigens in health and disease. Ann. Neurol. 2014, 76, 82-94.

147. Borda, T.; Rivera, R.P.; Joensen, L.; Gomez, R.M.; Sterin-Borda, L. Antibodies against cerebral M1 cholinergic muscarinic receptor from schizophrenic patients: Molecular interaction. J. Immunol. 2002, 168, 3667-3674.

148. Tanaka, S.; Matsunaga, H.; Kimura, M.; Tatsumi, K.; Hidaka, Y.; Takano, T.; Uema, T.; Takeda, M.; Amino, N. Autoantibodies against four kinds of neurotransmitter receptors in psychiatric disorders. J. Neuroimmunol. 2003, 141, 155-164.

149. Chandley, M.J.; Miller, M.N.; Kwasigroch, C.N.; Wilson, T.D.; Miller, B.E. Increased antibodies for the $\alpha 7$ subunit of the nicotinic receptor in schizophrenia. Schizophr. Res. 2009, 109, 98-101.

150. Roy, B.F.; Bowen, W.D.; Frazier, J.S.; Rose, J.W.; McFarland, H.F.; McFarlin, D.E.; Murphy, D.L.; Morihisa, J.M. Human antiidiotypic antibody against opiate receptors. Ann. Neurol. 1988, 24, 5763.

151. Singh, V.K.; Singh, E.A.; Warren, R.P. Hyperserotoninemia and serotonin receptor antibodies in children with autism but not mental retardation. Biol. Psychiatry 1997, 41, 753-755.

152. Frye, R.E.; Sequeira, J.M.; Quadros, E.V.; James, S.J.; Rossignol, D.A. Cerebral folate receptor autoantibodies in autism spectrum disorder. Mol. Psychiatry 2013, 18, 369-381.

153. Giana, G.; Romano, E.; Porfirio, M.C.; D’Ambrosio, R.; Giovinazzo, S.; Troianiello, M.; Barlocci, E.; Travaglini, D.; Granstrem, O.; Pascale, E.; et al. Detection of auto-antibodies to dat in the serum: Interactions with dat genotype and psycho-stimulant therapy for ADHD. J. Neuroimmunol. 2015, 278, 212-222.

154. Najjar, S.; Pearlman, D.; Zagzag, D.; Golfinos, J.; Devinsky, O. Glutamic acid decarboxylase autoantibody syndrome presenting as schizophrenia. Neurologist 2012, 18, 88-91.

155. Rout, U.K.; Mungan, N.K.; Dhossche, D.M. Presence of GAD65 autoantibodies in the serum of children with autism or ADHD. Eur. Child Adolesc. Psychiatry 2012, 21, 141-147.

156. Boeder, F. Über die serologische diagnostik der schizophrenie aus dem liquor nach der methode von lehmann-facius. Z. Gesamte Neurol. Psychiatr. 1939, 165, 462-467. (In German)

157. Lancaster, E.; Martinez-Hernandez, E.; Dalmau, J. Encephalitis and antibodies to synaptic and neuronal cell surface proteins. Neurology 2011, 77, 179-189.

158. Armangue, T.; Titulaer, M.J.; Malaga, I.; Bataller, L.; Gabilondo, I.; Graus, F.; Dalmau, J. Pediatric anti- $N$-methyl-D-aspartate receptor encephalitis-clinical analysis and novel findings in a series of 20 patients. J. Pediatr. 2013, 162, 850-856.

159. Steiner, J.; Walter, M.; Glanz, W.; Sarnyai, Z.; Bernstein, H.G.; Vielhaber, S.; Kastner, A.; Skalej, M.; Jordan, W.; Schiltz, K.; et al. Increased prevalence of diverse $\mathrm{N}$-methyl-D-aspartate glutamate receptor antibodies in patients with an initial diagnosis of schizophrenia: Specific relevance of IgG NR1a antibodies for distinction from $\mathrm{N}$-methyl-D-aspartate glutamate receptor encephalitis. JAMA Psychiatry 2013, 70, 271-278.

160. Pathmanandavel, K.; Starling, J.; Merheb, V.; Ramanathan, S.; Sinmaz, N.; Dale, R.C.; Brilot, F. Antibodies to surface dopamine-2 receptor and $\mathrm{N}$-methyl-D-aspartate receptor in the first episode of acute psychosis in children. Biol. Psychiatry 2015, 77, 537-547. 
161. Ezeoke, A.; Mellor, A.; Buckley, P.; Miller, B. A systematic, quantitative review of blood autoantibodies in schizophrenia. Schizophr. Res. 2013, 150, 245-251.

162. Masdeu, J.C.; Gonzalez-Pinto, A.; Matute, C.; De Azua, S.R.; Palomino, A.; De Leon, J.; Berman, K.F.; Dalmau, J. Serum IgG antibodies against the NR1 subunit of the NMDA receptor not detected in schizophrenia. Am. J. Psychiatry 2012, 169, 1120-1121.

163. De Witte, L.D.; Hoffmann, C.; van Mierlo, H.C.; Titulaer, M.J.; Kahn, R.S.; Martinez-Martinez, P.; European Consortium of Autoimmune Mental, D. Absence of $N$-methyl-D-aspartate receptor IgG autoantibodies in schizophrenia: The importance of cross-validation studies. JAMA Psychiatry 2015, 72, 731-733.

164. Borda, T.; Gomez, R.; Berria, M.I.; Sterin-Borda, L. Antibodies against astrocyte M1 and M2 muscarinic cholinoceptor from schizophrenic patients' sera. Glia 2004, 45, 144-154.

165. Moussavi, S.; Chatterji, S.; Verdes, E.; Tandon, A.; Patel, V.; Ustun, B. Depression, chronic diseases, and decrements in health: Results from the world health surveys. Lancet 2007, 370, 851-858.

166. Salmans, S. Depression: Questions You Have-Answers You Need; People's Medical Society: Allentown, PA, US, 1997.

167. Association, A.P. Diagnostic and Statistical Manual of Mental Disorders (DSM-5 ${ }^{\circ}$ ); American Psychiatric Association: Arlington, VA, USA, 2013.

168. Elhwuegi, A.S. Central monoamines and their role in major depression. Prog. Neuro Psychopharmacol. Biol. Psychiatry 2004, 28, 435-451.

169. Murphy, D.L.; Fox, M.A.; Timpano, K.R.; Moya, P.R.; Ren-Patterson, R.; Andrews, A.M.; Holmes, A.; Lesch, K.-P.; Wendland, J.R. How the serotonin story is being rewritten by new gene-based discoveries principally related to SLC6A4, the serotonin transporter gene, which functions to influence all cellular serotonin systems. Neuropharmacology 2008, 55, 932-960.

170. Roy, B.F.; Rose, J.W.; McFarland, H.F.; McFarlin, D.E.; Murphy, D.L. Anti-beta-endorphin immunoglobulin G in humans. Proc. Natl. Acad. Sci. USA 1986, 83, 8739-8743.

171. Lapteva, L.; Nowak, M.; Yarboro, C.H.; Takada, K.; Roebuck-Spencer, T.; Weickert, T.; Bleiberg, J.; Rosenstein, D.; Pao, M.; Patronas, N.; et al. Anti-N-methyl-D-aspartate receptor antibodies, cognitive dysfunction, and depression in systemic lupus erythematosus. Arthritis Rheum. 2006, 54, 2505-2514.

172. DeGiorgio, L.A.; Konstantinov, K.N.; Lee, S.C.; Hardin, J.A.; Volpe, B.T.; Diamond, B. A subset of lupus anti-DNA antibodies cross-reacts with the NR2 glutamate receptor in systemic lupus erythematosus. Nat. Med. 2001, 7, 1189-1193.

173. Keil, A.; Daniels, J.L.; Forssen, U.; Hultman, C.; Cnattingius, S.; Soderberg, K.C.; Feychting, M.; Sparen, P. Parental autoimmune diseases associated with autism spectrum disorders in offspring. Epidemiology 2010, 21, 805-808.

174. Kohane, I.S.; McMurry, A.; Weber, G.; MacFadden, D.; Rappaport, L.; Kunkel, L.; Bickel, J.; Wattanasin, N.; Spence, S.; Murphy, S.; et al. The co-morbidity burden of children and young adults with autism spectrum disorders. PLOS ONE 2012, 7, doi:10.1371/journal.pone.0033224.

175. Wang, L.; Zhou, D.; Lee, J.; Niu, H.; Faust, T.W.; Frattini, S.; Kowal, C.; Huerta, P.T.; Volpe, B.T.; Diamond, B. Female mouse fetal loss mediated by maternal autoantibody. J. Exp. Med. 2012, 209, 1083-1089.

176. Singer, H.S.; Morris, C.; Gause, C.; Pollard, M.; Zimmerman, A.W.; Pletnikov, M. Prenatal exposure to antibodies from mothers of children with autism produces neurobehavioral alterations: $A$ pregnant dam mouse model. J. Neuroimmunol. 2009, 211, 39-48. 
177. Camacho, J.; Jones, K.; Miller, E.; Ariza, J.; Noctor, S.; Van de Water, J.; Martinez-Cerdeno, V. Embryonic intraventricular exposure to autism-specific maternal autoantibodies produces alterations in autistic-like stereotypical behaviors in offspring mice. Behav. Brain Res. 2014, 266, 46-51.

178. Braunschweig, D.; Golub, M.S.; Koenig, C.M.; Qi, L.; Pessah, I.N.; Van de Water, J.; Berman, R.F. Maternal autism-associated IgG antibodies delay development and produce anxiety in a mouse gestational transfer model. J. Neuroimmunol. 2012, 252, 56-65.

179. Bauman, M.D.; losif, A.M.; Ashwood, P.; Braunschweig, D.; Lee, A.; Schumann, C.M.; Van de Water, J.; Amaral, D.G. Maternal antibodies from mothers of children with autism alter brain growth and social behavior development in the rhesus monkey. Transl. Psychiatry 2013, 3, doi:10.1038/tp.2013.47.

180. Braunschweig, D.; Ashwood, P.; Krakowiak, P.; Hertz-Picciotto, I.; Hansen, R.; Croen, L.A.; Pessah, I.N.; Van de Water, J. Autism: Maternally derived antibodies specific for fetal brain proteins. Neurotoxicology 2008, 29, 226-231.

181. Braunschweig, D.; Duncanson, P.; Boyce, R.; Hansen, R.; Ashwood, P.; Pessah, I.N.; HertzPicciotto, I.; Van de Water, J. Behavioral correlates of maternal antibody status among children with autism. J. Autism Dev. Disord. 2012, 42, 1435-1445.

182. Goines, P.; Van de Water, J. The immune system's role in the biology of autism. Curr. Opin. Neurol. 2010, 23, 111-117.

183. Vargas, D.L.; Nascimbene, C.; Krishnan, C.; Zimmerman, A.W.; Pardo, C.A. Neuroglial activation and neuroinflammation in the brain of patients with autism. Ann. Neurol. 2005, 57, 67-81.

184. Morris, C.M.; Zimmerman, A.W.; Singer, H.S. Childhood serum anti-fetal brain antibodies do not predict autism. Pediatr. Neurol. 2009, 41, 288-290.

185. Braunschweig, D.; Krakowiak, P.; Duncanson, P.; Boyce, R.; Hansen, R.L.; Ashwood, P.; HertzPicciotto, I.; Pessah, I.N.; Van de Water, J. Autism-specific maternal autoantibodies recognize critical proteins in developing brain. Transl. Psychiatry 2013, 3, doi:10.1038/tp.2013.50.

186. Todd, R.D.; Hickok, J.M.; Anderson, G.M.; Cohen, D.J. Antibrain antibodies in infantile autism. Biol. Psychiatry 1988, 23, 644-647.

187. Singer, H.S.; Morris, C.M.; Williams, P.N.; Yoon, D.Y.; Hong, J.J.; Zimmerman, A.W. Antibrain antibodies in children with autism and their unaffected siblings. J. Neuroimmunol. 2006, 178, 149-155.

188. Connolly, A.M.; Chez, M.G.; Pestronk, A.; Arnold, S.T.; Mehta, S.; Deuel, R.K. Serum autoantibodies to brain in landau-kleffner variant, autism, and other neurologic disorders. J. Pediatr. 1999, 134, 607-613.

189. Vojdani, A.; O'Bryan, T.; Green, J.A.; McCandless, J.; Woeller, K.N.; Vojdani, E.; Nourian, A.A.; Cooper, E.L. Immune response to dietary proteins, gliadin and cerebellar peptides in children with autism. Nutr. Neurosci. 2004, 7, 151-161.

190. Bashir, S.; Al-Ayadhi, L. Endothelial antibody levels in the sera of children with autism spectrum disorders. J. Chin. Med. Assoc. 2015, 78, 414-417.

191. Connolly, A.M.; Chez, M.; Streif, E.M.; Keeling, R.M.; Golumbek, P.T.; Kwon, J.M.; Riviello, J.J.; Robinson, R.G.; Neuman, R.J.; Deuel, R.M. Brain-derived neurotrophic factor and autoantibodies to neural antigens in sera of children with autistic spectrum disorders, landau-kleffner syndrome, and epilepsy. Biol. Psychiatry 2006, 59, 354-363. 
192. Goines, P.; Haapanen, L.; Boyce, R.; Duncanson, P.; Braunschweig, D.; Delwiche, L.; Hansen, R.; Hertz-Picciotto, I.; Ashwood, P.; Van de Water, J. Autoantibodies to cerebellum in children with autism associate with behavior. Brain Behav. Immunity 2011, 25, 514-523.

193. Wills, S.; Cabanlit, M.; Bennett, J.; Ashwood, P.; Amaral, D.G.; Van de Water, J. Detection of autoantibodies to neural cells of the cerebellum in the plasma of subjects with autism spectrum disorders. Brain Behav. Immunity 2009, 23, 64-74.

194. Wills, S.; Rossi, C.C.; Bennett, J.; Martinez-Cerdeno, V.; Ashwood, P.; Amaral, D.G.; Van de Water, J. Further characterization of autoantibodies to gabaergic neurons in the central nervous system produced by a subset of children with autism. Mol. Autism 2011, 2, doi:10.1186/2040-2392-2-5.

195. Rossi, C.C.; Van de Water, J.; Rogers, S.J.; Amaral, D.G. Detection of plasma autoantibodies to brain tissue in young children with and without autism spectrum disorders. Brain Behav. Immunity 2011, 25, 1123-1135.

196. Ramaekers, V.T.; Quadros, E.V.; Sequeira, J.M. Role of folate receptor autoantibodies in infantile autism. Mol. Psychiatry 2013, 18, 270-271.

197. Polanczyk, G.; de Lima, M.S.; Horta, B.L.; Biederman, J.; Rohde, L.A. The worldwide prevalence of ADHD: A systematic review and metaregression analysis. Am. J. Psychiatry 2007, 164, 942-948.

198. Biederman, J.; Monuteaux, M.C.; Mick, E.; Spencer, T.; Wilens, T.E.; Silva, J.M.; Snyder, L.E.; Faraone, S.V. Young adult outcome of attention deficit hyperactivity disorder: A controlled 10year follow-up study. Psychol. Med. 2006, 36, 167-179.

199. Swedo, S.E.; Leonard, H.L.; Garvey, M.; Mittleman, B.; Allen, A.J.; Perlmutter, S.; Lougee, L.; Dow, S.; Zamkoff, J.; Dubbert, B.K. Pediatric autoimmune neuropsychiatric disorders associated with streptococcal infections: Clinical description of the first 50 cases. Am. J. Psychiatry 1998, 155, 264-271.

200. Mercadante, M.T.; Busatto, G.F.; Lombroso, P.J.; Prado, L.; Rosario-Campos, M.C.; do Valle, R.; Marques-Dias, M.J.; Kiss, M.H.; Leckman, J.F.; Miguel, E.C. The psychiatric symptoms of rheumatic fever. Am. J. Psychiatry 2000, 157, 2036-2038.

201. Swedo, S.E. Sydenham's chorea: A model for childhood autoimmune neuropsychiatric disorders. JAMA 1994, 272, 1788-1791.

202. Yaddanapudi, K.; Hornig, M.; Serge, R.; De Miranda, J.; Baghban, A.; Villar, G.; Lipkin, W.I. Passive transfer of Streptococcus-induced antibodies reproduces behavioral disturbances in a mouse model of pediatric autoimmune neuropsychiatric disorders associated with streptococcal infection. Mol. Psychiatry 2010, 15, 712-726.

203. Perlmutter, S.J.; Leitman, S.F.; Garvey, M.A.; Hamburger, S.; Feldman, E.; Leonard, H.L.; Swedo, S.E. Therapeutic plasma exchange and intravenous immunoglobulin for obsessive-compulsive disorder and tic disorders in childhood. Lancet 1999, 354, 1153-1158.

204. Kirvan, C.A.; Swedo, S.E.; Snider, L.A.; Cunningham, M.W. Antibody-mediated neuronal cell signaling in behavior and movement disorders. J. Neuroimmunol. 2006, 179, 173-179.

205. Brimberg, L.; Benhar, I.; Mascaro-Blanco, A.; Alvarez, K.; Lotan, D.; Winter, C.; Klein, J.; Moses, A.E.; Somnier, F.E.; Leckman, J.F.; et al. Behavioral, pharmacological, and immunological abnormalities after streptococcal exposure: A novel rat model of sydenham chorea and related neuropsychiatric disorders. Neuropsychopharmacology 2012, 37, 2076-2087.

206. Lotan, D.; Benhar, I.; Alvarez, K.; Mascaro-Blanco, A.; Brimberg, L.; Frenkel, D.; Cunningham, M.W.; Joel, D. Behavioral and neural effects of intra-striatal infusion of anti-streptococcal antibodies in rats. Brain Behav. Immunity 2014, 38, 249-262. 
207. Hufner, K.; Frajo-Apor, B.; Hofer, A. Neurology issues in schizophrenia. Curr.Psychiatry Rep. 2015, $17,32$.

208. Steiner, J.; Bogerts, B. N-methyl-D-aspartate receptor autoantibodies in schizophrenia and affective disorders. Schizophr. Res. 2015, 162, doi:10.1016/j.schres.2015.01.009.

209. Malina, K.C.K.; Ganor, Y.; Levite, M.; Teichberg, I.V. Autoantibodies against an extracellular peptide of the GluR3 subtype of AMPA receptors activate both homomeric and heteromeric AMPA receptor channels. Neurochem. Res. 2006, 31, 1181-1190.

210. Lai, M.; Hughes, E.G.; Peng, X.; Zhou, L.; Gleichman, A.J.; Shu, H.; Matà, S.; Kremens, D.; Vitaliani, R.; Geschwind, M.D.; et al. AMPA receptor antibodies in limbic encephalitis alter synaptic receptor location. Ann. Neurol. 2009, 65, 424-434.

211. Ganor, Y.; Goldberg-Stern, H.; Cohen, R.; Teichberg, V.; Levite, M. Glutamate receptor antibodies directed against AMPA receptors subunit 3 peptide $B$ (GluR3B) can be produced in DBA/2J mice, lower seizure threshold and induce abnormal behavior. Psychoneuroendocrinology 2014, 42, 106-117.

212. Ramaekers, V.T.; Thöny, B.; Sequeira, J.M.; Ansseau, M.; Philippe, P.; Boemer, F.; Bours, V.; Quadros, E.V. Folinic acid treatment for schizophrenia associated with folate receptor autoantibodies. Mol. Genet. and Metabol. 2014, 113, 307-314.

213. Ho, A.; Michelson, D.; Aaen, G.; Ashwal, S. Cerebral folate deficiency presenting as adolescent catatonic schizophrenia: A case report. J. Child Neurol. 2010, 25, 898-900.

214. Matus, S.; Burgos, P.V.; Bravo-Zehnder, M.; Kraft, R.; Porras, O.H.; Farías, P.; Barros, L.F.; Torrealba, F.; Massardo, L.; Jacobelli, S.; et al. Antiribosomal-P autoantibodies from psychiatric lupus target a novel neuronal surface protein causing calcium influx and apoptosis. J. Exp. Med. 2007, 204, 3221-3234.

215. Pearlman, D.M.; Vora, H.S.; Marquis, B.G.; Najjar, S.; Dudley, L.A. Anti-basal ganglia antibodies in primary obsessive-compulsive disorder: Systematic review and meta-analysis. Br. J. Psychiatry 2014, 205, 8-16.

216. Maina, G.; Albert, U.; Bogetto, F.; Borghese, C.; Berro, A.C.; Mutani, R.; Rossi, F.; Vigliani, M.C. Anti-brain antibodies in adult patients with obsessive-compulsive disorder. J. Affect. Disord. 2009, 116, 192-200.

217. Aguilera-Albesa, S.; Crespo-Eguilaz, N.; Del Pozo, J.L.; Villoslada, P.; Sanchez-Carpintero, R. Antibasal ganglia antibodies and streptococcal infection in ADHD. J. Atten. Disord. 2015, doi:10.1177/1087054715580841.

218. Sanchez-Carpintero, R.; Albesa, S.A.; Crespo, N.; Villoslada, P.; Narbona, J. A preliminary study of the frequency of anti-basal ganglia antibodies and streptococcal infection in attention deficit/hyperactivity disorder. J. Neurol. 2009, 256, 1103-1108.

219. Hegvik, T.-A.; Husebye, E.S.; Haavik, J. Autoantibodies targeting neurotransmitter biosynthetic enzymes in attention-deficit/hyperactivity disorder (ADHD). Eur. Child Adolesc. Psychiatry 2013, 23, 115-117. 


\section{Chapter 3}

Neuronal surface autoantibodies in neuropsychiatric disorders: are there implications for depression? 


\begin{abstract}
:
Autoimmune diseases are affecting around $7.6-9.4 \%$ of the general population. A number of central nervous system disorders, including encephalitis and severe psychiatric disorders, have been demonstrated to associate with specific neuronal surface autoantibodies. It has become clear that specific autoantibodies targeting neuronal surface antigens and ion channels could cause severe mental disturbances. A number of studies have focused or are currently investigating the presence of autoantibodies in specific mental conditions such as schizophrenia and bipolar disorders. However, less is known about other conditions such as depression. Depression is a psychiatric disorder with complex etiology and pathogenesis. The diagnosis criteria of depression are largely based on symptoms but not on the origin of the disease. The question which arises is whether, in a subgroup of patients with depression, the symptoms might be caused by autoantibodies targeting membrane-associated antigens. Here, we describe how autoantibodies targeting membrane proteins and ion channels cause pathological effects. We discuss the physiology of these antigens and their pathogenicity in relation to depression. Finally, we summarize a number of studies detecting neuronal surface autoantibodies with a special focus on those that the cohorts include depression diagnosis and/ or show depressive symptoms.
\end{abstract}




\section{Introduction:}

Neuronal surface autoantibodies (NSAbs) have been described mainly in autoimmune encephalitis, a group of newly defined neuroimmunological disorders [1]. Those autoantibodies target essential neurotransmitter receptors, ion channels or associated proteins on the membrane of neuronal cells, such as N-Methyl-D-aspartate receptor (NMDAR) [2], $\alpha$ amino-3-hydroxy-5-methyl-4-isoxazolepropionic acid receptor (AMPAR) [3, 4], metabotropic glutamate receptor 1 (mGluR1) [5], metabotropic glutamate receptor 5 (mGluR5) [6], GABAB receptor (GABABR) [7], GABAA receptor (GABAAR) [8-10], leucine-rich, glioma inactivated 1 (LGI1) and contactin-associated protein-like 2 (Caspr2) [11], dipeptidyl aminopeptidase-like protein 6 (DPPX) [12-14], and dopamine receptor D2 (D2R) [15]. Antibody positive cases are associated with a spectrum of neurological disorders including limbic encephalitis, neuromyotonia, Morvan's syndrome, epilepsy and psychiatric disorders [16-19].

Depression is a psychiatric disorder with complex etiology and pathogenesis. The International Classification of Diseases (ICD) and The Diagnostic and Statistical Manual of Mental Disorders (DSM) are widely used for the diagnoses of this disorder, based on symptoms but not on the cause of the disease. There are several theories about the causes of depression and immune dysregulation is one of them. The relationship between the immune system and depression has been widely discussed. To date, most research has focused on pro-inflammatory cytokines and a few reviews also propose a direct link of autoantibodies and depression [20, 21]. Studies investigating the presence of autoantibodies in depression have focused on those targeting peripheral organs like the thyroid and intracellular antigens such as anti-nuclear antibodies and ribosomal-P antibodies [21-25]. During the past decade, it has become clear that NSAbs could cause severe neuropsychiatric disorders. Since some of the NSAbs interfere with neurotransmission pathways related to depression [26-28], a subtype of depression may be caused by antibody-mediated autoimmunity and therefore might potentially respond to immunotherapy. In the current review, we summarize the literature about NSAbs in autoimmune encephalitis and psychiatric disorders, with special focus on what is known regarding NSAbs in depression, evaluate the techniques used and how results can be interpreted and identify research gaps. Together, we aim to provide insight into the potential role of NSAbs in depression based on the function of relevant neurotransmitter receptors and ion channels as well as autoantibody effector mechanisms.

\section{How NSAbs reach the central nerves system}

Because neuronal surface proteins are the target of the autoantibodies discussed in this review, it is important to first understand how those autoantibodies get access to the central nerves system (CNS). Now it is widely accepted that the CNS is targeted by the immune system, yet the mechanism of how autoantibodies go through the blood-brain barrier (BBB) is still unclear. Under normal conditions, immunoglobulins go through the BBB at a very low rate; a good example is immunoglobulin $\mathrm{G}(\mathrm{IgG})$. IgG concentration in the cerebrospinal fluid (CSF) is approximately $1 \%$ of the levels in peripheral circulation [29-31]. This indicates that once the autoantibodies reach the CNS they can cause disease as it has been observed in autoimmune encephalitis. In certain situations, like inflammation, for example, during the group A Streptococcus infection, specific Th17 cells could migrate into the brain through the cribriform plate along olfactory sensory axons. The Th17 cells expressed IL-17A which induced 
endothelial tight junction breakdown, increasing BBB permeability and facilitating the penetration of $\mathrm{IgG}$ in the brain [32]. Additionally, the BBB may become leaky because of stroke, brain trauma, hemorrhages, microangiopathy or brain tumors, an antibody penetration rate might increase. In this regard, a study has reported that autoantibodies to NMDAR (antiNMDAR) seropositive schizophrenia patients with a history of neuro-trauma or birth complications had more severe neurological symptoms than seronegative patients. And intravenous injections of extracted Ig fractions ( $\operatorname{IgG}$, IgA, or IgM) from anti-NMDAR seropositive patients to BBB leaky (ApoE-/-) mice could induce psychosis-related response [33]. A further study confirmed that APOE4 carrier status and anti-NMDAR seropositivity together was significantly associated with schizoaffective disorder [34]. Those results indicate the importance of the BBB for anti-NMDAR mediated pathology.

Besides, intrathecal synthesis is another possible source for autoantibodies in the CNS. B-cells can migrate to the brain and produce autoantibodies locally [35-37]. This is also important to keep in mind when thinking about therapy because any potential drug against B cells has to pass the BBB to be effective. The evidence is mainly from studies analyzing autoantibodies in serum and CSF from encephalitis patients. It has been reported that in some encephalitis patients, autoantibodies targeting the NMDAR, AMPAR, GABABR, DPPX, mGluR1 or mGluR5 were found only in the CSF [38]. A post-mortem study showed the presence of CD138+ plasma cells in the brain of NMDAR encephalitis patients, which support the intrathecal synthesis of antibodies [36]. Intrathecal antibody synthesis was also described in a case with autoantibodies against the mGluR1 where the patient did not respond to immunotherapy, while serum antibody levels dropped but CSF levels were still high [39]. Other NSAbs, such as autoantibodies to LGI1, Caspr2, glycine receptor (GlyR) and GABAAR may, in rare instances, be identified only in serum but be absent in CSF [38]. However, if the autoantibodies are immuno-absorbed by the antigen in the brain, they might still have effects and play a pathogenic role even they are not detectable in the CSF [40].

\section{IgG effector functions}

Antibodies are Igs produced by B cells of the adaptive immune system. They are defined as $\operatorname{IgM}, \operatorname{IgG}, \operatorname{IgA}$, IgD and $\operatorname{IgE}$ isotypes according to heavy chain $\mathrm{C}$ domains. Though different types of NSAbs (IgM, IgA, IgG) have been found so far, IgG type is considered the most pathogenic related $[1,10,33]$. IgG, composed of two paired heavy chain and light chain, is the major antibody in body fluid and a crucial player in the humoral immune response. In humans, four different IgG isotypes (IgG1-4) containing similar amino acid sequences exist, which have different abilities to activate the complement system. IgG1-3 mediate pro-inflammatory activities, while IgG4 has anti-inflammatory activities [41]. IgG effector functions in myasthenia gravis (MG) and other well studied autoimmune disorders are explained as a paradigm (Figure 1).

\section{Antigenic modulation}

Antibodies of the IgG1-3 subtypes are able to crosslink the antigens because of their bivalent nature whereas the IgG4 subtype loses this ability after the fab-arm exchange with other unrelated IgG4 molecules [42]. Cross-linking autoantibodies are believed to bring the antigens to close together on the cell membrane and promote the degradation of the ligand-receptor complex [43]. In the case of $\mathrm{MG}$, anti-acetylcholine receptor autoantibodies (anti-AChR), mainly IgG1 and IgG3, are able to cross-link adjacent AChR molecules and lead to rapidly 
internalization by endocytosis and then are degraded $[44,45]$. Previous studies indicated that anti-NMDAR, IgG1-3, led to a reduction in the synaptic and extra-synaptic receptors and further decreased the synaptic plasticity and transmission [46-49]. Anti-GABAAR, IgG1, and IgG3, had a similar effect with a reduction of GABAAR clusters in both synaptic and extrasynaptic areas [8-10]. Application of anti-AMPAR (GluR1/2) to neuronal cultures significantly decreased the number of AMPAR clusters also at synaptic and extra-synaptic areas by increasing the internalization of AMPAR clusters, which could be reversed after autoantibody removal, yet the IgG subclasses were not analyzed in these studies $[4,50]$.

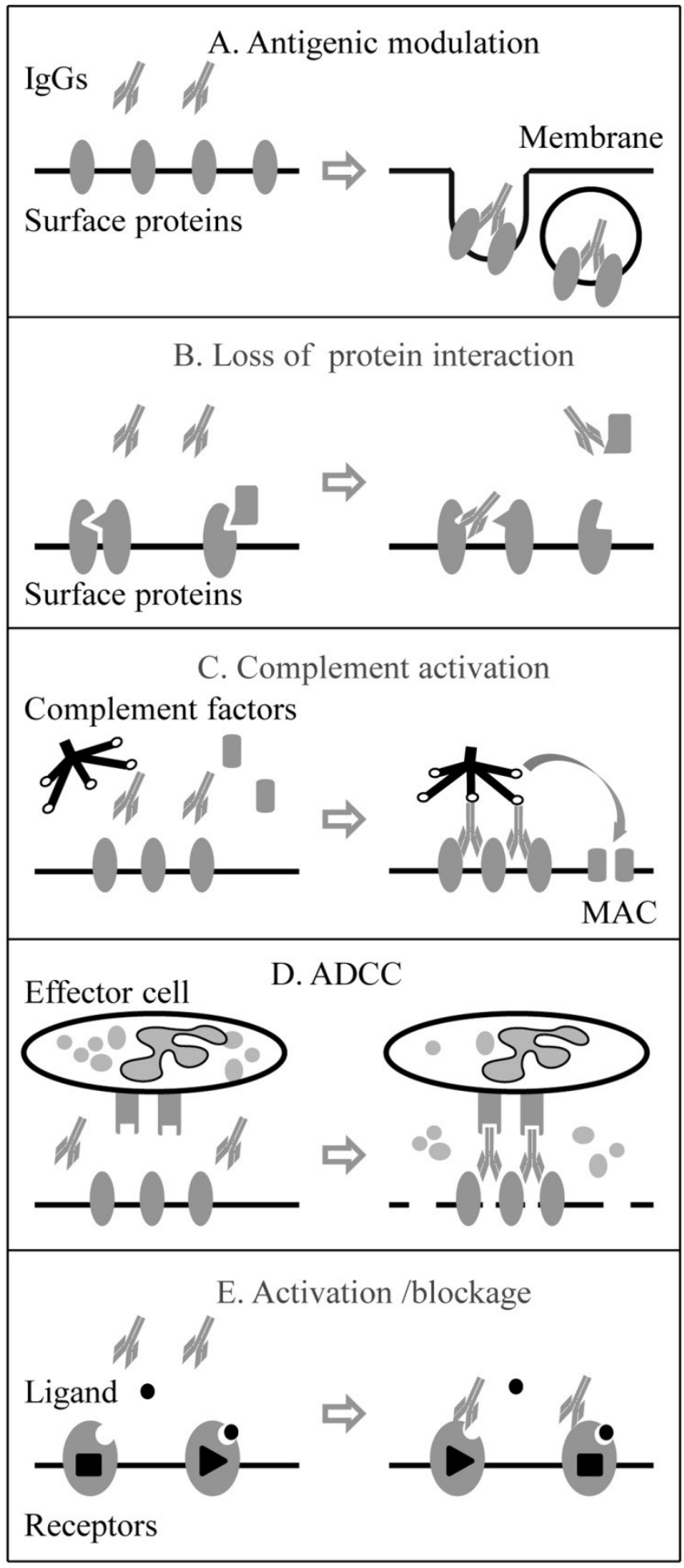

Figure 1. IgG autoantibody effector mechanisms. Neuronal surface proteins like G-protein coupled receptors, ionchannels and associated proteins can be the target of autoantibodies. (A) Autoantibodies can directly target surface proteins and induce their internalization by cross-linking of the antigens. (B) Autoantibodies can also target associate proteins and block protein-protein interaction. (C) Autoantibodies (IgG3>IgG1>lgG2) can activate the complement system and form the membrane attack complex (MCA) leading to damage of the membrane. (D) Autoantibodies bind to effector cell with certain Fc receptors (FCRs) can trigger antibody-dependent cell-mediated cytotoxicity (ADCC). (E) In addition, autoantibodies can be agonists or antagonists and activate or block the function of membrane receptors. 


\section{Complement activation}

IgG1-3 can activate the complement system by forming the membrane attack complex (MAC) and leading to membrane damage of targeted cells. Still, in MG, anti-AChR binding to AChRs, which are densely packed in the folds of the postsynaptic membrane of the neuromuscular junction, results in a very high density of AChR bound autoantibodies and hence, a very tightly packed Fc region. The complement system is activated with high efficiency and as a result, MAC is formed in the postsynaptic membrane. Together with antigenic modulation, complement activation causes severe endplate membrane damage [44, 51]. Brain biopsy findings support that complement activation and MAC deposition happens associated with acute neuronal cell death in anti-VGKC complex encephalitis and Rasmussen's encephalitis $[52,53]$.

\section{Antibody-dependent cell-mediated cytotoxicity}

Antibody-dependent cell-mediated cytotoxicity (ADCC) is the process when cytotoxic effector cells (immune cells) kill the antibody-targeted cell by releasing cytotoxic granules or cell deathinducing molecules. The process is activated when the Fc receptors (FcRs) on the effector cell surface bind to the Fc region of target-bound antibodies (IgG, IgA or IgE subtypes). Those effector cells include natural killer (NK) cells, monocytes, macrophages, neutrophils, eosinophils, and dendritic cells. In humans, the IgG1 subtype has the ability to trigger ADCC and is used widely in therapy for certain types of cancer [54, 55]. Neuromyelitis Optica (NMO) is a severe inflammatory demyelinating disease in CNS and autoantibodies against aquaporin4 (anti-AQP4), a water channel on astrocyte play a role in the pathology of NMO by triggering complement activation and ADCC [56]. In vitro, NMO patient serum and CSF IgG induced ADCC of glial cells transfected with AQP4 [57]. In vivo, anti-AQP4 produced large NMO lesions in mice, with loss of AQP4 and GFAP immunoreactivity, inflammation and demyelination. Those pathologies were largely reduced when injection of AQP4-IgG and complement to mice lacking the Fc receptor, and to normal mice injected with Fc receptor blocking antibody [58].

\section{Loss of receptor or ion-channel associated proteins}

Autoantibodies can target receptor or ion channel associated proteins. As a result, proteinprotein interaction between the receptor and the associated protein is interrupted with the consequence that those receptors or ion channels become dysfunctional. Autoantibodies to muscle-specific kinase (anti-MuSK) are another type of autoantibodies involved in the pathogenicity of MG. Anti-MuSK (predominant IgG4) binds to an extracellular epitope on MuSK at the neuromuscular junction, inhibits the pathway involved in the clustering of the AChRs in the membrane and leads to failure of neuromuscular transmission [59]. Autoantibodies to LGI1, a VGKC complex associated protein, play a similar role, resulting in reduced VGKC function at CNS synapses and increased cell excitability [60]. Besides, antiLGI1 also interferes with other surface receptors. LGI1 interacts with the ADAM22/23, epilepsy-related transmembrane proteins, and regulates AMPAR mediated synaptic transmission in the hippocampus [61, 62]. Additionally, an in vitro study shows that anti-LG11 from encephalitis patients block the binding of LGI1 to ADAM22 by neutralizing the ADAM22-binding domain of LGI1. The loss of LGI1-ADAM22 interaction could further reduce synaptic AMPAR, which indirectly associates with ADAM22 [63]. Importantly, this indicates that besides their direct effect in ion channel-receptors, autoantibodies may interfere 
with protein-protein interaction and have consequences in synapse formation, function, and maintenance.

\section{Activation, inactivation and functional receptor blockage of the receptors}

Autoantibodies may activate, inactivate or block ion-channels and neurotransmitter G-protein coupled receptors [64]. Serum IgG from MG patients has been shown to block the ACh-binding sites in cultured mammalian muscle cells [65] and cased acute and severe muscle weakness in rodents inflammation or necrosis [66]. Autoantibodies against the $\gamma$ subunit of the AChR which only present in embryonic forms of the receptor have been reported in some cases to block the AChR function and cause arthrogryposis congenital [67]. Anti-AMPAR (GluR3B subunit) autoantibodies (anti-AMPA-GluR3B) can activate AMPAR that contains the GluR3B subunit, leading to the spontaneous occurrence of ion currents [68, 69]. In an animal study, anti-AMPAGluR3B produced following immunization with the GluR3B peptide, bonded cultured neurons, evoked GluR ion channel activity and killed neurons by 'excitotoxicity'[70]. When autoantibodies target G-protein coupled receptors, they can interfere with signaling pathways, which might lead to slow effector responses. An example is Graves' disease, where autoantibodies against the thyroid-stimulating hormone (TSH) receptor stimulate the synthesis of thyroid hormone which is produced in excess and results in hyperthyroidism. Additionally, there are anti-TSH receptor antibodies that block the signal transduction and consequently reduce thyroid hormone production by targeting different epitopes of the receptor [71].

\section{The targets of NSAbs are relevant in the pathology of depression}

Monoamine imbalance is the main biochemical postulate of depression. Both serotonergic neurotransmission and dopaminergic neurotransmission play important roles in causing depressive symptoms [72]. Genetic studies suggest that certain polymorphisms within genes that encode for receptors or proteins, 1A serotonin receptor (5HT-1A) and D4 dopamine receptor, increase the risk of major depressive disorder (MDD) [73]. 5-HT 1A [74, 75] and D2DR [76, 77] levels are decreased in this disorder and both are the targets of several antidepressants [78].

Increasing evidence supports that glutamatergic and GABAergic systems are also involved in depression $[27,28]$. Glutamate is the predominant excitatory neurotransmitters in the CNS [79, 80]. Blockade of glutamate uptake from the synapse has been reported to reduce sensitivity to reward, a symptom of depression [81]. Ketamine and other NMDAR antagonists have antidepressants effects [82]. Antidepressants such as imipramine can enhance the synaptic expression of GluR1, a subunit of AMPAR [83].

Interestingly, GABA concentration is reduced in cortical brain and CSF in MDD and this deficit could be reversed by chronic treatment with selective serotonin reuptake inhibitors and electro-convulsive therapy [84-86]. Studies reported that cortical GABA $\mathrm{A}$ affinity and/or number were reduced in MDD. Additionally, in mouse models heterozygous for the $\gamma 2$ subunit of $\mathrm{GABA}_{\mathrm{A}} \mathrm{R}\left(\gamma 2^{+/-}\right)$, which showed unaltered $\mathrm{GABA}_{\mathrm{A}} \mathrm{R}$ numbers but loss of $\mathrm{GABA}_{\mathrm{A}} \mathrm{R}$ benzodiazepine binding sites, animals exhibited a modest functional deficit in $\mathrm{GABA}_{\mathrm{A}} \mathrm{Rs}$ and anxious-depressive behavior $[87,88]$.

Thus, if the above-mentioned neurotransmitter receptors or relevant proteins are targeted by autoantibodies, including ion channels and associated proteins, they could potentially cause depression-like symptoms. Below, we summarize NSAbs that target antigens that are relevant in the pathology of depression (For an illustration see Figure 2). 


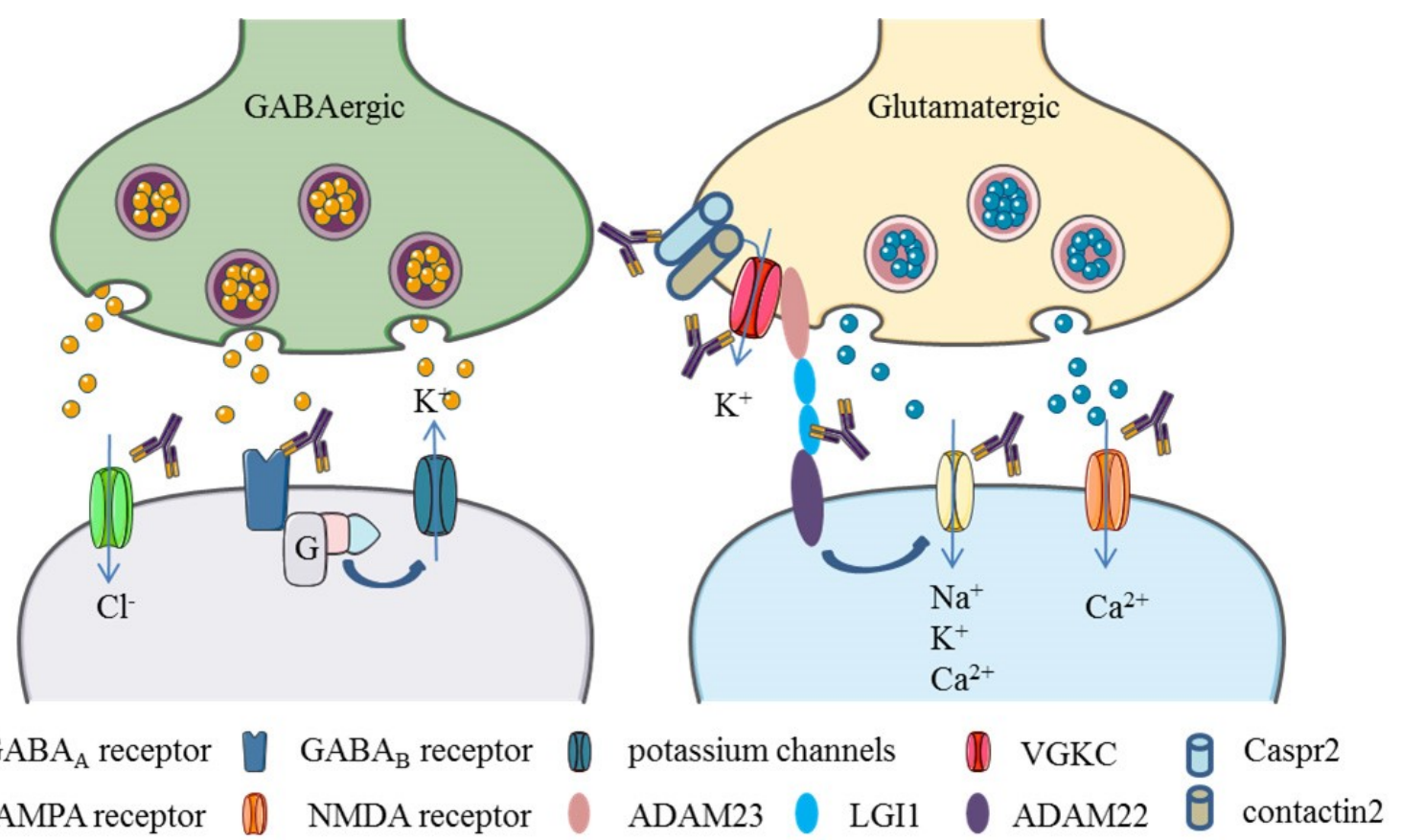

Figure 2. Neuronal surface autoantibodies target neuronal receptors, ion channels and/or associated proteins that commonly affect GABA and Glutamate transmission in the brain.

1. GABA receptor activation causes chloride anions influx and potassium flow-out, resulting in the hyperpolarization of the post-synaptic neurons. Autoantibodies to GABAA or GABAB receptors cause internalization of those membrane proteins and block the GABA transmission, leading to excitation of the post-synaptic neurons.

2. Glutamate receptors activation causes polarization of the post-synaptic neurons by positive ions $(\mathrm{Ca} 2+, \mathrm{Na}+, \mathrm{K}+)$ influx. Autoantibodies to NMDA and AMPA receptors drive internalization of those receptors and block the glutamate transmission.

3. Potassium channels can be activated by GABA B receptors through $G$ proteins. Some proteins like LG11 and caspr2, contactin2, ADAM22, and ADAM23 are associated with voltage-gated potassium channels. LGI1 can enhance AMPA receptor-mediated synaptic transmission by bind to ADAM22. Autoantibodies target those associated proteins would cause voltage-gated potassium channels or AMPA receptor dysfunction.

\section{Evidence of NSAbs in depression}

\section{Anti-glutamate receptor autoantibodies}

\section{Anti-NMDAR}

The NMDAR, as an ionotropic glutamate receptor, contains two GluN1 and two GluN2 (A-D) subunits (alternatively called NR1 and NR2) forming heterotetramers. The subunit GluN2 can be replaced by the GluN3 (A/B) subunit, which has an inhibitory effect on receptor activity $[89,90]$. NMDAR has a variety of physiological roles and any dysfunctions, either enhanced or decreased activity, may result in neuropsychiatric disorders such as schizophrenia, bipolar disorder, major depressive disorder, substance-induced psychosis, Huntington's disease, Alzheimer's disease, and neuropsychiatric systemic lupus erythematosus (NPSLE) [91]. In addition, higher gene expression levels of NR1 and NR2 (A-D) are detected in female patients with MDD [92]. Prolonged inhibition of the NMDAR by phencyclidine leads to memory loss, thought disorder, depression, and personality changes [93]. Antagonists of the NMDAR like 
ketamine also have rapid antidepressant effects [94, 95]. All in all, these studies suggest that NMDAR plays a critical role in psychiatric disorders including depression.

Anti-NMDAR in autoimmune encephalitis was first described in 3 patients with ovarian teratoma and commonly presenting with psychiatric symptoms followed by neurological manifestations including seizures, movement disorder and dysfunction of the autonomous nervous system [2]. The methods used for detection were immunohistochemistry (IHC) on rat brain tissues, immunocytochemistry on live hippocampal neurons and fixed cell-based assay (CBA). The autoantibodies identified were present both in CSF and serum. Later studies revealed that the extracellular N-terminal domain of the NR1 subunit is the main epitope of those autoantibodies [96]. A case series showed that in more than two-thirds of cases with NMDAR encephalitis patients were initially seen by psychiatrists or admitted to psychiatric centers because they showed prominent psychiatric symptoms including anxiety, agitation, bizarre behavior, delusional or paranoid thoughts, and visual or auditory hallucinations [97]. Consequently, researchers broaden the search for anti-NMDAR to psychiatric disorders, mainly first-episode psychosis. Bipolar and major depressive disorders were usually included as psychiatric disorder controls. One meta-analysis indicated higher odds of anti-NMDAR in psychotic and affective disorders[98]. An affective disorder cohort consisted of 148 patients was screened for anti-NMDAR, in which 24 (16.2\%) were seropositive ( 5 were IgG, $15 \operatorname{IgA}$, and $7 \mathrm{IgM})$. The prevalence in this cohort was higher than in healthy controls (10.8\%) [34]. In this study, the method used was fixed CBA and the dilution of serum used was from 1 in 10 and titers for positive cases were double-determined in two laboratories. The results have been argued because of the much higher prevalence of anti-NMDAR in healthy control than in other groups' study results $[34,99,100]$. Further complementary investigations, using a dilution of 1:320, identified a lower percentage of positive individuals in a cohort of depression patients. Anti-NMDAR (IgG, IgA, and $\operatorname{IgM}$ ) were found $4.1 \%$ in depression, still higher than healthy control $(1.7 \%)$ at a significant level $[33,98]$. The author explained the increased number of seropositive anti-NMDAR cases in affective disorder cohort by the fact that the mean age of the affective disorder group was higher than in the control group (autoantibody prevalence is generally increasing with age) [33]. Another study using the same methods found $10.6 \%$ (1.9\% $\mathrm{IgG})$ positive for anti-NMDAR affective disorder cohort $(\mathrm{n}=310)$ but no significant difference to healthy control [101]. Additionally, another study analyzed a depression cohort $(\mathrm{n}=70)$ and found $2(2.9 \%)$ seropositive patients for NMDAR (both IgA) and 1 seropositive $(0.4 \%)(\operatorname{IgM})$ result in healthy control $(n=230)$ but none of them were IgG [100]. Repeat experiment was performed and higher seropositive cases were found both in health and disease group[102]. Early studies by Dickerson et.al [103] (ELISA, Using a peptide of NR2, n=28) and Zandi et.al [104] using variations of the methodology (live CBA) did not report any positive results in a depression cohort. Passive transfer of anti-NMDAR (NR1) to mice could cause depressive-like symptoms [105]. However, the correlation of symptoms in animal models with those observed in humans needs to be further demonstrated [106].

In contrast to anti-NMDAR in autoimmune encephalitis which mainly targets the NR1 subunit, Lapteva and colleagues found that autoantibodies targeting the NR2 subunit of NMDAR were associated to depression in systemic lupus erythematosus (SLE) patients [107]. In fact, antiNR2A/B autoantibodies were thought to be a subset of the anti-double-stranded DNA (dsDNA) antibodies [108]. The epitope identified to be targeted by the antibodies in this study was a pentapeptide Asp/Glu-Trp-Asp/Glu-Tyr-Ser/Gly. This sequence present on the NR2A/B subunit is a mimotope of anti-dsDNA. This was confirmed by showing that affinity-purified 
antibodies from SLE patients targeting this peptide also bind to dsDNA [108, 109]. Moreover, those autoantibodies mediated apoptotic death of neurons in vivo and in vitro [108]. Several studies have investigated the role of anti-NR2 in NPSLE and found that the antibody may lead to dysfunction of NMDAR in vitro, and that passive transfer of anti-NR2 in animals induced neuronal apoptosis and affects animal memory and cognitive ability $[110,111]$.

Anti-NMDAR autoantibodies in depression are still questionable since most of these studies considered the depression cohorts as a control group and numbers were relatively small. Variations in the methodology make it difficult to compare results from different groups, which is a common fact that should be kept in mind through this review. In particular, the methodology varies among studies (CBA or ELISA), or the same methodology is used following different experimental conditions (fixed or live CBA) by different groups, different subunits of the antigens are employed (NR1, NR1, and NR2a/b together in CBA, NR2 peptide in ELISA), different body fluids (serum, plasma or CSF), different immunoglobulins detected (IgG, $\operatorname{IgA}$, and/or $\operatorname{IgM}$ ) and different dilutions of the sample used (from 1:10 to 1:320) [17].

\section{Anti-AMPAR}

AMPAR is another ionotropic glutamate receptor which mediates the fast excitatory neurotransmission in the CNS [112]. The majority of AMPAR are tetramers composed of two GluR2 and either two GluR1, 3 or 4 subunits that combine in a brain region-dependent manner $[113,114]$. GluR1/2 and GluR2/3 receptors are highly expressed in the synaptic CA3-CA1 areas of the hippocampus. Besides, they are also expressed in the cerebellum and caudateputamen [115].

Lai and colleagues first reported autoantibodies to AMPAR (GluR1 and GluR2 subunits) in limbic encephalitis [4]. The clinical feature of this type of autoimmune encephalitis is shortterm memory deficits, emotional/behavioral changes, and seizures, often paraneoplastic, treatment-responsive, and has a tendency to relapse[4]. GluR3 has been identified as an autoantigen in Rasmussen's encephalitis which the clinical characteristics of these patients were mainly epilepsy and language problems $[116,117]$. An anti-AMPAR (GluR1) positive case was reported with breast ductal infiltrating adenocarcinoma that showed behavioral changes, depressed mood, and memory loss during the process of the disease without seizures [3]. In contrast, screening for anti-AMPAR (GluR1 and GluR2) in a depression cohort $(\mathrm{n}<380)$ by fixed CBA using 1:10 diluted serum did not report any positive cases [100, 101].

\section{Anti-GABA receptors autoantibodies}

\section{Anti-GABA $\mathbf{R}$}

$\mathrm{GABA}_{\mathrm{A}} \mathrm{R}$ is an ionotropic receptor and $\mathrm{GABA}$ is the ligand. There are several subunit isoforms $(\alpha, \beta, \gamma)$ for the $\mathrm{GABA}_{\mathrm{A}} \mathrm{R}$, which determine the receptor's agonist affinity, the chance of opening, conductance, and other properties. Subunits of $\mathrm{GABA}_{\mathrm{A}} \mathrm{R}$ have a different distribution in the brain and may respond with different sensitivity to GABA, leading to a different function. A decline in $\mathrm{GABA}_{\mathrm{A}} \mathrm{R}$ signaling triggers hyperactivity in neurological disorders such as insomnia, anxiety, and epilepsy.

Autoantibodies to $\mathrm{GABA}_{\mathrm{A}} \mathrm{R}$ were recently identified in autoimmune encephalitis. The clinical feature varies in different studies. Petit-Pedrol et al. reported a series of 18 patients with anti$\mathrm{GABA}_{\mathrm{A}} \mathrm{R}$, of whom 6 had high titer antibodies detected both in blood and CSF and showed 
severe encephalitis and refractory seizures [8]. The other patients with lower titers in serum had different diagnoses. Six showed encephalitis with seizures, four had the stiff-person syndrome, and two had opsoclonus-myoclonus. Anti- $\mathrm{GABA}_{\mathrm{A}} \mathrm{R}$ in lower titers was also found in 5 of these 12. The autoantibodies targeted $\alpha 1$ and $\beta 3$ subunits and caused selective reduction of the synaptic $\mathrm{GABA}_{\mathrm{A}} \mathrm{R}$ [8]. 2 anti-GABA $\mathrm{R}$ encephalitis patients were reported and their autoantibodies targeted the $\beta 3$ subunits [9]. Later, a case study identified the main antigens as $\alpha 1 / \gamma 2$ in a group of patients with seizures and cognitive or neuropsychiatric problems. Some of these patients had mood changes ( 2 in 11 showed depression symptoms and the autoantibodies targeted to $\alpha 1$ or undefined; 3 showed anxiety and the autoantibodies targeted to $\alpha 1, \gamma 2$ or undefined subunits) [10]. A cohort of purely depression disorders has not been tested so far.

\section{Anti-GABABR}

$\mathrm{GABA}_{\mathrm{B}}$ receptors are metabotropic transmembrane receptors that are linked to G-proteins gated potassium channels [118]. There are two $\mathrm{GABA}_{\mathrm{B}}$-receptor subtypes, $\mathrm{GABA}_{\mathrm{B} 1} \mathrm{R}$, and $\mathrm{GABA}_{\mathrm{B} 2} \mathrm{R}$, assembling into functional heterogenic complexes $[119,120]$. $\mathrm{GABA}_{\mathrm{B} 1} \mathrm{R}(-/-)$ mice, which lack functional GABA(B) receptors, showed more anxiety and decreased immobility (antidepressant-like behavior) and $\mathrm{GABA}_{\mathrm{B}} \mathrm{R}$ selective antagonist CGP56433A showed antidepressant effects as well [121].

Autoantibodies to the $\mathrm{GABA}_{\mathrm{B}} \mathrm{R}$ (anti- $\mathrm{GABA}_{\mathrm{B}} \mathrm{R}$ ) were reported in limbic encephalitis (15 in 410 cases) [7]. In all patients, autoantibodies to $\mathrm{GABA}_{B} R$ targeted the $\mathrm{GABA}_{\mathrm{B} 1} \mathrm{R}$ and only one targeted $\mathrm{GABA}_{\mathrm{B} 2} \mathrm{R}[122,123]$. If anti-GABA $\mathrm{B}$ inactivates synaptic and extra-synaptic $\mathrm{GABA}_{\mathrm{B}} \mathrm{R}$, it could potentially cause anxiety but not depression. Additionally, one anti$\mathrm{GABA}_{\mathrm{B}} \mathrm{R}(\mathrm{B} 1 / \mathrm{B} 2)$ positive was found in a depression cohort $(\mathrm{n}<310)$ by fixed CBA using 1:10 diluted serum with all the controls being seronegative $(n>1693)$ [101]. To date, there are only limited studies that focus on this antigen and further investigations should be performed to extend the knowledge about autoantibody effector mechanisms.

\section{Anti-Monoamine receptors autoantibodies}

\section{Anti-5HT 1A receptor and Anti-D2 antibodies}

5-HT1A receptor is a subtype of serotonin receptor expressed widely in the limbic system and has implications in the control of mood, cognition, and memory [124]. D2R is a dopamine receptor and has long isoforms (located mainly on the post-synaptic membrane) and short isoforms (mainly on the pre-synaptic membrane), coded by alternative splicing of the same DRD2 gene [125]. It's highly expressed in basal ganglia and also cortex, hippocampus and in the area of the substantia nigra and is involved in synaptic plasticity and memory formation [126]. Both receptors are coupled with G-proteins that inhibit adenylyl cyclase, as well as other second messenger cascades [124, 127].

The presence in serum of IgG autoantibodies against 5HT-1A (anti-5HT1A) and dopamine receptor $\mathrm{D}_{2}$ (anti-D2R) in psychiatric disorders was studied by radioimmunoassay (RIA) [128]. $7.9 \%$ of the mood disorder patients including $33 \mathrm{MDD}$ had anti-5HT1A and $9.5 \%$ had antiD2R compared to healthy controls which were seronegative. Anti-D2R was significantly associated with the severity of guilt feeling and depressive mood. To our knowledge, no further experiments have been reported detecting or investigating the role of anti-5HT1A in psychiatric disorders. 
IgG autoantibodies against D2R were identified by flow cytometry CBA with a cut-off at three standard deviations above the control mean using transfected HEK cells in a subgroup of children with basal ganglia encephalitis [15]. 12 of 17 children (aged $0.4-15$ years, nine males) with basal ganglia encephalitis had anti-D2R, compared with 0 in 67 controls. The 12 anti-D2R positive patients had movement disorders and psychiatric disturbance characterized by Parkinsonism, dystonia, chorea, emotional lability, attention deficit, and psychosis. A later study showed a specific and significant reduction of D2R when transfected cells were incubated with anti-D2R and the extracellular N-terminus of D2R was revealed as the main immunogenic region [129]. 3 anti-D2R positive cases out of 43 were reported in the first episode of acute psychosis in children and the 17 controls studied were seronegative [130]. This is the first report of serum IgG autoantibodies to surface D2R in pediatric patients with isolated psychosis. And 3 of the patients were previously diagnosed with other types of mental disorders: one patient had attention-deficit/ hyperactivity disorder, behavior disorder, one had depression and anxiety, prematurity and one had anorexia nervosa [130].

\section{Anti-VGKC complex and associated proteins autoantibodies}

\section{Anti-LGI1, anti-Caspr2, and anti-DPPX}

Voltage-gated potassium channels (VGKC), typically formed by 4 different $\alpha$ subunits (there are $40 \alpha$ subunits known), each associated with a $\beta$ subunit (more than $12 \beta$ auxiliary proteins to $\alpha$ subunits), play a crucial role in returning the depolarized cell such as neurons to a resting state $[26,131]$. Typically, they are tetramers of four certain $\alpha$ subunits arranged as a ring, each contributing to the wall of the transmembrane $\mathrm{K}+$ pore. Additionally, there are other associated proteins like LGI1, Caspr2, Contactin2, ADAM22, and ADAM23, which can affect the function of VGKC and AMPAR (mentioned in the antibody effector function section) [132].

Autoantibodies to the VGKC complex (anti-VGKC complex) have been known for a long time and are involved in the pathogenesis of neuromyotonia, Morvan's syndrome, epilepsy and limbic encephalitis [26, 133, 134]. In recent years, researchers identified by CBA and IHC that the VGKC associated proteins LGI1 and Caspr2 are actually the main targets in autoimmune encephalitis. Kv4.2, a subtype of VGKC, is widely expressed in the CNS and autoantibodies directed against DPPX (an auxiliary subunit of Kv4.2 channels) (anti-DPPX) was also identified, yet in approximately $19 \%$ of the seropositive cases for the VGKC complex by RIA the antigen/s remain unknown $[11,14]$. Epilepsy and limbic encephalitis are more frequently related to anti-LGI1, while peripheral nerve hyperexcitability disorders, like Morvan's syndrome, are more common in anti-Caspr2 positive cases [135]. Anti-LGI1 patients present a clinical spectrum of confusion, depression, paranoia, behavior disturbances, visual hallucinations, and dementia at onset of the disease [136-138]. 2 seropositive (one IgG type) anti-Caspr2 were found in 310 affective disorders, while in the same study, none anti-LGI1 and anti-DPPX seropositive cases were reported [101]. The largest described cohort of antiDPPX (IgG) positive patients consists of 20 cases. Those sera or CSF positive cases were found in patients referred for evaluation of paraneoplastic neurologic autoimmunity (totally tested $83)$ and 41,812 samples submitted for evaluation of neural autoantibodies $(0.02 \%$ positive antiDPPX). Out of the 20 anti-DPPX positive patients, $20 \%$ showed depressive symptoms [14]. 


\section{Take-home message}

Although an increasing number of studies have substantially improved our knowledge on autoimmunity in the CNS, still large controversy exists, especially due to the variation in the methodology used. Also, our knowledge is largely based on findings from autoimmune encephalitis cohorts. There are several methodological aspects which have to be considered when detecting NSAbs in psychiatric disorders, especially in depression or other mood disorders. Firstly, the antigens targeted by the autoantibodies can be composed of several subunits. Autoantibodies against each of the subunits can have different clinical significance and implications [1]. A good example is the detection of NMDA NR1 antibodies and N2A/B antibodies. Anti-NR1 is believed to be pathogenic in NMDAR encephalitis [96]. However, anti-N2A/B plays a role in NPSLE [107]. When autoantibodies target different subunits of other glutamate receptors or GABA receptors, they may cause different clinical symptoms. At the same time, most NSAbs target epitopes only if the antigens are expressed in their native conformation. Techniques like CBA, IHC of brain sections optimized to detect membrane proteins (rodent), and immunocytochemistry of cultures of rodent live hippocampal neurons fit this requirement. Thirdly, different concentrations of the same autoantibody might have different effects and biological relevance. For example, high titers of anti-GABA $\mathrm{R}$ are specific for severe encephalitis and refractory seizures patients and low titers present in a broad range of neurology disorders and may lack specificity [8]. Another aspect which needs to be taken into account is the value of serum and CSF for detecting autoantibodies. The use of CSF for detecting NSAbs in depression has not been evaluated to date. Finally, NSAbs should be tested in a "panel" rather than a single one because of the overlap between symptoms and signs of different autoimmune encephalitis and psychotic disorders [139]. Also, the coexistence of several NSAbs occurs in the same individual and cause combine manifestations $[9,140$, $141]$.

To summarize, NSAbs, targeting important neuronal receptors or interfering with ion channels and associated protein function, are responsible for psychiatric symptoms in autoimmune encephalitis cases. At the moment, several studies reported the presence of anti-NMDAR (NR1 and NR2B), anti-5-HT1A and D2R in depression cohorts. However, due to the heterogeneity of the methodology, variation in the samples used and the limited cohort size, there is insufficient evidence to support those NSAbs can cause depression without other obviously neurological symptoms. In the future, large cohorts, longitudinal studies need to be performed using sensitive, quantitative and reproducible methods without loss of antigen conformation. Finally, analysis of autoantibodies targeting neuronal surface antigens relevant to the pathology of depression should be performed.

\section{Acknowledgment}

The authors thank the Netherlands Organization for Scientific Research "Graduate School of Translational Neuroscience Program" (022005019), the Brain Foundation of the Netherlands (KS2012(1)-157) and the ZonMW NWO Program Translationeel onderzoek (40-41200-989257); as well as the Veni Fellowship of the Netherlands Organization for Scientific Research (916.10.148), a fellowship of the Brain Foundation of the Netherlands (FS2008(1)-28), the Prinses Beatrix Fonds (Project WAR08-12) and the China Scholarship Council (201507720015). 
Author Contributions: S. Zong contributes to the design and writing of the paper. C. Hoffmann, M.Mané-Damas contributed the writing and corrections; P. Molenaar helped with the corrections of the review; M. Losen helped with the design and the corrections of the review; P. Martinez supervised the design and helped to write and correct the review.

\section{Reference}

1. Graus, F., et al., A clinical approach to diagnosis of autoimmune encephalitis. The Lancet Neurology, 2016. 15(4): p. 391-404.

2. Dalmau, J., et al., Paraneoplastic Anti-N-methyl-D-aspartate Receptor Encephalitis Associated with Ovarian Teratoma. Annals of neurology, 2007. 61(1): p. 25-36.

3. Bataller, L., et al., REVERSIBLE PARANEOPLASTIC LIMBIC ENCEPHALITIS ASSOCIATED WITH ANTIBODIES TO THE AMPA RECEPTOR. Neurology, 2010. 74(3): p. 265-267.

4. Lai, M., et al., AMPA receptor antibodies in limbic encephalitis alter synaptic receptor location. Annals of neurology, 2009. 65(4): p. 424-434.

5. Savitz, J.B. and W.C. Drevets, Neuroreceptor imaging in depression. Neurobiology of Disease, 2013. 52: p. 49-65.

6. Drevets, W.C., et al., Serotonin-1A receptor imaging in recurrent depression: replication and literature review. Nuclear medicine and biology, 2007. 34(7): p. 865-877.

7. Lancaster, E., et al., Antibodies to the $G A B A(B)$ receptor in limbic encephalitis with seizures: case series and characterisation of the antigen. Lancet neurology, 2010. 9(1): p. 67-76.

8. Petit-Pedrol, M., et al., Encephalitis with refractory seizures, status epilepticus, and antibodies to the $G A B A(A)$ receptor: a case series, characterisation of the antigen, and analysis of the effects of antibodies. The Lancet. Neurology, 2014. 13(3): p. 276-286.

9. Ohkawa, T., et al., Identification and Characterization of GABA\&It;sub\&gt;A\&lt;/sub\&gt; Receptor Autoantibodies in Autoimmune Encephalitis. The Journal of Neuroscience, 2014. 34(24): p. 8151.

10. Pettingill, P., et al., Antibodies to GABAA receptor $\alpha 1$ and $\gamma 2$ subunits Clinical and serologic characterization. Neurology, 2015. 84(12): p. 1233-1241.

11. Irani, S.R., et al., Antibodies to Kv1 potassium channel-complex proteins leucine-rich, glioma inactivated 1 protein and contactin-associated protein-2 in limbic encephalitis, Morvan's syndrome and acquired neuromyotonia. Brain, 2010. 133(9): p. 2734-2748.

12. Boronat, A., et al., Encephalitis and antibodies to DPPX, a subunit of Kv4.2 potassium channels. Annals of neurology, 2013. 73(1): p. 120-128.

13. Balint, B., et al., Progressive encephalomyelitis with rigidity and myoclonus A new variant with DPPX antibodies. Neurology, 2014. 82(17): p. 1521-1528.

14. Tobin, W.O., et al., DPPX potassium channel antibody: Frequency, clinical accompaniments, and outcomes in 20 patients. Neurology, 2014. 83(20): p. 1797-1803.

15. Dale, R.C., et al., Antibodies to surface dopamine-2 receptor in autoimmune movement and psychiatric disorders. Brain, 2012. 135(11): p. 3453-3468.

16. Vincent, A., et al., Autoantibodies associated with diseases of the CNS: new developments and future challenges. The Lancet Neurology, 2011. 10(8): p. 759-772.

17. Lennox, B.R., et al., Prevalence and clinical characteristics of serum neuronal cell surface antibodies in first-episode psychosis: a case-control study. The Lancet Psychiatry, 2016. 
18. Pollak, T.A., et al., Prevalence of anti-N-methyl-d-aspartate (NMDA) receptor antibodies in patients with schizophrenia and related psychoses: a systematic review and meta-analysis. Psychological Medicine, 2014. 44(12): p. 2475-2487.

19. León-Caballero, J., et al., Bipolar disorder and antibodies against the N-methyl-d-aspartate receptor: A gate to the involvement of autoimmunity in the pathophysiology of bipolar illness. Neuroscience \& Biobehavioral Reviews, 2015. 55: p. 403-412.

20. Chen, Y., et al., Emerging tendency towards autoimmune process in major depressive patients: A novel insight from Th17 cells. Psychiatry Research, 2011. 188(2): p. 224-230.

21. Iseme, R.A., et al., Autoantibodies and depression: Evidence for a causal link? Neuroscience \& Biobehavioral Reviews, 2014. 40: p. 62-79.

22. Dama, M., M. Steiner, and R. Van Lieshout, Thyroid peroxidase autoantibodies and perinatal depression risk: A systematic review. Journal of affective disorders, 2016. 198: p. 108-121.

23. Bai, R., et al., Depressive and Anxiety Disorders in Systemic Lupus Erythematosus Patients without Major Neuropsychiatric Manifestations. Journal of Immunology Research, 2016. 2016.

24. Laske, C., et al., Autoantibody reactivity in serum of patients with major depression, schizophrenia and healthy controls. Psychiatry Research, 2008. 158(1): p. 83-86.

25. Postal, M. and S. Appenzeller, The importance of cytokines and autoantibodies in depression. Autoimmunity Reviews, 2015. 14(1): p. 30-35.

26. Gutman, G.A., et al., International Union of Pharmacology. LIII. Nomenclature and Molecular Relationships of Voltage-Gated Potassium Channels. Pharmacological Reviews, 2005. 57(4): p. 473-508.

27. Sanacora, G., G. Treccani, and M. Popoli, Towards a glutamate hypothesis of depression: An emerging frontier of neuropsychopharmacology for mood disorders. Neuropharmacology, 2012. 62(1): p. 63-77.

28. Möhler, H., The GABA system in anxiety and depression and its therapeutic potential. Neuropharmacology, 2012. 62(1): p. 42-53.

29. Cutler, R.W.P., G.V. Watters, and J.P. Hammerstad, The origin and turnover rates of cerebrospinal fluid albumin and gamma-globulin in man. Journal of the Neurological Sciences, 1970. 10(3): p. 259-268.

30. Reiber, H., Flow rate of cerebrospinal fluid (CSF) - A concept common to normal blood-CSF barrier function and to dysfunction in neurological diseases. Journal of the Neurological Sciences, 1994. 122(2): p. 189-203.

31. Hoffmann, C., et al., Autoantibodies in Neuropsychiatric Disorders. Antibodies, 2016. 5(2).

32. Dileepan, T., et al., Group A Streptococcus intranasal infection promotes CNS infiltration by streptococcal-specific Th17 cells. The Journal of Clinical Investigation, 2016. 126(1): p. 303-317.

33. Hammer, C., et al., Neuropsychiatric disease relevance of circulating anti-NMDA receptor autoantibodies depends on blood-brain barrier integrity. Mol Psychiatry, 2014. 19(10): p. 1143-1149.

34. Hammer, C., et al., Apolipoprotein E4 carrier status plus circulating anti-NMDAR1 autoantibodies: association with schizoaffective disorder. Mol Psychiatry, 2014. 19(10): p. 1054-1056.

35. Ransohoff, R.M., P. Kivisakk, and G. Kidd, Three or more routes for leukocyte migration into the central nervous system. Nat Rev Immunol, 2003. 3(7): p. 569-581.

36. Martinez-Hernandez, E., et al., Analysis of complement and plasma cells in the brain of patients with anti-NMDAR encephalitis. Neurology, 2011. 77(6): p. 589-593. 
37. Hansen, H., et al., Persistent intrathecal antibody synthesis 15 years after recovering from anti- n-methyl-d-aspartate receptor encephalitis. JAMA Neurology, 2013. 70(1): p. 117-119.

38. Leypoldt, F., T. Armangue, and J. Dalmau, Autoimmune encephalopathies. Annals of the New York Academy of Sciences, 2015. 1338(1): p. 94-114.

39. Smitt, P.S., et al., Paraneoplastic Cerebellar Ataxia Due to Autoantibodies against a Glutamate Receptor. New England Journal of Medicine, 2000. 342(1): p. 21-27.

40. Castillo-Gomez, E., et al., The brain as immunoprecipitator of serum autoantibodies against NMethyl-D-aspartate receptor subunit NR1. Annals of Neurology, 2016. 79(1): p. 144-151.

41. Gomez, A.M., et al., Antibody effector mechanisms in myasthenia gravis-Pathogenesis at the neuromuscular junction. Autoimmunity, 2010. 43(5-6): p. 353-370.

42. Koneczny, I., et al., IgG4 autoantibodies against muscle-specific kinase undergo Fab-arm exchange in myasthenia gravis patients. Journal of Autoimmunity, 2017. 77: p. 104-115.

43. Chatenoud, L. and J.-F. Bach, Antigenic modulation - a major mechanism of antibody action. Immunology Today, 1984. 5(1): p. 20-25.

44. Drachman , D.B., et al., Myasthenic Antibodies Cross-Link Acetylcholine Receptors to Accelerate Degradation. New England Journal of Medicine, 1978. 298(20): p. 1116-1122.

45. Pumplin, D. and D. Drachman, Myasthenic patients' IgG causes redistribution of acetylcholine receptors: freeze-fracture studies. The Journal of Neuroscience, 1983. 3(3): p. 576-584.

46. Mikasova, L., et al., Disrupted surface cross-talk between NMDA and Ephrin-B2 receptors in anti-NMDA encephalitis. Brain, 2012. 135(5): p. 1606-1621.

47. Jantzen, S.U., et al., In vitro neuronal network activity in NMDA receptor encephalitis. BMC Neuroscience, 2013. 14: p. 17-17.

48. Hughes, E.G., et al., Cellular and Synaptic Mechanisms of Anti-NMDA Receptor Encephalitis. The Journal of Neuroscience, 2010. 30(17): p. 5866-5875.

49. Tüzün, E., et al., Evidence for antibody-mediated pathogenesis in anti-NMDAR encephalitis associated with ovarian teratoma. Acta neuropathologica, 2009. 118(6): p. 737-743.

50. Peng, X., et al., Cellular Plasticity Induced by Anti- $\alpha$-Amino-3-Hydroxy-5-Methyl-4Isoxazolepropionic Acid (AMPA) Receptor Encephalitis Antibodies. Annals of Neurology, 2015. 77(3): p. 381-398.

51. Engel, A.G. and K. Arahata, The Membrane Attack Complex of Complement at the Endplate in Myasthenia Gravisa. Annals of the New York Academy of Sciences, 1987. 505(1): p. 326-332.

52. Bien, C.G., et al., Immunopathology of autoantibody-associated encephalitides: clues for pathogenesis. Brain, 2012. 135(5): p. 1622-1638.

53. Whitney, K.D., P.I. Andrews, and J.O. McNamara, Immunoglobulin $G$ and complement immunoreactivity in the cerebral cortex of patients with Rasmussen's encephalitis. Neurology, 1999. 53(4): p. 699.

54. Ochoa, M.C., et al., Antibody-dependent cell cytotoxicity: immunotherapy strategies enhancing effector NK cells. Immunol Cell Biol, 2017.

55. Teillaud, J.-L., Antibody-dependent Cellular Cytotoxicity (ADCC), in eLS. 2001, John Wiley \& Sons, Ltd.

56. Lucchinetti, C.F., et al., A role for humoral mechanisms in the pathogenesis of Devic's neuromyelitis optica. Brain, 2002. 125(7): p. 1450-1461.

57. Bennett, J.L., et al., Intrathecal Pathogenic Anti-Aquaporin-4 Antibodies in Early Neuromyelitis Optica. Annals of neurology, 2009. 66(5): p. 617-629. 
58. Ratelade, J., et al., INVOLVEMENT OF ANTIBODY-DEPENDENT CELL-MEDIATED CYTOTOXICITY IN INFLAMMATORY DEMYELINATION IN A MOUSE MODEL OF NEUROMYELITIS OPTICA. Acta neuropathologica, 2013. 126(5): p. 699-709.

59. Koneczny, I., et al., IgG4 autoantibodies against muscle-specific kinase undergo Fab-arm exchange in myasthenia gravis patients. Journal of Autoimmunity, 2016.

60. Lalic, T., et al., Human limbic encephalitis serum enhances hippocampal mossy fiber-CA3 pyramidal cell synaptic transmission. Epilepsia, 2011. 52(1): p. 121-131.

61. Fukata, Y., et al., Epilepsy-related ligand/receptor complex LGI1 and ADAM22 regulate synaptic transmission. Science, 2006. 313(5794): p. 1792-1795.

62. Fukata, Y., et al., Disruption of LGI1-linked synaptic complex causes abnormal synaptic transmission and epilepsy. Proceedings of the National Academy of Sciences, 2010. 107(8): p. 3799-3804.

63. Ohkawa, T., et al., Autoantibodies to Epilepsy-Related LGI1 in Limbic Encephalitis Neutralize LGI1-ADAM22 Interaction and Reduce Synaptic AMPA Receptors. The Journal of Neuroscience, 2013. 33(46): p. 18161-18174.

64. Vincent, A., Unravelling the pathogenesis of myasthenia gravis. Nat Rev Immunol, 2002. 2(10): p. 797-804.

65. Howard, F.M., et al., Clinical Correlations of Antibodies That Bind, Block, or Modulate Human Acetylcholine Receptors in Myasthenia Gravisa. Annals of the New York Academy of Sciences, 1987. 505(1): p. 526-538.

66. Gomez, C.M. and D.P. Richman, Anti-acetylcholine receptor antibodies directed against the alpha-bungarotoxin binding site induce a unique form of experimental myasthenia. Proceedings of the National Academy of Sciences of the United States of America, 1983. 80(13): p. 4089-4093.

67. Riemersma, S., et al., Association of arthrogryposis multiplex congenita with maternal antibodies inhibiting fetal acetylcholine receptor function. Journal of Clinical Investigation, 1996. 98(10): p. 2358-2363.

68. Levite, M. and Y. Ganor, Autoantibodies to glutamate receptors can damage the brain in epilepsy, systemic lupus erythematosus and encephalitis. Expert review of neurotherapeutics, 2008. 8(7): p. 1141-1160.

69. Levite, M., GLUTAMATE RECEPTOR ANTIBODIES IN NEUROLOGICAL DISEASES: Anti-AMPAGluR3 antibodies, Anti-NMDA-NR1 antibodies, Anti-NMDA-NR2A/B antibodies, Anti-mGluR1 antibodies or Anti-mGluR5 antibodies are present in subpopulations of patients with either: Epilepsy, Encephalitis, Cerebellar Ataxia, Systemic Lupus Erythematosus (SLE) and Neuropsychiatric SLE, Sjogren's syndrome, Schizophrenia, Mania or Stroke. These autoimmune anti-glutamate receptor antibodies can bind neurons in few brain regions, activate glutamate receptors, decrease glutamate receptor's expression, impair glutamate-induced signaling and function, activate Blood Brain Barrier endothelial cells, kill neurons, damage the brain, induce behavioral/psychiatric/cognitive abnormalities and Ataxia in animal models, and can be removed or silenced in some patients by immunotherapy. Journal of Neural Transmission, 2014. 121(8): p. 1029-1075.

70. Levite, M., et al., Autoantibodies to the glutamate receptor kill neurons via activation of the receptor ion channel. Journal of autoimmunity, 1999. 13(1): p. 61-72.

71. Saravanan, P. and C.M. Dayan, THYROID AUTOANTIBODIES. Endocrinology and Metabolism Clinics of North America, 2001. 30(2): p. 315-337. 
72. Elhwuegi, A.S., Central monoamines and their role in major depression. Progress in NeuroPsychopharmacology and Biological Psychiatry, 2004. 28(3): p. 435-451.

73. Gatt, J.M., et al., Specific and common genes implicated across major mental disorders: $A$ review of meta-analysis studies. Journal of Psychiatric Research, 2015. 60: p. 1-13.

74. Savitz, J., I. Lucki, and W.C. Drevets, 5-HT1A receptor function in major depressive disorder. Progress in Neurobiology, 2009. 88(1): p. 17-31.

75. Kim, D., et al., Decreased expression of 5-HT1A in the circumvallate taste cells in an animal model of depression. Archives of Oral Biology, 2017. 76: p. 42-47.

76. Park, S.K., et al., Par-4 Links Dopamine Signaling and Depression. Cell, 2005. 122(2): p. 275287.

77. Glantz, L.A., et al., Pro-apoptotic Par-4 and dopamine D2 receptor in temporal cortex in schizophrenia, bipolar disorder and major depression. Schizophrenia Research, 2010. 118(13): p. 292-299.

78. Citrome, L., Brexpiprazole: a new dopamine $D_{2}$ receptor partial agonist for the treatment of schizophrenia and major depressive disorder. Drugs of today (Barcelona, Spain: 1998), 2015. 51(7): p. 397-414.

79. Cotman, C.W., et al., Anatomical organization of excitatory amino acid receptors and their pathways. Trends in Neurosciences, 1987. 10(7): p. 273-280.

80. Stevens, C.F., A finger on brain receptors. Nature, 1989. 342(6250): p. 620-621.

81. Bechtholt-Gompf, A.J., et al., Blockade of astrocytic glutamate uptake in rats induces signs of anhedonia and impaired spatial memory. Neuropsychopharmacology, 2010. 35(10): p. 20492059.

82. ladarola, N.D., et al., Ketamine and other N-methyl-D-aspartate receptor antagonists in the treatment of depression: a perspective review. Therapeutic advances in chronic disease, 2015. 6(3): p. 97-114.

83. Du, J., et al., The Anticonvulsants Lamotrigine, Riluzole, and Valproate Differentially Regulate AMPA Receptor Membrane Localization: Relationship to Clinical Effects in Mood Disorders. Neuropsychopharmacology, 2006. 32(4): p. 793-802.

84. Sanacora, G., et al., Reduced cortical y-aminobutyric acid levels in depressed patients determined by proton magnetic resonance spectroscopy. Archives of general psychiatry, 1999. 56(11): p. 1043-1047.

85. Sanacora, G., et al., Increased occipital cortex GABA concentrations in depressed patients after therapy with selective serotonin reuptake inhibitors. American Journal of Psychiatry, 2002. 159(4): p. 663-665.

86. Sanacora, G., et al., Increased cortical GABA concentrations in depressed patients receiving ECT. American Journal of Psychiatry, 2003. 160(3): p. 577-579.

87. Klumpers, U.M., et al., Reduced parahippocampal and lateral temporal GABAA-[11C] flumazenil binding in major depression: preliminary results. European journal of nuclear medicine and molecular imaging, 2010. 37(3): p. 565-574.

88. Shen, Q., et al., Y-Aminobutyric acid-type A receptor deficits cause hypothalamic-pituitaryadrenal axis hyperactivity and antidepressant drug sensitivity reminiscent of melancholic forms of depression. Biological psychiatry, 2010. 68(6): p. 512-520.

89. Vyklicky, V., et al., Structure, function, and pharmacology of NMDA receptor channels. Physiological Research, 2014. 63: p. S191. 
90. Traynelis, S.F., et al., Glutamate Receptor Ion Channels: Structure, Regulation, and Function. Pharmacological Reviews, 2010. 62(3): p. 405-496.

91. Lakhan, S., M. Caro, and N. Hadzimichalis, NMDA Receptor Activity in Neuropsychiatric Disorders. Frontiers in Psychiatry, 2013. 4(52).

92. Martucci, L., et al., N-methyl-d-aspartate receptor NR2B subunit gene GRIN2B in schizophrenia and bipolar disorder: Polymorphisms and mRNA levels. Schizophrenia Research, 2006. 84(23): p. 214-221.

93. Ellison, G., The N-methyl-d-aspartate antagonists phencyclidine, ketamine and dizocilpine as both behavioral and anatomical models of the dementias. Brain Research Reviews, 1995. 20(2): p. 250-267.

94. Berman, R.M., et al., Antidepressant effects of ketamine in depressed patients. Biological psychiatry, 2000. 47(4): p. 351-354.

95. Han, Y., et al., Efficacy of ketamine in the rapid treatment of major depressive disorder: a metaanalysis of randomized, double-blind, placebo-controlled studies. Neuropsychiatric Disease and Treatment, 2016. 12: p. 2859.

96. Gleichman, A.J., et al., Anti-NMDA Receptor Encephalitis Antibody Binding Is Dependent on Amino Acid Identity of a Small Region Within the GluN1 Amino Terminal Domain. The Journal of neuroscience : the official journal of the Society for Neuroscience, 2012. 32(32): p. 1108211094.

97. Dalmau, J., et al., Anti-NMDA-receptor encephalitis: case series and analysis of the effects of antibodies. Lancet neurology, 2008. 7(12): p. 1091-1098.

98. Pearlman, D.M. and S. Najjar, Meta-analysis of the association between N-methyl-d-aspartate receptor antibodies and schizophrenia, schizoaffective disorder, bipolar disorder, and major depressive disorder. Schizophrenia research, 2014. 157(1-3): p. 249-258.

99. Titulaer, M. and J. Dalmau, Antibodies to NMDA receptor, blood-brain barrier disruption and schizophrenia: a theory with unproven links. Molecular psychiatry, 2014. 19(10): p. 1054.

100. Steiner, J., et al., Increased prevalence of diverse $n$-methyl-d-aspartate glutamate receptor antibodies in patients with an initial diagnosis of schizophrenia: Specific relevance of igg nr1a antibodies for distinction from $n$-methyl-d-aspartate glutamate receptor encephalitis. JAMA Psychiatry, 2013. 70(3): p. 271-278.

101. Dahm, L., et al., Seroprevalence of autoantibodies against brain antigens in health and disease. Annals of Neurology, 2014. 76(1): p. 82-94.

102. Steiner, J., et al., Prevalence of n-methyl-d-aspartate receptor autoantibodies in the peripheral blood: Healthy control samples revisited. JAMA Psychiatry, 2014. 71(7): p. 838-839.

103. Dickerson, F., et al., A Combined Marker of Inflammation in Individuals with Mania. PLoS ONE, 2013. 8(9): p. e73520.

104. Zandi, M.S., et al., Disease-relevant autoantibodies in first episode schizophrenia. Journal of neurology, 2011. 258(4): p. 686-688.

105. Planagumà, J., et al., Human N-methyl D-aspartate receptor antibodies alter memory and behaviour in mice. Brain, 2015. 138(1): p. 94-109.

106. Desestret, V., O. Pascual, and J. Honnorat, A mouse model of autoimmune encephalitis. Brain, 2015. 138(1): p. 5-8.

107. Lapteva, L., et al., Anti-N-methyl-D-aspartate receptor antibodies, cognitive dysfunction, and depression in systemic lupus erythematosus. Arthritis \& Rheumatism, 2006. 54(8): p. 25052514. 
108. DeGiorgio, L.A., et al., A subset of lupus anti-DNA antibodies cross-reacts with the NR2 glutamate receptor in systemic lupus erythematosus. Nature medicine, 2001. 7(11): p. 11891193.

109. Putterman, C. and B. Diamond, Immunization with a Peptide Surrogate for Double-stranded DNA (dsDNA) Induces Autoantibody Production and Renal Immunoglobulin Deposition. The Journal of Experimental Medicine, 1998. 188(1): p. 29-38.

110. Kowal, C., et al., Human lupus autoantibodies against NMDA receptors mediate cognitive impairment. Proceedings of the National Academy of Sciences of the United States of America, 2006. 103(52): p. 19854-19859.

111. Chang, E.H., et al., Selective Impairment of Spatial Cognition Caused by Autoantibodies to the N-Methyl-d-Aspartate Receptor. EBioMedicine, 2015. 2(7): p. 755-764.

112. Shepherd, J.D. and R.L. Huganir, The Cell Biology of Synaptic Plasticity: AMPA Receptor Trafficking. Annual Review of Cell and Developmental Biology, 2007. 23(1): p. 613-643.

113. Palmer, C.L., L. Cotton, and J.M. Henley, The Molecular Pharmacology and Cell Biology of $\alpha$ Amino-3-hydroxy-5-methyl-4-isoxazolepropionic Acid Receptors. Pharmacological reviews, 2005. 57(2): p. 253-277.

114. Greger, I.H., E.B. Ziff, and A.C. Penn, Molecular determinants of AMPA receptor subunit assembly. Trends in Neurosciences, 2007. 30(8): p. 407-416.

115. Sprengel, R., Role of AMPA receptors in synaptic plasticity. Cell and Tissue Research, 2006. 326(2): p. 447-455.

116. Rogers, S., et al., Autoantibodies to glutamate receptor GluR3 in Rasmussen's encephalitis. Science, 1994. 265(5172): p. 648-651.

117. Mantegazza, R., et al., Antibodies against GluR3 peptides are not specific for Rasmussen's encephalitis but are also present in epilepsy patients with severe, early onset disease and intractable seizures. Journal of Neuroimmunology, 2002. 131(1-2): p. 179-185.

118. Emson, P.C., GABAB receptors: structure and function, in Progress in Brain Research, E.D.A. James M. Tepper and J.P. Bolam, Editors. 2007, Elsevier. p. 43-57.

119. Kaupmann, K., et al., GABAB-receptor subtypes assemble into functional heteromeric complexes. Nature, 1998. 396(6712): p. 683-687.

120. Jones, K.A., et al., $G A B A B$ receptors function as a heteromeric assembly of the subunits GABABR1 and GABABR2. Nature, 1998. 396(6712): p. 674-679.

121. Mombereau, C., et al., Genetic and Pharmacological Evidence of a Role for GABAB Receptors in the Modulation of Anxiety- and Antidepressant-Like Behavior. Neuropsychopharmacology, 2004. 29(6): p. 1050-1062.

122. Batocchi, A.P., G.D. Marca, and G. Frisullo, Complement-mediated cytotoxicity of antibodies to the GABAB receptor. The Lancet Neurology, 2010. 9(4): p. 343.

123. Lancaster, E., M. Lai, and J. Dalmau, Complement-mediated cytotoxicity of antibodies to the GABAB receptor - Authors' reply. The Lancet Neurology, 2010. 9(4): p. 343-344.

124. Barnes, N.M. and T. Sharp, A review of central 5-HT receptors and their function. Neuropharmacology, 1999. 38(8): p. 1083-1152.

125. Usiello, A., et al., Distinct functions of the two isoforms of dopamine D2 receptors. Nature, 2000. 408(6809): p. 199-203.

126. Beaulieu, J.-M. and R.R. Gainetdinov, The physiology, signaling, and pharmacology of dopamine receptors. Pharmacological reviews, 2011. 63(1): p. 182-217. 
127. Vallar, L. and J. Meldolesi, Mechanisms of signal transduction at the dopamine D2 receptor. Trends in Pharmacological Sciences, 1989. 10(2): p. 74-77.

128. Tanaka, S., et al., Autoantibodies against four kinds of neurotransmitter receptors in psychiatric disorders. Journal of Neuroimmunology, 2003. 141(1-2): p. 155-164.

129. Sinmaz, N., et al., Dopamine-2 receptor extracellular $\mathrm{N}$-terminus regulates receptor surface availability and is the target of human pathogenic antibodies from children with movement and psychiatric disorders. Acta Neuropathologica Communications, 2016. 4: p. 126.

130. Pathmanandavel, K., et al., Antibodies to Surface Dopamine-2 Receptor and N-Methyl-DAspartate Receptor in the First Episode of Acute Psychosis in Children. Biological Psychiatry, 2015. 77(6): p. 537-547.

131. Pongs, O., et al., Functional and Molecular Aspects of Voltage-Gated K+ Channel 6 Subunits. Annals of the New York Academy of Sciences, 1999. 868(1): p. 344-355.

132. Long, S.B., E.B. Campbell, and R. MacKinnon, Crystal Structure of a Mammalian VoltageDependent $<e m>$ Shaker $</ e m>$ Family $K<$ sup $>+</$ sup $>$ Channel. Science, 2005. 309(5736): p. 897-903.

133. Hart, I.K., et al., Autoantibodies detected to expressed $K+$ channels are implicated in neuromyotonia. Annals of neurology, 1997. 41(2): p. 238-246.

134. Vincent, A., Autoimmune channelopathies: John Newsom-Davis's work and legacy: A summary of the Newsom-Davis Memorial Lecture 2008. Journal of Neuroimmunology, 2008. 201-202: p. 245-249.

135. Irani, S.R., et al., Cell-surface central nervous system autoantibodies: Clinical relevance and emerging paradigms. Annals of Neurology, 2014. 76(2): p. 168-184.

136. Mayasi, Y., D. Takhtani, and N. Garg, Leucine-rich glioma-inactivated protein 1 antibody encephalitis: A case report. Neurology ${ }^{\circledR}$ Neuroimmunology \& Neuroinflammation, 2014. 1(4): p. e51.

137. Casault, C., et al., Jerking \&amp; confused: Leucine-rich glioma inactivated 1 receptor encephalitis. Journal of Neuroimmunology, 2015. 289: p. 84-86.

138. Messelmani, M., et al., Limbic encephalitis associated with leucine-rich glioma-inactivated 1 antibodies. Annals of Saudi medicine, 2015. 35(1): p. 76.

139. Al-Diwani, A., et al., Synaptic and Neuronal Autoantibody-Associated Psychiatric Syndromes: Controversies and Hypotheses. Frontiers in Psychiatry, 2017. 8: p. 13.

140. Gresa-Arribas, N., et al., Antibodies to Inhibitory Synaptic Proteins in Neurological Syndromes Associated with Glutamic Acid Decarboxylase Autoimmunity. PLOS ONE, 2015. 10(3): p. e0121364.

141. Sinmaz, N., et al., Autoantibodies in movement and psychiatric disorders: updated concepts in detection methods, pathogenicity, and CNS entry. Annals of the New York Academy of Sciences, 2015. 1351(1): p. 22-38. 


\section{Chapter 4}

Novel neuronal surface autoantibodies in plasma of patients with depression and anxiety

Shenghua Zong, Carolin Hoffmann, Marina Damas et.al., Submitted to JAMA Psychiatry 


\section{Chapter 5}

\section{Low prevalence of autoantibodies related to neuronal and rheumatic autoimmune disease in sera of patients with psychotic disorders}

Corresponding manuscripts (this chapter was divided into 2 manuscripts when submitted for publication):

1. Carolin Hoffmann*, Shenghua Zong*, Marina Mané-Damas, et al., JAMA Psychiatry, 2019, accepted. (* authors contributed equally to this manuscript)

2. Carolin Hoffmann, Shenghua Zong, Marina Mané-Damas, et al., in 


\section{Chapter 6}

Autoantibodies to glutamic acid decarboxylase 65 (GAD65-Abs) and other neuronal antigens in a cohort suspected of GAD-Ab related disorders: comparison of diagnostic methods and suggestions for clinical practice 


\section{Chapter 7}

General discussion 
Over the past decade, the spectrum of antibody-mediated brain disorders has been largely expanded; this is due to the discovery of novel pathogenic neuronal surface autoantibodies (NSAbs) in the last years, relevant to the fields of neurology and psychiatry. While increasing studies focus on autoantibodies against N-methyl-d-aspartate receptor (NMDAR) in a subgroup of psychotic disorder patients, few studies exist which have thoroughly analyzed the presence of other neuronal autoantibodies in mental disorders. To evaluate if neuronal autoantibodies (known and novel) are more common in neuropsychiatric disorders including psychotic, depression and anxiety disorders, we screened for neuronal autoantibodies in plasma of 1739 depression or anxiety patients and 492 controls. Further, we investigated these autoantibodies in sera of 621 patients with psychotic disorders, 70 individuals with affective disorders, 41 with other mental disorders and 257 controls. The approach used in this thesis is designed to investigate the presence of different autoantibodies in the peripheral circulation system of patients with a combination of immunohistochemistry (IHC), cell-based assay (CBA) and staining on live cultured neurons. Furthermore, in a cohort of GAD-Ab related disorders patients, we aim to compare GAD65-Ab detection methods and to search for other neuronal autoantibodies besides GAD. We tested 96 consecutive sera for GAD65-Ab from suspected diagnosis of autoimmune encephalitis, epilepsy, diabetes mellitus type 1 or latent autoimmune diabetes in adults (DM1/LADA) patients.

\section{Known neuronal surface autoantibodies are rare in neuropsychiatric disorders}

NSAbs are well characterized with a large number of cases reported and most of their pathogenic roles are demonstrated in autoimmune encephalitis (AE). When extending NSAbs detection to psychiatric disorders, prior knowledge about NSAbs in AE should be kept in mind. $\mathrm{AE}$ is a rare group of brain disorders with a prevalence of 13.7/100,000 and an incidence of $0.8 / 100,000$ person-per year. NMDAR encephalitis is the most common type in this group, with a prevalence of $0.6 / 100,000$ [1]. According to an observational study by Kayser et al, only $4 \%$ of cases of NMDAR encephalitis presented with isolated psychiatric symptoms [2].

In chapter 4 and chapter $\mathbf{5}$, we report our findings on the detection of neuronal autoantibodies in 3316 blood (plasma or serum) samples from mental disorder patients and controls. The spectrum of diseases covered from psychosis, schizophrenia (SZ) to bipolar disorder, depression, and anxiety including also disorder and non-disorder controls. The initial step was using optimized immunohistochemistry (IHC) method on rat brain tissue, which could detect most of the known neuronal autoantibodies as well as autoantibodies to unidentified antigens that share the same epitope across species [3]. However, except for six samples which were clearly anti-GAD65 positive and one weak positive sample for anti-Caspr2, we did not find a typical pattern for other known neuronal autoantibodies by this method.

In accordance with our results, Snijders et al. using the same method did not find any known neuronal autoantibodies in a subpopulation of patients with bipolar disorder type I (BD-I) $(n=104)$ [4]. Similarly, in our earlier study where we analyzed the presence of anti-NMDAR IgG autoantibodies in schizophrenia plasma samples, the only two putative positive samples detected by a commercial cell-based assay (CBA) were neither confirmed by an in house CBA nor by IHC [5].

We further screened all the IHC positive samples by fixed CBA for eight known neuronal autoantibodies. Only one anti-Caspr 2 case and a few GAD65-Ab positive cases were confirmed. 
Fixed CBA is the most widely used method for detecting neuronal autoantibodies in AE patients. It is a sensitive method which employs a low sample dilution (blood 1: 10 or CSF 1:1) which potentially increases the rate of false positives [6]. Studies that used fixed CBA found up to $10 \%$ neuronal autoantibodies in psychiatric disorders but also in controls $[7,8]$. Thus, the presence of these autoantibodies in the circulation tested positive only by one method, obviously does not allow a firm conclusion as to whether those autoantibodies play a pathophysiological role in any of these psychiatric disorders. Besides, it would not justify by itself immunotherapy to the patients. One requirement to exert a brain effect is that the autoantibodies can cross the blood-brain barrier (BBB) and be detectable in CSF. The largest study using CSF from psychotic patients showed that $0.8 \%$ (1 out of 125 ) samples had antiNMDAR autoantibodies [9] but another study from Oviedo-Salcedo et al failed to find any neuronal autoantibodies in the CSF in 124 psychotic patients [10], unfortunately, both studies did not include controls.

In contrast to the results of IHC and fixed CBA, we detected weak positives NSAbs including autoantibodies to LGI1, Caspr2, GABAAR, and GABABR in the plasma of our cohorts with no prevalence difference between the disorder group and controls by live CBA. Thus. we concluded that those autoantibodies detected by live CBA were not disease-specific. NSAbs detected by live CBA has been mostly reported in first-episode psychosis [11-13]. In the largest study using only live CBA methodology by Lennox BR et.al identified 3\% (7 out of 228 ) of patients with first-episode psychosis with autoantibodies against NMDAR compared to none was found in controls $(n=105)$ [13]. While we did not detect any anti-NMDAR positive cases in our studies by live or fixed CBA. The difference in results might be due to different strategies of cohort selection or varying method sensitivity/specificity between laboratories. From our experience, the NSAbs weakly positive samples found by live CBA from mental disorder patients only reacted to a few of the transfected cells (Figure 1), which is obviously different from the positive control we used (from autoimmune encephalitis patients) which normally showed autoantibody reactivity on all the transfected cells and could be confirmed by fixed CBA and IHC. Category these samples equally as NSAbs positive is somehow misleading. It is important to establish standard criteria in how to read out the live CBA results in the future so that we can separate samples only that are positive on live CBA from the ones that could react to all the transfected cells and be positive by different methods.

\section{Novel neuronal surface autoantibodies were detected in patients with anxiety}

Although no difference in the prevalence of known neuronal autoantibodies between psychiatric disorder groups and controls was found, we detected several autoantibodies against unknown antigens by IHC (Chapter 4 and Chapter 5). There are several explanations. First, the disorder and non-disorder control groups are not entirely free from other somatic diseases. Some (systemic) autoimmune conditions may contribute to the existence of the autoantibodies. Secondly, it is known that neuronal autoantibodies may occur in the general population and by no means are necessarily associated with disease $[6,14]$. Lastly, as former studies revealed the importance of $\mathrm{BBB}$ integrity in antibody-related brain disorders $[14,15]$; it is still an open question as to whether those circulating autoantibodies could cross the BBB and reach the brain in sufficient levels to cause disease. Previous studies have been mainly focused on the question as to whether neuronal autoantibodies are related to psychotic (especially anti-NMDA) or bipolar disorders $[4,16,17]$. The relation of novel NSAbs to depression or anxiety has barely 


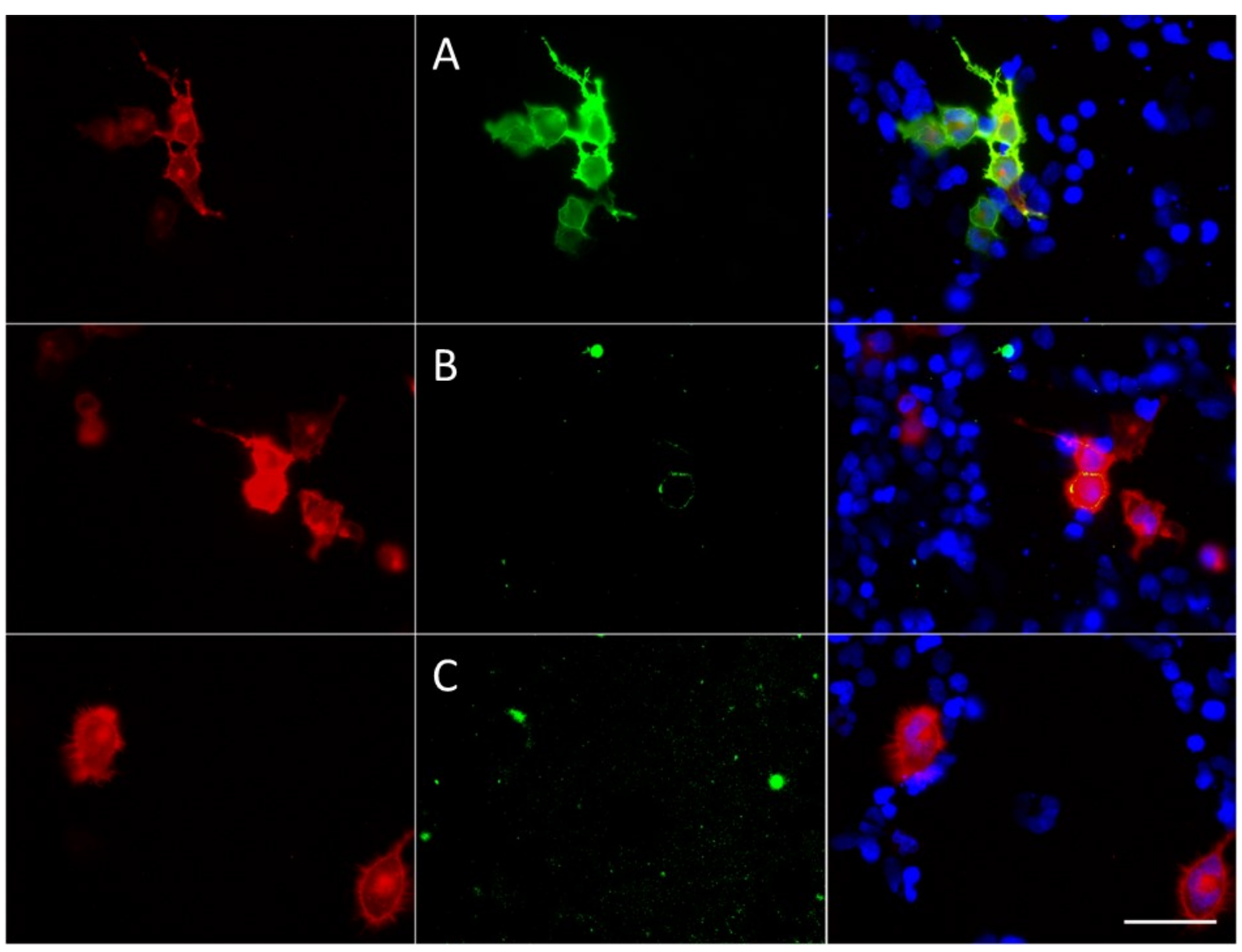

Figure 1. The live CBA staining images given by anti-Caspr2 autoantibodies positive serum/plasma from different patients and control. HEK cells were transfected with mCherry tagged Caspr2 (red), human serum/plasma was incubated on the cells and the IgGs binding to Caspr2 proteins were probed by goat-anti-human IgG-488 (Green). (A) serum from an autoimmune encephalitis patient showed strong reactivity on the transfected cells (positive control). (B) Plasma from anxiety and depression patient. (C) Plasma from a control (C). Nuclei were stained by DAPI (blue). Scale bar=50 $\mu \mathrm{m}$.

been studied. Our further research applying these samples on live cultured neurons showed only that some of them had autoantibodies targeting unknown neuronal surface proteins (novel NSAbs), all of which were from current anxiety patients (Chapter 4). This suggests a possible pathophysiological involvement of autoantibodies in a subgroup of psychiatric disorders patients and warrants further research to identify what the autoantibodies are targeting.

\section{Analysis of intracellular autoantibodies with a special focus on anti-GAD autoantibodies}

In chapter 5, besides neuronal autoantibodies, we investigated the prevalence of systemic autoimmune rheumatic disease-related antibodies in sera of a sub-cohort consisting of 199 patients with psychotic disorders, 45 with affective disorders, 23 patients with other mental disorders and 152 healthy individuals. The anti-nuclear antibody (ANA) reactivity of sera to ANAs on HEp-2 cells was increased in schizoaffective individuals compared to healthy $(\mathrm{p}=$ 0.032). However, the number of sera tested positive (the possibility of false positives should 
also be taken into consideration) for specific antigens here was too low for relevant statistical analysis

In chapter 6, we confirmed that serum levels of GAD65-Ab in patients with GAD65-Ab related encephalitis or epilepsy were higher than in patients with DM1/LADA although high levels of GAD65-Ab $(>10000 \mathrm{U} / \mathrm{mL})$ that could be detected by CBA and IHC existed in both groups [18]. Thus, the presence of GAD65-Ab and their correlation to neurological manifestations have to be interpreted with caution, since the direct involvement of the autoantibodies in encephalitis or epilepsy is debated. We need to analyze this in a more mechanistic fashion and analyze what is the putative disease mechanism caused by the antiGAD autoantibodies. Besides, a small portion of patients suspected of GAD65-Ab related disorders had other neuronal autoantibodies and their clinical significance should be studied. We detected a case with anti-Hu and another with anti-mGluR1 autoantibodies in patients suspected to be autoimmune, which emphasizes the value of IHC for detecting autoantibodies that are not tested routinely in the clinic $[16,19,20]$.

\section{Limitations of our study}

As described above, the main findings of this thesis are based on the results from chapter 4, 5 and 6. In Chapter 4 and 5, although we reported that autoantibodies to unknown neuronal antigens were found, not all the known antigens that have been reported were tested by CBA in this study (including D2R, mGluR5, mGluR1, neurexin-3 $\alpha$, IgLON5, DNER (Tr), Glycine receptor and amphiphysin) but were excluded according to the IHC patterns empirically; 2) our study did not include other potential pathogenic brain autoantibodies, including autoantibodies targeting other cell types (astrocytes, microglia); 3) we only analyzed peripheral blood samples, while no CSF material was available, so the question as to whether those antibodies pass the blood-brain-barrier in sufficient amounts still remains to be investigated. In Chapter 6, besides the IHC methods limitation mentioned above, the GAD positive neuropsychiatric cohort is relatively small.

\section{Further perspectives}

Detection of novel neuronal surface autoantibodies in a pure anxiety or depression cohort

In Chapter 4, we reported that all the novel NSAbs positive patients had anxiety but not depression which generally has not been reported earlier. Still the small positive numbers and high comorbidity of depression and anxiety make it difficult to claim they are more common in anxiety than in depression. Therefore, whether those autoantibodies specifically are associated with anxiety needs to be further investigated in a follow-up study including purely current anxiety patients without a depression diagnosis. The estimated size of the cohort according to our findings ( $1.7 \%$ positives) should be of approximately 300 patients to find at least 5-6 antibody-positive patients.

To identify the antigens targeted by the autoantibodies and investigate if autoantibodies bind to other cell types besides neurons in neuropsychiatric cohorts

In chapter 4, antigen identification and further analysis of autoantibody effector functions are needed for further demonstrate the initial hypothesis that NSAbs ca be causative of a subgroup of psychiatric disorders. Immunoprecipitation and mass spectrometry are commonly used to identify novel antigens. When we performed the immunoprecipitation method with all NSAbs 
positive samples, none of them gave a specific band compared to healthy controls. One possible reason is that some reagents used during this procedure break the antibody-antigen interaction and thus render the autoantibody ineffective in pulling down the antigen. Additionally, the density/ concentration of the antigen and limitations in sample processing and analysis during mass spectrometry might have hindered the process.

Besides, there are autoantibodies which target other proteins that may have been neglected. Such antigens could be present on the surface of other cell types such as microglia and astrocytes. Test samples may potentially be positive on IHC but negative on live neurons simply because they target other cells in the brain. We have evidence for this in the case of a patient with depression whose serum showed strong staining on glial cells (Figure 2).

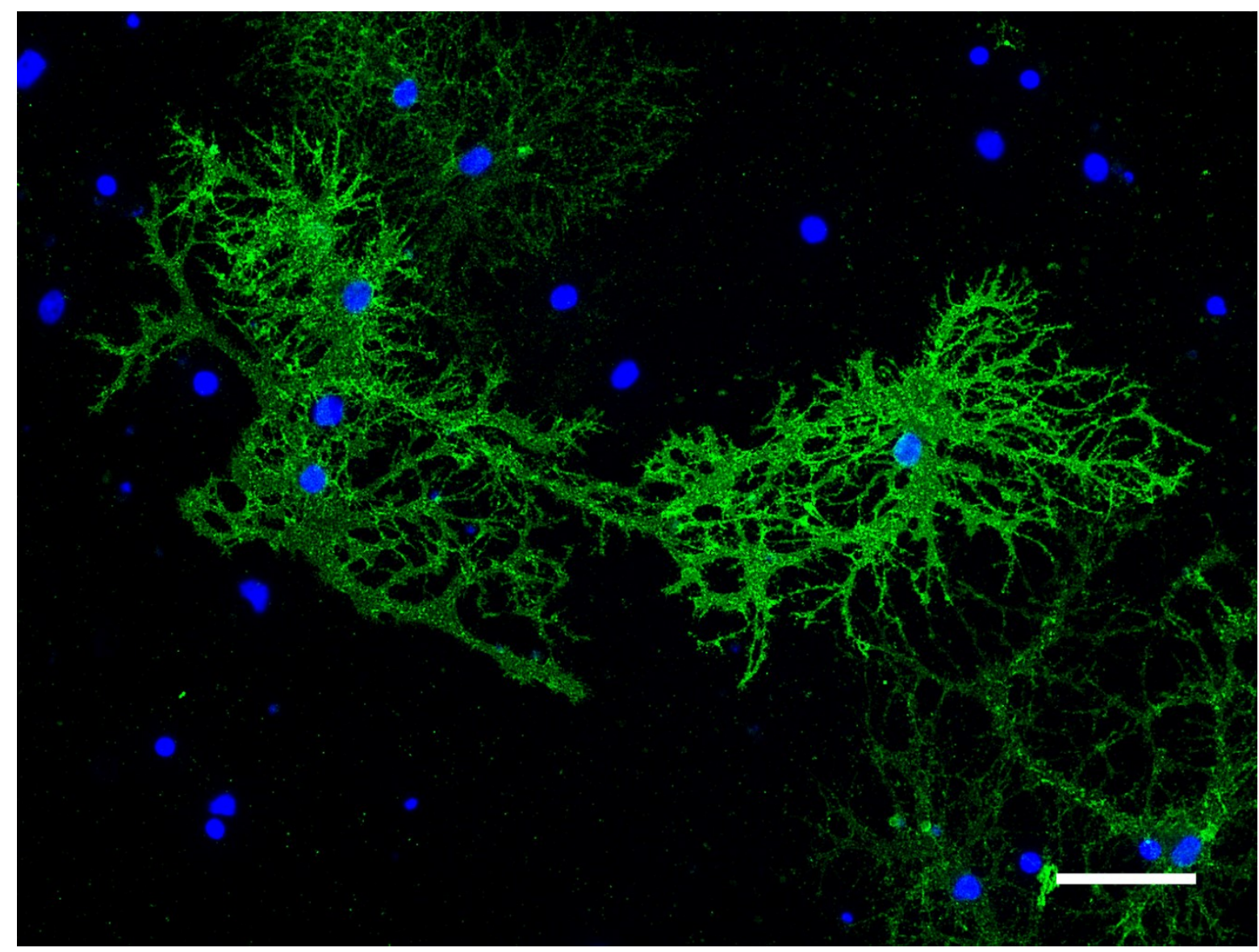

Figure 2. Plasma autoantibodies reacted strongly on cells other than neurons when performing live neuronal stainings. Primary cultured hippocampus cells were used. Plasma was incubated on the cells and the IgGs binding to cell surface proteins were probed by goat-anti-human IgG-488 (Green). Nuclei were stained by DAPI (blue). (Scale bar=50 $\mu \mathrm{m}$ ).

Because we did not include cultures of these types of cells, we are uncertain about how many positive samples exist in our cohort targeting those cells.

\section{Autoimmune mechanisms beyond autoantibodies to GAD should be studied further in} patients suspected of GAD-Ab related disorders

GAD is a rate-limiting enzyme that catalyzes the decarboxylation of glutamate to GABA and GAD-Abs showed impairment in GABAergic neurons. In contrast, previous studies did not support that autoantibodies could pass through the cell membrane and target the cytoplasmic 
antigens. Thus, it suggested that other associated neuronal surface autoantibodies co-exist with GAD-Abs [21, 22]. In Chapter 6, we detected only one case with anti-Hu autoantibodies in ten GAD-Abs positive patients with neurological symptoms. So far, it has been reported that GAD-Abs can be a useful biomarker for stiff person syndrome and related disorders; the causative factor, however, still needs to be identified.

\section{Overall conclusion:}

The observation that a small subgroup of current anxiety but not psychotic disorders patients had novel NSAbs in the peripheral circulation opens the possibility that some patients are in fact autoimmune patients and thus would benefit from immunotherapy. This finding is important because the autoimmune subgroup of patients can be treated targeting the cause of the problem in contrast to traditional pharmacological approaches which treat only the symptomatology. It would, therefore, be important to replicate the current findings using robust methods and paired serum and CSF samples. The identification of novel antigens targeted by the autoantibodies will help to understand their cause-effect. Besides, a small portion of patients suspected of GAD65-Ab related disorders had other neuronal autoantibodies and their clinical significance should be studied individually.

\section{Reference}

1. Dubey, D., et al., Autoimmune encephalitis epidemiology and a comparison to infectious encephalitis. Annals of neurology, 2018. 83(1): p. 166-177.

2. Kayser, M.S., et al., Frequency and characteristics of isolated psychiatric episodes in anti-Nmethyl-d-aspartate receptor encephalitis. JAMA neurology, 2013. 70(9): p. 1133-1139.

3. Dalmau, J., C. Geis, and F. Graus, Autoantibodies to Synaptic Receptors and Neuronal Cell Surface Proteins in Autoimmune Diseases of the Central Nervous System. Physiological reviews, 2017. 97(2): p. 839-887.

4. Snijders, G., et al., No neuronal autoantibodies detected in plasma of patients with a bipolar I disorder. Psychiatry Research, 2018. 259: p. 460-462.

5. de Witte, L.D., et al., Absence of N-Methyl-D-Aspartate Receptor IgG Autoantibodies in Schizophrenia: The Importance of Cross-Validation StudiesN-Methyl-D-Aspartate Receptor IgG Autoantibodies in SchizophreniaLetters. JAMA Psychiatry, 2015. 72(7): p. 731-733.

6. Dahm, L., et al., Seroprevalence of autoantibodies against brain antigens in health and disease. Annals of neurology, 2014. 76(1): p. 82-94.

7. Hammer, C., et al., Neuropsychiatric disease relevance of circulating anti-NMDA receptor autoantibodies depends on blood-brain barrier integrity. Molecular Psychiatry, 2013. 19: p. 1143.

8. Scott, J.G., et al., The prevalence and treatment outcomes of antineuronal antibody-positive patients admitted with first episode of psychosis. BJPsych open, 2018. 4(2): p. 69-74.

9. Endres, D., et al., Immunological findings in psychotic syndromes: a tertiary care hospital's CSF sample of 180 patients. Frontiers in Human Neuroscience, 2015. 9(476).

10. Oviedo-Salcedo, T., et al., Absence of cerebrospinal fluid antineuronal antibodies in schizophrenia spectrum disorders. The British Journal of Psychiatry, 2018. 212(5): p. 318-320.

11. Zandi, M.S., et al., Disease-relevant autoantibodies in first episode schizophrenia. Journal of neurology, 2011. 258(4): p. 686-688. 
12. Gaughran, F., et al., Brain-relevant antibodies in first-episode psychosis: a matched casecontrol study. Psychological medicine, 2018. 48(8): p. 1257-1263.

13. Lennox, B.R., et al., Prevalence and clinical characteristics of serum neuronal cell surface antibodies in first-episode psychosis: a case-control study. The Lancet Psychiatry, 2017. 4(1): p. 42-48.

14. Levin, E.C., et al., Brain-reactive autoantibodies are nearly ubiquitous in human sera and may be linked to pathology in the context of blood-brain barrier breakdown. Brain Research, 2010. 1345: p. 221-232.

15. Hammer, C., et al., Neuropsychiatric disease relevance of circulating anti-NMDA receptor autoantibodies depends on blood-brain barrier integrity. Molecular psychiatry, 2014. 19(10): p. 1143.

16. Pollak, T.A., A.A. Al-Diwani, and B. Lennox, Neuronal surface autoantibodies, encephalitis and psychosis: from neurology to psychiatry. Adv Clin Neurosci Rehabil, 2017. 17(2): p. 6-10.

17. Jézéquel, J., et al., Dynamic disorganization of synaptic NMDA receptors triggered by autoantibodies from psychotic patients. Nature communications, 2017. 8(1): p. 1791-1791.

18. Gresa-Arribas, N., et al., Antibodies to Inhibitory Synaptic Proteins in Neurological Syndromes Associated with Glutamic Acid Decarboxylase Autoimmunity. PLOS ONE, 2015. 10(3): p. e0121364.

19. Linnoila, J.J., M.R. Rosenfeld, and J. Dalmau. Neuronal surface antibody-mediated autoimmune encephalitis. in Seminars in neurology. 2014. NIH Public Access.

20. Zong, S., et al., Neuronal Surface Autoantibodies in Neuropsychiatric Disorders: Are There Implications for Depression? Frontiers in Immunology, 2017. 8(752).

21. Chang, T., et al., Neuronal Surface and Glutamic Acid Decarboxylase Autoantibodies in Nonparaneoplastic Stiff Person SyndromeCell Surface Antibodies in Stiff Person SyndromeCell Surface Antibodies in Stiff Person Syndrome. JAMA Neurology, 2013. 70(9): p. 1140-1147.

22. Gresa-Arribas, N., et al., Antibodies to inhibitory synaptic proteins in neurological syndromes associated with glutamic acid decarboxylase autoimmunity. PloS one, 2015. 10(3): p. e0121364-e0121364. 


\section{Appendix I Valorization}

Note: Different from a formal discussion on the academic way, I would like to write the valorization part into a story.

5 years ago in 2014, when the first time I had a skype with Prof. Pilar Martinez, who was an assistant professor then, and she said there was an ongoing project about detecting neuronal autoantibodies in psychiatric disorders in her group, I should have never imagined that one day, we would search those autoantibodies from neurological patients with psychiatric symptoms to psychosis, schizophrenia, bipolar, depression and anxiety! Nevertheless, now we found that a subgroup of patients with anxiety potentially had a relation to novel neuronal surface autoantibodies! At the beginning, I was fascinated immediately when Dr. Carolin Hoffmann, who was still a $\mathrm{PhD}$ student, and later became my colleague and one of my closest friend in Maastricht, explained me the hypothesis that there might be a subgroup of psychiatric patients who were actually caused by neuronal autoantibodies and thus could be treated by immunotherapy. As a resident in neurosurgery department, I personally faced the question that why some patients developed psychiatric symptoms after traumatic injury or head surgeries and never gave my patients a really satisfying answer. I knew the etiology of psychiatric disorders were so diverse and hard to clearly mapped. I thought, wow, this would be a chance to approve a direct causative of those sticky disorders, at least in some of them. Then I decided to come and gave a shot. In the second year in 2015, our first-round test of anti-NMDAR autoantibodies in psychosis turned out to be negative [1]. Still, I brought our idea to a famous hospital in Beijing to seek collaboration, I met Prof. Guan. He welcomed me well and gave me a lot of positive feedbacks including sharing their autoantibodies positive samples to us, which in the end did not work out because of the ethical rules. He also asked me a question which I remembered for a while: "Do you really think those autoantibodies could be found in purely psychiatric patients? You may go too far". At that time, I said I was not sure.

If we had a chance to go back to 12 years ago, when 2007, Prof. Dalmau described the first cases-series of NMDAR autoantibodies encephalitis [2], I guess at that moment, no one could imagine that his research was actually lightening the whole field of autoantibodies mediated central nervous disorders and followed by the discovery of more than 13 novel neuronal surface autoantibodies [3]! Autoimmune encephalitis is a rare disease. When we apply the concept of neuronal autoantibodies mediated disorder to psychiatric disorders, it is still a rare condition as indicated in Chapter 4 and Chapter 5 as well as previous studies $[4,5]$. Be as it may, it is already a solid fact of their existence. There is no second condition that ties psychology and neurology so close that specialists from both fields are working together to gain the knowledge about it and thus helping the patients. Some patients have already benefited from it and the trend of enclosing more input in research is going on. Another aspect is using those functional autoantibodies as a tool to study the basic biological changes in psychiatric disorders [6]. Those basic mechanism might be common in psychiatric patients without autoantibodies. In this way, not only the patients who have autoantibodies but all would benefit from it.

Over the years, there are contradictories exist in this field as we described in Chapter 1, Chapter 2 and Chapter 3. One of the main possible reasons is the methodology problems. I worked years in developing and comparing the autoantibody detecting methods as showed in Chapter 4, Chapter 5 and Chapter 6 and deeply understand the method gaps exist between researchers, labs and countries. The development of new techniques is coming up but still needs 
to be optimized, the communication between researchers is ongoing but still needs to boost and the barriers between countries have never been broken. Even though, I personally have seen lot of improvements already. Last November on a lancet summit, I asked Prof. Dalmau of the diagnostic value of Immunohistochemistry method he developed, which led the findings of all the novel neuronal autoantibodies in his group. He mentioned he always used this method in his lab for diagnosis and believed that it still was a very useful method in finding unknown autoantibodies [7]. I also met Prof. Guan there. Different from the opinion he gave years ago, his group brought 3 posters all of which gave a large space for psychiatric symptoms. He also wrote a letter to explain the pictographs of encephalitis in Chinese characters in Lancet Neurology this year [8]. He showed his social medium later that they actually worked very closely with psychiatrists from Beijing and tried to diagnose some anti-NMDAR encephalitis at the early stage. Another thing has to mention, their lab has already put anti-GAD65 tests in the routine neuronal autoantibody test panel which they did not perform before. What will be the future of other even rare neuronal autoantibodies that have not been covered by commercial kits? As we showed in current dissertation, before better methods developed, the tissue-based assay is still a good choice.

All in all, as a novel field, our current research takes out the first step. It emphasizes the importance of continuously studying autoimmunity in neuropsychiatric disorders, the comparing between methods and developing new techniques as well as the communicating between researchers, researchers to clinicians and societies. Still there are many confusions that need to be clarified in the future. It would be of great that we look back 10 years later and I am looking forward to it!

\section{Reference}

1. de Witte, L.D., et al., Absence of N-Methyl-D-Aspartate Receptor IgG Autoantibodies in Schizophrenia: The Importance of Cross-Validation StudiesN-Methyl-D-Aspartate Receptor IgG Autoantibodies in SchizophreniaLetters. JAMA Psychiatry, 2015. 72(7): p. 731-733.

2. Dalmau, J., et al., Paraneoplastic anti-N-methyl-D-aspartate receptor encephalitis associated with ovarian teratoma. Annals of neurology, 2007. 61(1): p. 25-36.

3. Dalmau, J., C. Geis, and F. Graus, Autoantibodies to Synaptic Receptors and Neuronal Cell Surface Proteins in Autoimmune Diseases of the Central Nervous System. Physiological reviews, 2017. 97(2): p. 839-887.

4. Schou, M., et al., Prevalence of serum anti-neuronal autoantibodies in patients admitted to acute psychiatric care. Psychological Medicine, 2016. 46(16): p. 3303-3313.

5. Lennox, B.R., et al., Prevalence and clinical characteristics of serum neuronal cell surface antibodies in first-episode psychosis: a case-control study. The Lancet Psychiatry, 2017. 4(1): p. 42-48.

6. Pollak, T.A., et al., Autoantibodies to central nervous system neuronal surface antigens: psychiatric symptoms and psychopharmacological implications. Psychopharmacology, 2016. 233(9): p. 1605-1621.

7. Dalmau, J., NMDA receptor encephalitis and other antibody-mediated disorders of the synapse. Neurology, 2016. 87(23): p. 2471.

8. Guan, H., Pictographs of encephalitis in Chinese characters. The Lancet Neurology, 2019. 18(4): p. 331. 


\section{Appendix II Acknowledgements}

Throughout the writing of this dissertation, I have received a great deal of support and assistance from my supervisors, colleagues, friends, and families. Firstly, I would like to thank my supervisor, Prof. Dr. Pilar Martinez, whose expertise was invaluable in the formulating of the research topic, the guidelines to conduct most of my experiments and methodology in particular. I still remember the first day when we met, your passionate smile and practical suggestions calmed me so much, especially at that moment I was still shaking about my decision of coming to the Netherlands to start my real research life. During the past five years, you advised me on multiple projects, you discussed with me on all the results step by step, you carefully corrected on each of my manuscripts. I can't imagine how could I complete these though work without your guidance.

Equally grateful in my heart to my co-supervisor Dr. Mario Losen. Your rich knowledge in fundament research really brings every detail to my brain, and your strict and serious work style do keep improving all my manuscripts to the next level! Together with Pilar, both of your help to me is not only shown in my academic study but also in daily life! It is a huge change in my life when I moved from China to the Netherlands. You may not remember that day I shared with Pilar the news about Yumi's born. After joyful congratulations, the first question she asked me was how would I take the baby home. Before my answer, Pilar already said I would call Mario to drive you home. To you it would be only a simple kind offer, but to me, there was an emotion wave at my heart. When my families were still thousands of miles away, you and Pilar are the people who always stand behind me.

The same thanks go to my co-supervisor Dr. Rob Rhoul. As you may know, I was a clinical doctor and proud of what I was doing before. Also, my study topic here actually is so close to neurology although we always claim we are working on psychiatry disorders. For these reasons, I always want a supervisor who is working in the hospital, best from neurology department. Then when we have the GAD project and increasingly meetings between us make this possible. You may not notice I was so happy that you can be one of my co-supervisors. Definitely a lot of important and valuable advises from you. Thank you!

I would also like to thank other senior researchers that helped a lot with my main projects in Maastricht. Peter, you have checked almost all my manuscripts and gave tremendous suggestions and feedbacks to make them to the next level. Can't say more words for the work! Jan, most of the time, you responded to me immediately after I asked or requested something from you. We got many samples directly from your hands and even once you sent them to the lab when I was just at the step of using samples! Marc, thanks for sharing your research experiences and your comments on my projects, especially we discussed on why researchers in this field did not use human brain slices directly to do the IgG staining, you told me actually you had tried that before and stated the problem with it. Such valuable information that made me know clearer about which direction should go. Wim, thank you for every time you passed by my office, always came in and say hello to me and shared your knowledge about the culture difference between China and Europe, which definitely helped me to adapt myself easier in the new environments. Bart, thanks for your welcome comments on my daily work in the 
department and also feedbacks directly on the PTSD project. In the last 2 years when I got some results from our cross-sectional studies, I started to realize the importance of longitudinal study and it happened that we had the chance to explore this with the PTSD cohort. Also, the same thanks for Laurence's help during this study, your patient communication and actively attitudes on the collaboration! Anita, when I am writing this part, I just received your card about Julia's born, congratulations! Now you are 2 babies' mother, proud of you! So great to have discussions with you on the clinical things, the reality in the current research filed and the potential future directions. I really see the ambitions in your talk and hope we can continue these works in the future.

I would like also to acknowledge other senior researchers and friends in Maastricht who helped a lot during my stay in Maastricht. Ping, how could I describe my gratitude for your help during my study in Maastricht! You are the one who introduced me to Pilar and made this happen! Together with Qing, we consulted you so many times about work and daily life kinds of stuff. I still remember in the first few weeks when we came here, you helped us to call the energy company to make the contract for our apartment. When Qing was pregnant, you came to help her with the future plan, and when Yumi was born, you and Kaimei (mooi) visited us and played with Yumi. You must not notice but I have to say, although most of the time, we mainly discussed daily life or Qing's project when we gathered, still I learned from you the professional attitude, strict and efficient to work! Thanks a lot! Harry, thanks for the help during my scholarship application procedure and your care of my daily life in Maastricht. Your work definitely helped a lot of Chinese students who want to get a better study opportunity. You also gave me a lot of chances to communicate with you directly about the university polices on Chinese students. Sunny, thanks for the trust to let me participant in the event about startups in Maastricht meeting investors from China. Indeed, you may not know I visited one of the investors in the summer this year who was very interested in my proposal! Also, thanks for providing me other similar opportunities and your comments on my projects! Hope we can communicate more in the future!

I would also like to thank many scientists from outside of Maastricht for their support and trust in my work that directly related to my thesis. Prof. Penninx from Amsterdam provided the most directly help in analyzing the results of NSAbs tests in the NESDA cohort. You are the scientist I have met who really has a full view of the field of depression and anxiety and runs the project in such a successful way. Gerard, we met several times during the NESDA research days, visited your office and communicated continuously by email! Thanks a lot for your practical suggestions! Prof. Dalmau from Barcelona, thanks for the technique helps, direct communication during conferences and daily emails. Your suggestions do make me be surer about where I have reached and where would be the next step. Thanks, Dr. Titulaer from Rotterdam and Dr. Waters from Oxford for providing us the materials (plasmids, blood samples), the communicating and the feedback on my results as well. These three scientists also shared their materials like plasmids, antibodies or blood samples with us, the details were described in the acknowledgment part of the according chapters. Besides, I would also like to thank for the scientists that provided their help during my study, even some of them were not turned into a publication, including Prof. Maarten Reith from New York, Prof. Randy Blakely from FAU and Dr. Amy Eshleman from OHSU who provided the SERT, DAT and 
NET cell line, Prof. Masaki Fukata from NIPS, Japan who sent me the plasmids containing GABAAR subunits, Prof. Yoshinori Moriyama from Okayama University who sent me the VGLUT antibodies and proteins, Prof. Salah El Mestikawy from Sorbonne Université, Paris (UPMC) and Dr. Etienne Herzog from Universite de Bordeaux who shared the VGLUT plasmids, Dr. Romana Höftberger and Dr. Inga Koneczny from Medical University of Vienna who shared the anti-NF155 antibodies and positive controls and Dr. Luis Querol from Barcelona who shared the NF-155 plasmid with us.

Here I want to thank greatly to my dear colleagues. As mentioned above, Inga also worked in Maastricht for a period of time, during which I learned ELISA from you. Your passion for academic impressed me a lot! Thank you also for the daily suggestions and helps. Abhishek, Ece, and Murat, thank you for the guidance in the lab in my early $\mathrm{PhD}$ study, your suggestions helped me a lot to improve my experimental skills and made me know better in this the field we were working with. Jo, you were the most experienced $\mathrm{PhD}$ when I came here, both in the lab and in life. Impressed me a lot when I heard your things about making ice cream using liquid nitrogen, repairing your phones by yourself, and your collection of all the postcards on the wall. You made me the travel to Achen for Christmas Market and for the first time trying glue wine and knowing the concept of Limburg carnival. Thank you! The same to Yara, jajaja, Jo and you are together now in Munich! For some reason, you are like my big sister although, in real life, I do not have a sister at all in my family, all brothers! Carolin Hoffman, no matter how many words should I put here would be just not enough. From my interview, you already started to plan for my stay. Also, the first day I came to the lab, you arranged almost everything for me. What a great introduction tour! I later realized that you had such a good relationship with most of the collages in our department, and actually for this reason, to date I always feel that I am one of the Chinese students who mingled so well among colleagues. Not to mention that you taught me all the lab techniques hand by hand and introduced me to the most influential labs and scientists in this field one by one. If a $\mathrm{PhD}$ student can be another $\mathrm{PhD}$ student's supervisor, you will definitely on my supervision list. Also, it is hard to not mention in someday of our lab day out, we chatted about the basic concept different between Europe and China and that lovely day you mentioned you wanted to be a mother someday after you PhD and own your farm with your boyfriend Joao. And now it already comes true!!! Congrats for that, and the best words here also to Joaquim and Joao. I also enjoyed when we visited each other many times to make Chinese food or European food together, which made me understand the culture much better and deeper than I expected. It is a pity that Qing and I were not there for your wedding but for sure hope someday, we, together with Yumi may have the chance to visit you and your families in Portugal.

Marina! What a lovely smart girl! When I, the one fresh off the boat, came to Maastricht, 2 months later, you were here too. Immediately, I felt like that when I enter a class, you were my classmate, while Jo and Carolin were all a bit like teachers. We worked and studied together which made the tense study and training things much easier and more interesting. Also, your Kala Ok and group events that made the life in Maastricht not boring at all. Besides these charming parts in your characters, I also want to say the strict and efficient way you do have when we work together, which leaned me a lot actually. Good luck with your writing and animal experiments! Simone, similar to Marina, we all started our PhD studies in the same 
year and experienced similar stages in the lab. Because both of us living with families and had a daughter, your suggestions were always very practical and tailored for my situation. Thanks a lot! Now, we almost will defend our dissertation on the same day (in the end, I will be 1week earlier!), good luck with everything and hope to see you soon in Maastricht! Caterina, Qian, Daan, Nikita and Tanya, so glad that we worked together in the same group and had the chance to discuss our results, share our opinions and helped each other in the lab! Here I also would like to thank Koen as well when so many times we went to the same events and made jokes. Keep on your boxing and Cheers bro! Artemis, for many times, small talks with you really made me feel relax and deepen my understanding of Europe cultures. Also, I would like to thank other colleagues, Roy, Fred, Maarten, Joao, Ehsan, Gusta, Marion, Shannen, for many times, we went to the same events and shared stories, a lot of pleasant memories build my life in Maastricht! For many other colleagues, Britt, Marion, Sandra, Sarah, Anne, Wouter, Christian, Roel, Glenn, Pim, Nick, Milaine, Dean, Elentina Sylvana, Alix, Bethany, Perla, Rose, Ellis, Kyonghwan, Gowoon, Majed, Mohammed, Faris, Faisal and many may not mentioned here who belong to our big lunch group, I really enjoyed the talks, greetings and jokes you have made! There were also my students doing their intership here such as Nils, Nienke, and Sofia who did part of the work and I reaaly enjoyed the time that we worked together. Thanks!

I would also like to thank my colleagues that we worked together as $\mathrm{PhD}$ representatives of the MHeNS, including Nynke, Lotta, Simone, Lotter, Angelique. The way we arranged things as organizers really deepen my knowledge of how things went on and the true school structure or strategies that I did not reach before. We gathered together many times in the school restaurant, the coffee shops and tried snacks at Nynke's place. A lot of fun! The same thank my colleagues that we worked together as lab day-out committee members including Govert, Roy, Danny, and Thoe. Really a good chance to work on the same event and let it happen!

I would also like to thank other senior scientists from the department, including Jos, Yasin, Daniel, Gunter, Ali, you are the ones who enriched my knowledge of neuroscience. Also, I would thank the support I have received from our tech-team, especially Hellen, Marjan, Denise, Marcella, and Rachelle. I would thank Rachelle and Ankie for their help during my study here in Maastricht.

I would also like to thank my best friends Junfang and Jieyi. We had the chance to spend our 7 years in the same class in China during our medical study and 3 years Maastricht. Now both of you already successfully start your career as medical doctors in one of the most famous hospitals in China. Good job! I always remember the huge help you made to me in my first year here and later the joyful of so many times we visited each other and traveled together. And even at almost the same month, we two families had babies and became parents! Zhiqi, what a handsome baby! How wonderful a sence when you and Yumi seated in Kaimei's swing chair!Thoes lovely day! Cheers for friendship!

I would like also thank my other friends from China, including Shuo, Yuan and Quan, Xiaoqing, Yilin, Qi, Jianqin and Guilin, Ning, Shujin, Aomin, Huajie, Ming, Xinying, Tianyu, Lianci, Han, Ying, Shijie, Longping, Wenjie, Wenting, Letong, Yi, Shunxin, Xinwei, Jianhua ..., I may not write my words separately for each of you but deeply in my 
heart, I always feel lucky that we have the chance to study in the same university far away from home. The life in Maastricht is great but sometimes also could be hard, nothing could compare the help from you guys that we do share the same values and backgrounds.

Ma and Pa, Ma in law and Pa in law, my brothers and my sisters in law, you are the people who always stand behind me and I always know, no matter what happens here, there is a warmly place called home!

And also thank my daughter Yumi, you never know how much the motivation I got from you. Actually, you may never know you are always so strong, so determined and always try so hard when you want to get something, which turns out to protect my dream much better than you may ever think.

In the end, I would thank the most my wife Qing. Words will never express enough about what I feel but still, I will try gathering sentences here to describe it. People always say life is like a box of cholates. When I look back that many amazing things happened during my PhD study, there were 2 things always jumped out immediately, one was that you married me in the summer of 2015 and another was later you gave birth to Yumi in the spring of 2017! You just ignored the uncertainty of life and bravely moved forward to me which really swept away all my hesitation and worries! I would say my PhD study is largely part of your work because, the really truth is, your courage inspires my courage and your determination builds my determination...... Looking forward to tasting the next box of chocolates with you! 


\section{Appendix III Publications}

\section{Refereed articles}

1. Zong, S. *, Hoffmann, C.*, Mane-Damas M., et al. Absence of autoantibodies against neuronal surface antigens in sera of patients with psychotic disorders. JAMA Psychiatry (accepted) (IF 15.9)

2. Mané-Damas M., Hoffmann C., Zong S., et al. Autoimmunity in psychotic disorders. Where we stand, challenges and opportunities. Autoimmunity Reviews (2019) 18(9):102348. doi: https://doi.org/10.1016/j.autrev.2019.102348. (IF 8.7)

3. Hoffmann, C., Stevens, J.*, Zong, S*., et al. (2018). Alpha7 acetylcholine receptor autoantibodies are rare in sera of patients diagnosed with schizophrenia or bipolar disorder. PLOS ONE, 13(12), [e0208412]. dio: https://doi.org/10.1371/journal.pone.0208412 (IF 2.8)

4. Zong, S., Hoffmann, C., Mane-Damas, M., Molenaar, P., Losen, M., \& Martinez-Martinez, P. (2017). Neuronal Surface Autoantibodies in Neuropsychiatric Disorders: Are There Implications for Depression? Frontiers in Immunology, 8, [752]. DOI: 10.3389/fimmu.2017.00752. (IF 6.4)

5. Hoffmann, C.*, Zong, S.*, Mane-Damas, M.*, Molenaar, P., Losen, M., \& Martinez-Martinez, P. (2016). Autoantibodies in Neuropsychiatric Disorders. ANTIBODIES, 5(2), [9]. DOI: 10.3390/antib5020009. (IF N/A)

Manuscripts in process:

1. Shenghua Zong, Carolin Hoffmann, Marina Damas, Nils Kappelmann, Peter Molenaar, Gerard van Grootheest, Brenda W.J.H. Penninx, Rob P.W. Rouhl, Mario Losen1, Pilar Martinez-Martinez. Novel neuronal surface autoantibodies in plasma of depression and Anxiety (in process, submitted to JAMA Psychiatry, IF 15.9).

2. Shenghua Zong, Carolin Hoffmann, Marina Damas, Anita M.Vinke, Xingzhen Zhang, Jan G.M.C. Damoiseaux, Rob P.W.Rouhl, Mario Losen, Pilar Martinez Martinez. Detection of Glutamic acid decarboxylase (GAD) and other neuronal autoantibodies in suspected GAD related disorders (in process).

3. Shenghua Zong, Nijs, Laurence de., Marina Damas, B. Rutten, Pilar Martinez. Higher prevalence of Low reactivity anti-neural (hippocampal) autoantibodies in the serum of PTSD. (In process).

4. Shenghua Zong, Anita Vinke, Carolin Hoffmann, Marina Damas, Jan G.M.C. Damoiseaux, Rob P.W.Rouhl, Mario Losen, Pilar Martinez Martinez. A case report of encephalitis patient with mGluR1 autoantibodies. (In process)

5. Mané-Damas M, Vinke A, Hoffmann C, Zong S, Losen M, Molenaar P, Damoiseaux J, Koudijs S, Rouhl R, Martinez Martinez P. Unidentified neuronal surface IgG autoantibodies in a case of Hashimoto encephalopathy (in process, Neurology - Neuroimmunology \& Neuroinflammation, impact factor 7.4)

Oral presentations:

- Searching for novel neuronal surface autoantibodies in depression/anxiety. By: Zong, S. Maastricht Immunology Seminar, January $17^{\text {th }}, 2019$, Maastricht.

Posters: 
1. Neuronal autoantibodies in psychotic disorder. By: Hoffmann, C., Zong, S., Damas, M., et al. Conference: The Lancet Summit: Inflammation and Immunity in Disorders of the Brain and Mind, November $15-17^{\text {th }}, 2018$, Barcelona (Spain).

2. Unidentified neuronal surface IgG autoantibodies in a case of Hashimoto encephalopathy. By: Damas, M., Hoffmann, C., Zong, S., et al. Conference: The Lancet Summit: Inflammation and Immunity in Disorders of the Brain and Mind, November 15-17 th 2018 , Barcelona (Spain).

3. Tracking anti-neuronal surface autoantibodies at different time points (waves 1, 3 and 5) and their clinical significance. By: Zong, S., Damas, M., Hoffmann, C., et al. Conference: $15^{\text {th }}$ annual NESDA day, June $5^{\text {th }}, 2018$, Amsterdam.

4. Screening for neuronal autoantibodies in plasma from the Netherlands study of depression and anxiety. By: Zong, S., Hoffmann, C., Damas, M., et al. Conference: $14^{\text {th }}$ annual NESDA day, May $31^{\text {st }}, 2017$, Groningen.

5. Detection of neuronal autoantibodies in plasma from the Netherlands study of depression and anxiety. By: Zong, S., Hoffmann, C., Damas, M., et al. Conference: MHeNS $9^{\text {th }}$ annual research day, November, $30^{\text {th }}$ 2016, Maastricht.

6. Analysis of auto-antibodies in psychotic disorder. By: Hoffmann, C., Zong, S., Damas, M., et al. Conference: The Lancet Neurology Autoimmune Disorders Conference, March 27 ${ }^{\text {th }}, 2015$, Barcelona (Spain). 


\section{Appendix IV Curriculum Vitae}

Shenghua Zong was born on the $11^{\text {th }}$ of October, 1987 in Ruzhou, Henan province, China. He grew up and received his pre-university education in his hometown. In 2006, he was admitted to the medical school of Zhengzhou University and majored in clinical medicine. After 7 years' study including 3 years clinical training in the first affiliated hospital of Zhengzhou University, in July 2013, he got his master's degree. In the last year (2012) of the medical education, he passed the Practitioners Exam in China and obtained the Medical practitioner's qualification certificate which licensed him as a medical doctor. Then he worked one year as a resident (on the training to become a neurosurgeon) in Nanjing Benq hospital, an affiliated hospital of the Nanjing Medical University. In October 2014, he came to the Netherlands and worked in Prof. Pilar Martinez's lab, Maastricht University, as a research assistant and become a PhD candidate later. In 2015, he was awarded a national scholarship from China Scholarship Council which supported 3 years of his PhD study at the Department of Psychiatry and Neuropsychology, School for Mental Health and Neuroscience, Division III (Neuroscience), Maastricht University. He worked on the project of detecting neuronal autoantibodies in neuropsychiatric disorders and also got involved in teaching and grand application under the supervision of Prof. Pilar Martinez, Dr. Mario Losen and Dr. Rob. P.W. Rouhl. The results of his research are presented in the current dissertation and parts of them have been published. During his PhD study, he also organized the department lab day-out as one of the committee members in 2016. He was also one of the department PhD student representatives during 2016-2017. He is applying for grants at the moment to continue his research. 


\section{Appendix V Thesis defenses from MHeNs - School for Mental Health and Neuroscience}

2013

Rob Havermans: Bipolar disorder in daily life; Mood and cortisol responses to naturally occurring events. Supervisor: Prof.dr. M. de Vries; Co-Supervisor: Dr. N. Nicolson.

Véronique Moers-Hornikx: Deep brain stimulation and the cerebellum. Supervisors: Prof.dr. J. Vles / Prof.dr. Y. Temel; Co-Supervisor: Dr. G. Hoogland.

Nicole Veldhorst-Janssen: Intranasal delivery of rapid acting drugs.Supervisors: Prof.dr. M. Marcus / Prof.dr. C. Neef; Co-Supervisor: Dr. P.H. van der Kuy.

Stéphanie Knippenberg: Vitamin D and Multiple Sclerosis: immunological and clinical outcome. Supervisor: Prof.dr. J. Cohen-Tervaert; Co-Supervisors: Dr. J. Damoiseaux / Dr. Y. Bols.

Erik D. Gommer: Dynamic Cerebral Autoregulation: from methodology towards clinical application. Supervisors: Prof.dr. W.H. Mess / Prof.dr. R.B. Panerai, UK; Co-Supervisor: Dr.ir. J.P.H. Reulen.

Olga A.H. Reneerkens: Can PDE inhibition improve cognition?:SETPTTanslational insights. Supervisor: Prof.dr. H.W.M. Steinbusch; Co-Supervisor: Dr. J. Prickaerts;.

Lyzel S. Elias-Sonnenschein: Clinical and biomarker correlates of genetic risk factors for Alzheimer's disease. Supervisor: Prof.dr. F.R.J. Verhey; Co-Supervisor: Dr. P.J. Visser.

Diego F. Mastroeni: Epigenetic Dysregulation and the Pathophysiology of Supervisors: Prof.dr. H.W.M. Steinbusch / Prof.dr. P.D. Coleman, Sun City, Arizona; Co-Supervisors: Dr. B.P.F. Rutten / Dr. D.L.A. van den Hove.

Leonidas Chouliaras: Epigenetic Regulation in Aging and Alzheimer's disease: A translational perspective. Supervisor: Prof.dr. H.W.M. Steinbusch; Co-Supervisors: Dr. B.P.F. Rutten / Dr. D.L.A. van den Hove.

Liesbeth Knaepen: Perinatal events and altered pain sensitivity in later life. Supervisors: Prof.dr. E.A.J. Joosten / Prof.dr. D. Tibboel, EUR; Co-Supervisor: Dr. J. Patijn.

Marisela Martinez-Claros: Hippocampal plasticity and corticosterone: From dendrites to behaviour. Supervisor: Prof.dr. H.W.M. Steinbusch; Co-Supervisors: Dr. J.L. Pawluski / Dr. J. Prickaerts.

Marcus D. Lancé: A circle of improvement in bleeding management: from laboratory to clinic and back. Supervisors: Prof.dr. M.A.E. Marcu / Prof.dr. J.W.M. Heemskerk; Co-Supervisor: Dr. Y.M.C. Henskens.

Hilde Braakman: Imaging the brain; neuronal correlates of cognitive impairment in children with frontal lobe epilepsy. Supervisors: Prof.dr. A.P. Aldenkamp / Prof.dr. J.S.H. Vles; Co-Supervisors: Dr.ir. W.H. Backes / Dr. P.A.M. Hofman.

Willem H. van Zwam: Aneurysmal subarachnoid hemorrhage: imaging strategies and costeffectiveness aspects in diagnostic work-up and post-therapeutic follow-up. Supervisors: Prof.dr. J.T. Wilmink / Prof.dr. J.E. Wildberger; Co-Supervisor: Dr. P.A.M. Hofman.

Klara De Cort: The Pathogenesis of Panic Disorder. Supervisors: Prof.dr. I. Myin-Germeys 
/ Prof.dr. E.J.L. Griez; Co-Supervisors: Dr. K.R.J. Schruers / Dr. I. Van Diest, Leuven.

Kim van Wijck: Mind the Gap; experimental studies on splanchnic hyperfusion and gastrointestinal integrity loss in man. Supervisors: Prof.dr. W.A. Buurman / Prof.dr. C.H.C. Dejong; Co-Supervisor: Dr. K. Lenaerts.

Yvette Roke: Antipsychotic-induced hyperprolactinemia in children and adolescents with mainly autism spectrum disorders. Prevalence, symptoms, clinical consequences and genetic risk factors. Supervisors: Prof.dr. P.N. van Harten / Prof.dr. J.K. Buitelaar (RUN); Co-Supervisor: Dr. A. Boot (UMCG).

Fleur Goezinne: Retinal detachment surgery: pre and postoperative prognostic factors. Supervisors: Prof.dr. F. Hendrikse / Prof.dr. C.A.B. Webers; Co-Supervisor: Dr. E.C. La Heij (Amsterdam).

Ralph L.J.G. Maassen: The Merits of Videolaryngoscopy during Glottic Visualisation for Endotracheal Intubation. Supervisors: Prof.dr. M. Marcus / Prof.dr. A. van Zundert (University of Queensland).

Maria J. de Sousa Guerreiro: The role of sensory modality in age-related distraction. Supervisor: Prof.dr. C.M. van Heugten; Co-Supervisor: Dr. P.W.M. van Gerven.

Ine Rayen: Effects of developmental fluoxetine exposure on neurobehavioral outcomes.

Supervisor: Prof.dr. H.W.M. Steinbusch; Co-Supervisors: Dr. J.L. Pawluski / Dr. T.D. Charlier (Ohio University, USA).

Nynke M.G. Bodde: Psychogenic non-epileptic seizures; a separate disorder or part of a continuum? Supervisors: Prof.dr. R. van Oostenbrugge / Prof.dr. K. Vonck (UZ Gent);Co-Supervisors: Dr. R. Lazeron / Dr. A. de Louw (Epilepsiecentrum Kempenhaeghe, Heeze).

Alejandro M. Gomez: Novel strategies for making myasthenia less gravis: targeting plasma cells and the neuromuscular junction. Supervisor: Prof.dr. M.H. De Baets; Co-Supervisors: Dr. M. Losen / Dr. P. Martinez-Martinez.

Mohammad S. Rahnama'i: Prostaglandins and Phosphodiesterases in the Urinary Bladder Wall. Supervisors: Prof.dr. Ph. Van Kerrebroeck / Prof.dr. S. de Wachter (Universiteit Antwerpen); CoSupervisor: Dr. G. van Koeveringe.

Mariken B. de Koning: Studying biomarkers in populations at genetic and clinical high risk for psychosis. Supervisors: Prof.dr. T. Amelsvoort / Prof.dr. J. Booij (AMC).

Fabien Boulle: Epigenetic regulation of BDNF/TrkB signaling in the pathophysiology and treatment of mood disorders. Supervisors: Prof.dr. H.W.M. Steinbusch /Prof.dr. L. Lanfumey (Universiteit Parijs); Co-Supervisors: Dr. D. van den Hove / Dr. G. Kenis.

2014

Iris Nowak-Maes: Tinnitus; assessment of quality of life \& cost-effectiveness. Supervisors: Prof.dr. M. Peters / Prof.dr. B. Kremer; Co-Supervisors: Dr. M. Joore / Dr. L. Anteunis.

Marjolein Huijts: Cognitive function in patients with cerebral small vessel disease. Supervisor: Prof.dr. R.J. van Oostenbrugge; Co-Supervisors: Dr. A.A. Duits / Dr. J. Staals. 
Markus Gantert: Fetal inflammatory injury as origin of long term disease: Lessons from animal models. Supervisors: Prof.dr. B. Kramer / Prof.dr. L. Zimmermann; Co-Supervisor: Dr. A. Gavilanes.

Elke Kuypers: Fetal development after antenatal exposures: Chorioamnionitis and maternal glucocorticoids. Supervisors: Prof.dr. B.W. Kramer / Prof.dr. H.W. Steinbusch / Prof.dr. Suhas G. Kallapur (University of Cincinnati, Ohio, USA).

Pieter Kubben: Ultra low-field strength intraoperative MRI for Glioblastoma Surgery. Supervisor: Prof.dr. J.J. van Overbeeke; Co-Supervisor: Dr. H. van Santbrink.

Laura Baijens: Surface electrical stimulation of the neck for oropharyngeal dysphagia in Parkinson's disease: therapeutic aspects and reliability of measurement. Supervisor: Prof.dr. B. Kremer; CoSupervisor: Dr. R. Speyer, Townsville.

Janneke Hoeijmakers: Small fiber neuropathy and sodium channels; a paradigm shift. Supervisor: Prof.dr. R.J. van Oostenbrugge; Co-Supervisors: Dr. C.G. Faber / Dr. I.S.J. Merkies.

Stephanie Vos: The Role of biomarkers in preclinical and prodromal Alzheimer's disease. Supervisor: Prof.dr. F.R. Verhey; Co-Supervisor: Dr. P.J. Visser.

Muriël Doors: The Value of Optical Coherence Tomography in Anterior Segment Surgery. Supervisors: Prof.dr. R.M. Nuijts / Prof.dr. C.A. Webers; Co-Supervisor: Dr. T.T.J.M. Berendschot.

Anneke Maas: Sleep problems in individuals with genetic disorders associated with intellectual disability. Supervisors: Prof.dr. I. Curfs / Prof.dr. R. Didden.

Sebastiaan van Gorp: Translational research on spinal cord injury and cell-based therapies; a focus on pain and sensorimotor disturbances. Supervisors: Prof.dr. B. Joosten/ Prof.dr. M. van Kleef; CoSupervisors: Dr. J. Patijn /Dr. R. Deumens, KU Leuven.

Andrea Sannia: High risk newborns and brain biochemical monitoring. Supervisor: Prof.dr. J.S.H. Vles; Co-Supervisors: Dr. D. Gazzolo, Alessandria, Italy / Dr. A.W.D. Gavilanes.

Julie A.D.A. Dela Cruz: Dopamine mechanisms in learning and memory: Evidence from rodent studies. Supervisors: Prof.dr. H.W.M. Steinbusch / Prof.dr. R.J. Bodnar, New York; Co-Supervisor: Dr. B.P.F. Rutten.

René Besseling: Brain wiring and neuronal dynamics; advances in MR imaging of focal epilepsy. Supervisors: Prof.dr. A.P. Aldenkamp / Prof.dr.ir. W.H. Backes; Co-Supervisor: dr. J.F.A. Jansen.

Maria Quint-Fens: Long-term care after stroke; development and evaluation of a long- term intervention in primary care. Supervisors: Prof.dr. J.F.M. Metsemakers / Prof.dr. C.M. van Heugten / Prof.dr. M. Limburg, Almere; Co-Supervisor: dr. G.H.M.I. Beusmans.

Veronique Moulaert: Life after survival of a cardiac arrest; the heart of the matter. Supervisors: Prof.dr. J.A. Verbunt / Prof.dr. C.M. van Heugten / Prof.dr. D.T. Wade, Oxford, UK.

Feikje Smeets: The hallucinatory-delusional state: a crucial connection in the psychosis symptom network. Supervisor: Prof.dr. J. van Os; Co-Supervisor: Dr. T. Lataster. 
Lies Clerx: Alzheimer's disease through the MR-eye; novel diagnostic markers and the road to clinical implementation". Supervisor: Prof.dr. F. Verhey; Co-Supervisors: Dr. P.J. Visser / P. Aalten.

Sonny Tan: The subthalamic nucleus in Parkinson's disease. Supervisors: Prof.dr. Y. Temel / Prof.dr. H.W.M. Steinbusch / Prof.dr. T. Sharp, Oxford, UK / Prof.dr. V. Visser-Vandewalle, Koln.

Koen van Boxem: The use of pulsed radiofrequency in the managementistepiof chronic lumbosacral radicular pain. Supervisors: Prof.dr. M. van Kleef / Prof.dr. E.A.J. Joosten; Co-Supervisor: Assoc. Prof.dr. J. van Zundert.

Jérôme Waterval: Hyperostosis cranialis interna. Supervisors: Prof.dr. J.J. Manni / Prof.dr. R.J. Stokroos. Sylvie Kolfschoten-van der Kruijs: Psychogenic non-epileptic seizures; the identification of neurophysiological correlates. Supervisors: Prof.dr. A.P. Aldenkamp / Prof.dr. K.E.J. Vonck, Universiteit Gent; Co-Supervisors: Dr. J.F.A. Jansen / Dr. R.H.C. Lazeron, Kempenhaeghe.

Wouter Pluijms: Spinal cord stimulation and pain relief in painful diabetic: polyneuropathy, a translational approach. Supervisors: Prof.dr. M. van Kleef / Prof.dr. E.A. Joosten; Co-supervisor: Dr. C.G. Faber.

Ron Handels: Health technology assessment of diagnostic strategies for Alzheimer's disease. Supervisors: Prof.dr. F.R.J. Verhey / Prof.dr. J.L. Severens (EUR); Co-Supervisor: Dr. M.A. Joore / Dr. C.A.G. Wolfs.

Evelyn Peelen: Regulatory T cells in the pathogenesis of Multiple Sclerosis: potential targets for vitamin D therapy. Supervisors: Prof.dr. R.M.M. Hupperts / Prof.dr. J.W. Cohen Tervaert; Co-Supervisor: Dr. J.G.M.C. Damoiseaux / Dr. M.M.G.L.Thewissen, Diepenbeek.

Reint Jellema: Cell-based therapy for hypoxic-ischemic injury in the preterm brain. Supervisors: Prof.dr. B.W.W. Kramer / Prof.dr. H.W.M. Steinbusch; Co-Supervisor: Dr. W.T.V. Germeraad / Dr. P. Andriessen, Veldhoven.

Maria Wertli: Prognosis of Chronic Clinical Pain Conditions: The Example of Complex Regional Pain Syndrome 1 and Low Back Pain. Supervisors: Prof.dr. M. van Kleef; Co-Supervisor: Dr. F. Brunner, Zürich / Dr. R. Perez, VUmc.

Dagmar Zeef: An experimental model of Huntington's disease: Validation \& Stimulation. Supervisors: Prof.dr. Y. Temel / Prof.dr. H.W.M. Steinbusch; Co-supervisor: Dr. A. Jahanshahi.

Jeroen Decoster: Breaking Down Schizophrenia into phenes, genes and environment. Supervisors: Prof.dr. I. Myin-Germeys / Prof.dr. M. De Hert, KU Leuven; Co-Supervisor: Dr. R. van Winkel.

Eaja Anindya Sekhar Mukherjee: Fetal Alcohol Spectrum Disorders: exploring prevention and management. Supervisor: Prof.dr. L.M.G. Curfs; Co-Supervisor: Prof. S. Hollins, St. George's University of London, UK.

Catherine van Zelst: Inside out; On stereotype awareness, childhood trauma and stigma in psychosis. Supervisors: Prof.dr. Ph. Delespaul / Prof.dr. J. van Os.

Ibrahim Tolga Binbay: Extended Psychosis Phenotype in the Wider Social Environment. Supervisor: Prof.dr. J. van Os; Co-Supervisor: Dr. M. Drukker. 
Frank Van Dael: OCD matters in psychosis. Supervisors: Prof.dr. J. van Os / Prof.dr. I. Myin-Germeys.

Pamela Kleikers: NOXious oxidative stress: from head toe too and back. Supervisors: Prof.dr. H.H.H.W. Schmidt / Prof.dr. H.W.M. Steinbusch; Co-Supervisor: Dr. B. Janssen.

José Luis Gerardo Nava: In vitro assay systems in the development of therapeutic interventions strategies for neuroprotection and repair. Supervisors: Prof.dr.med. J. Weis / Prof.dr. H.W.M. Steinbusch; Co-Supervisor: Dr. G.A. Brook, RWTH Aachen.

Eva Bollen: Cyclic nucleotide signaling and plasticity. Supervisors: Prof.dr. H.W.M. Steinbusch / Prof.dr. R. D’Hooge, KU Leuven; Co-Supervisor: Dr. J. Prickaerts.

2015

Jessica A. Hartmann: A good laugh and a long sleep; Insights from prospective and ambulatory assessments about the importance of positive affect and sleep in mental health. Supervisor: Prof.dr. J. van Os; Co-Supervisors: C.J.P. Simons / Dr. M. Wichers.

Bart Ament: Frailty in old age; conceptualization and care innovations. Supervisors: Prof.dr. G.I.J.M. Kempen / Prof.dr. F.R.J. Verhey; Co-Supervisor: Dr. M.E. de Vugt.

Mayke Janssens: Exploring course and outcome across the psychosis-continuum. Supervisor: Prof.dr. I. Myin-Germeys; Co-Supervisor: Dr. T. Lataster.

Dennis M.J. Hernau: Dopayours is not dopamine: genetic, environmental and pathological variations in dopaminergic stress processing. Supervisor: Prof.dr. I. Myin- Germeys; Co-Supervisors: Prof.dr. F.M. Mottaghy / Dr. D. Collip.

Ingrid M.H. Brands: The adaptation process after acquired brain injury Pieces of the puzzle. Supervisors: Prof.dr. C.M. van Heugten / Prof.dr. D.T. Wade, Oxford UK; Co-Supervisors: Dr. S.Z. Stapert / Dr. S. Köhler.

Francesco Risso: Urinary and salivary S100B monitoring in high risk infants. Supervisor: Prof.dr. J.S.H. Vles; Co-Supervisors: Dr. D. Gazzolo, Genoa,Italy / Dr. A.W.D. Gavilanes.

Alessandro Borghesi: Stem and Progenitor Cells in Preterm Infants: Role in the Pathogenesis and Potential for Therapy. Supervisor: Prof.dr. L. Zimmermann; Prof.dr. B. Kramer; Co-Supervisors: Dr. D. Gazzolo, Genoa, Italy / Dr. A.W.D. Gavilanes.

Claudia Menne-Lothmann: Affect dynamics; A focus on genes, stress, and an opportunity for change. Supervisor: Prof.dr. J. van Os; Co-Supervisors: Dr. M. Wichers / Dr. N. Jacobs.

Martine van Nierop: Surviving childhood new perspectives on the link between childhood trauma and psychosis. Supervisors: Prof.dr. I. Myin-Germeys / Prof.dr. J. van Os; Co-Supervisor: Dr. R. van Winkel. Sylvia Klinkenberg: VNS in children; more than just seizure reduction. Supervisors: Prof.dr. J. Vles / Prof.dr. A. Aldenkamp; Co-Supervisor: Dr. H. Majoie.

Anouk Linssen: Considerations in designing an adult hearing screening programme. Supervisor: Prof.dr. B. Kremer; Co-Supervisors: Dr. L. Anteunis / Dr. M. Joore. 
Janny Hof: Hearing loss in young children; challenges in assessment and intervention. Supervisors: Prof.dr. B. Kremer / Prof.dr. R. Stokroos / Prof.dr. P. van Dijk, RUG; Co-Supervisor: Dr. L. Antheunis.

Kimberly Cox-Limpens: Mechanisms of endogenous brain protection; Clues from the transcriptome. Supervisors: Prof.dr. J. Vles / Prof.dr. L. Zimmermann; Co-Supervisor: Dr. A. Gavilanes.

Els Vanhoutte: Peripheral Neuropathy outcome measures; Standardisation (PeriNomS) study part 2: Getting consensus. Supervisors: Prof.dr. C. Faber / Prof.dr. P. van Doorn; Co-Supervisor: Dr. I. Merkies, Spaarne ziekenhuis Hoofddorp.

Mayienne Bakkers: Small fibers, big troubles; diagnosis and implications of small fiber neuropathy. Supervisors: Prof.dr. C. Faber / Prof.dr. M. de Baets; Co-Supervisor: Dr. I. Merkies, Spaarne ziekenhuis Hoofddorp.

Ingrid Kramer: Zooming into the micro-level of experience: An approach for understanding and treating psychopathology. Supervisor: Prof.dr. J. van Os; Co-Supervisors: Dr. M. Wichers, UMC Groningen / Dr. C. Simons.

Esther Bouman: Risks and Benefits of Regional Anesthesia in the Perioperative Setting. Supervisors: Prof.dr. M. van Kleef / Prof.dr. M. Marcus, HMC, Qatar / Prof.dr. E. Joosten; Co-Supervisor: Dr. H. Gramke.

Mark Janssen: Selective stimulation of the subthalamic nucleus in Parkinson's disease; dream or near future. Supervisors: Prof.dr. Y. Temel / Prof.dr. V. Visser-Vandewalle, Keulen / Prof.dr. A. Benazzouz, Bordeax, France.

Reina de Kinderen: Health Technology Assessment in Epilepsy; economic evaluations and preference studies. Supervisors: Prof.dr. S. Evers / Prof.dr. A. Aldenkamp; Co-Supervisor: Dr. H. Majoie / Dr. D. Postulart, GGZ O-Brabant.

Saskia Ebus: Interictal epileptiform activity as a marker for clinical outcome. Supervisors: Prof.dr. A. Aldenkamp / Prof.dr. J. Arends, TUE / Prof.dr. P. Boon, Universiteit Gent, België.

Inge Knuts: Experimental and clinical studies into determinants of panic severity. Supervisor: Prof.dr. I. Myin-Germeys; Co-Supervisor: Dr. K. Schruers; Influencing panic.

Nienke Tielemans: Proactive coping post stroke: The Restored4Stroke Self-Management study. Supervisors: Prof.dr. C. van Heugten / Prof.dr. J. Visser-Meily, UMC Utrecht; Co-Supervisor: Dr. V. Schepers, UMC Utrecht.

Tom van Zundert: Improvements Towards Safer Extraglottic Airway Devices. Supervisors: Prof.dr. A.E.M. Marcus / Prof.dr. W. Buhre / Prof.dr. J.R. Brimacombe, Queensland, Australia / Prof.dr. C.A. Hagberg.

Tijmen van Assen: Anterior Cutaneous Nerve Entrapment Syndrome Epidemiology and surgical management. Supervisors: Prof.dr. G.L. Beets / Prof.dr. M. van Kleef / Dr. R.M.H. Roumen / Dr. M.R.M. Scheltinga, MMC Veldhoven.

Rohit Shetty: Understanding the Clinical, Immunological and Genetic Molecular Mechanisms of Keratoconus. Supervisors: Prof.dr. R.M.M.A. Nuijts / Prof.dr. C.A.B. Webers. 
Christine van der Leeuw: Blood, bones and brains; peripheral biological endophenotypes and their structural cerebral correlates in psychotic disorder. Supervisor: Prof.dr. J. van Os; Co-supervisor: Dr. M. Marcelis.

Sanne Peeters: The Idle Mind Never Rests; functional brain connectivity across the psychosis continuum. Supervisor: Prof.dr. J. van Os; Co-supervisor: dr. M. Marcelis.

Nick van Goethem: $\alpha 7$ nicotinic acetylcholine receptors and memory processes: mechanistic and behavioral studies. Supervisor: Prof.dr. H.W.M. Steinbusch; Co- supervisor: Dr. J. Prickaerts.

Nicole Leibold: A Breath of fear; a translational approach into the mechanisms of panic. Supervisor: Prof.dr. H.W.M. Steinbusch; Co-supervisors: Dr. K.R.J. Schruers / Dr. D.L.A. van den Hove.

Renske Hamel: The course of mild cognitive impairment and the role of comorbidity. Supervisor: Prof.dr. F.R.J. Verhey; Co-supervisors: Dr. I.H.G.B. Ramakers / Dr. P.J. Visser.

Lucia Speth: Effects of botulinum toxin A injections and bimanual task-oriented therapy on hand functions and bimanual activities in unilateral Cerebral Palsy. Supervisors: Prof.dr. J. Vles; Prof.dr. R. Smeets; Co-supervisor: Dr. Y. Janssen-Potten, Adelante Hoensbroek.

Yuan Tian: The effects of Lutein on the inflammatory pathways in age-related macular degeneration (AMD). Supervisors: Prof.dr. C. Webers; Prof.dr. A. Kijlstra, WUR; Co- supervisor: Dr. M. Spreeuwenberg; Dr. H. Tange.

Peggy Spauwen: Cognition and Type 2 diabetes; the interplay of risk factors. Supervisors: Prof.dr. F. Verhey; Prof.dr. C. Stehouwer; Co-supervisor: Dr. M. van Boxtel

Marc Hilhorst: Crescentic glomerulonephritis in ANCA associated vasculitis. Supervisors: Prof.dr. J. Cohen-Tervaert; Co-supervisor: Dr. P. van Paassen

Martin Gevonden: The odd one out: exploring the nature of the association between minority status and psychosis. Supervisors: Prof.dr. J-P. Selten; Prof.dr. J. Booij, Uva; Prof.dr. I. Myin-Germeys

Bart Biallosterski: Structural and functional aspects of sensory-motor Interaction in the urinary bladder. Supervisors: Prof.dr. Ph. Van Kerrebroeck; Prof.dr. S. De Wachter, UvAntwerpen; Co-supervisors: Dr. G. van Koeveringe; Dr. M. Rahnama'i.

Alexandra König: The use of information and communication technologies (ICT) for the assessment of patients with Alzheimer's Disease and related disorders. Supervisors: prof.dr. F. Verhey; prof.dr. Ph. Robert, Nice, Fr; Co-supervisors: dr. P. Aalten; dr. R. David, Nice. Fr.

Michelene Chenault: Assessing Readiness for Hearing Rehabilitation. Supervisors: prof.dr. M.P.F. Berger; prof.dr. B. Kremer; Co-supervisor: dr. L.J.C. Anteunis.

Anand Vinekar: Retinopathy of Prematurity. Recent advances in tele-medicine screening, risk factors and spectral domain optical coherence tomography imaging. Supervisor: prof.dr. C.A.B. Webers; Cosupervisor: dr. N.J. Bauer

Fleur van Dooren: Diabetes and Depression: exploring the Interface between Pathophysiological and Psychological factors. Supervisors: prof.dr. F.R.J. Verhey; prof.dr. J.K.L. Denollet, UvT; prof.dr. F. Pouwer, UvT; Co-supervisor: dr. M.T. Schram. 
Gabriëlla Pons van Dijk: Taekwondo and physical fitness components in middle-aged healthy volunteers; the Sekwondo study. Supervisors: prof.dr. J. Lodder; prof.dr. H. Kingma; Co-supervisor: dr. A.F. Lenssen.

Yara Pujol López: Development and psychoneuroimmunological mechanisms in depression. Supervisor: prof.dr. H.W.M. Steinbusch; Co-supervisors: Dr. G. Kenis; Dr. D. van den Hove; Dr. Aye Mu Myint, München.

Romina Gentier: UBB+1; an important switch in the onset of Alzheimer's disease. Supervisors: Prof. H. Steinbusch; Prof. D. Hopkins; Co-supervisor: Dr. F. van Leeuwen.

Sanne Smeets: Insights into insight: studies on awareness of deficits after acquired brain injury. Supervisor: Prof. C. van Heugten; Prof. R. Ponds; Co-supervisor: Dr. I. Winkens

Kim Beerhorst: Bone disease in chronic epilepsy: fit for a fracture. Supervisor: Prof. A. Aldenkamp; Prof. R. van Oostenbrugge; Co-supervisor: Dr. P. Verschuure.

Alex Zwanenburg: Cerebral and cardiac signal monitoring in fetal sheep with hypoxic- ischemic encephalopathy. Supervisor: Prof. T. Delhaas; Prof. B. Kramer; Co-supervisors: Dr. T. Wolfs; Dr. P. Andriessen, MMC.

Ismail Sinan Guloksuz: Biological mechanisms of environmental stressors in psychiatry. Supervisor: Prof. J. van Os; Co-supervisors: Dr. B. Rutten; Dr. M. Drukker.

Seyed Ehsan Pishva MD: Environmental Epigenetics in mental health and illness. Supervisor: Prof.dr. J. van Os; Co-supervisors: Dr. B.P.F. Rutten; Dr. G. Kenis.

Ankie Hamaekers: Rescue ventilation using expiratory ventilation assistance; innovating while clutching at straws. Supervisors: Prof.dr. W.F. Buhre; Prof.dr. M. van Kleef.

Rens Evers. 22q11.2 deletion syndrome: intelligence, psychopathology and neurochemistry at adult age. Supervisors: Prof.dr. L.M.G. Curfs; Prof.dr. T. v. Amelsvoort.

Sarah-Anna Hescham. Novel insights towards memory restoration. Supervisor: Prof.dr. Y. Temel; Cosupervisor: Dr. A. Blokland; Dr. A. Jahanshahi.

João P. da Costa Alvares Viegas Nunes. Insulin receptor sensitization improves affective pathology in various mouse models. Supervisor: Prof.dr. H.W.M. Steinbusch; Co- supervisors: Dr. K-P. Lesch; Dr. T. Strekalova; Dr.B.H. Cline, Oxford.

Yanny Ying-Yee Cheng. Clinical Outcomes After Innovative Lamellar Corneal Transplantation Surgery. Supervisor: Prof.dr. R.M.M.A. Nuijts; Co-supervisor: Dr. J.S.A.G. Schouten.

2016

Oliver Gerlach. Parkinson's disease, deterioration during hospitalization. Supervisor: Prof.dr. R. van Oostenbrugge; Co-supervisor: Dr. W. Weber.

Remo Arts. Intracochlear electrical stimulation to suppress tinnitus. Supervisor: Prof.dr. R.J. Stokroos; Co-supervisor: Dr. E.L.J. Georg. 
Mitchel van Eeden. The $€$ - Restore4stroke study: Economic evaluation of stroke care in the Netherlands. Supervisors: Prof.dr.mr. S.M.A.A. Evers; Prof.dr. C.M. v. Heugten; Co-supervisor: dr. G.A.P. van Mastrigt.

Pim Klarenbeek. Blood pressure and cerebral small vessel disease. Supervisor: Prof.dr. R.J. van Oostenbrugge; Co-supervisor: Dr. J. Staals.

Ramona Hohnen. Peripheral pharmacological targets to modify bladder contractility. Supervisor: Prof.dr. Ph.E.V. van Kerrebroeck; Co-supervisors: Dr. G.A. van Koeveringe; Dr. M.A. Sahnama'i; Dr. C. Meriaux.

Ersoy Kocabicak. Deep brain stimulation of the subthalamic nucleus: Clinical and scientific aspects. Supervisors: Prof.dr. Y. Temel; Prof.dr. K. van Overbeeke; Co-supervisor: Dr. A. Jahanshahi.

Sven Akkerman. Temporal aspects of cyclic messenger signaling in object recognition memory; a pharmalogical approach. Supervisor: Prof.dr. H.W.M. Steinbusch;Co-supervisors: dr. J. Prickaerts; dr. A. Blokland.

Anja Moonen. Emotion and Cognition in Parkinson's disease; etiology and neurobiological mechanisms. Supervisor: Prof.dr. F.R.J. Verhey; Co-supervisor: dr. A.F.G. Leentjens.

Anna Schüth. Three-dimensional bladder tissue morphology. Supervisors: Prof.dr. G.A. van Koeveringe; Prof.dr. M. v. Zandvoort, Aachen; Prof.dr. Ph. V. Kerrebroeck.

Elisabeth van der Ven. Ethnic minority position as risk indicator for autism- Spectrum and psychotic disorders. Supervisors: Prof.dr. J.P. Selten; Prof.dr. J. van Os.

Zuzana Kasanova. Environmental reactivity for better or worse; The impact of stress and reward on neurochemistry, affect and behavior across the psychosis continuum. Supervisor: Prof.dr. I. MyinGermeys, KU Leuven/UM; Co-supervisor: dr. D. Collip.

Danielle Lambrechts. Ketogenic diet therapies; treatment for children and adults with refractory epilepsy. Supervisors: Prof.dr. H.J.M. Majoie; Prof.dr. J.S.H. Vles; Prof.dr. A.P. Aldenkamp; Cosupervisor: dr. A.J.A. de Louw, Kempenhaghe, Heeze.

Frank van Bussel. Advanced MRI in diabetes; cerebral biomarkers of cognitive decrements. Supervisors: Prof.dr.ir. W.H. Backes; Prof.dr. P.A.M. Hofman; Co-supervisor: dr. J.F.A. Jansen.

Lisa Schönfeldt. Neurostimulation to treat brain injury? Supervisors: Prof.dr. Y. Temel; Prof.dr. S. Hendrikx, Hasselt; Co-supervisor: dr. A. Jahanshahi.

Rianne Geerlings. Transition in patients with childhood-onset epilepsy; a long way to adulthood. Supervisor: Prof.dr. A.P. Aldenkamp; Co-supervisors:dr. A.J.A. de Louw, dr. L.M.C. Gottmer, Kempenhaeghe.

Nele Claes. B cells as multifactorial players in multiple sclerosis pathogenesis: insights from therapeutics. Supervisors: Prof.dr. V. Somers, Hasselt; Prof.dr. R. Hupperts Co-supervisors: Prof.dr. P. Stinissen, dr. J. Fraussen, Hasselt.

Olaf Schijns. Epilepsy surgery and biomarkers from history to molecular imaging. Supervisors: Prof.dr. J.J. van Overbeeke; Prof.dr. H. Clustermann, Aachen; Co-supervisors: dr. G. Hoogland; dr. M.J.P. v. Kroonenburgh. 
Lizzy Boots. Balanced and Prepared; development and evaluation of a supportive e- health intervention for caregivers of people with early-stage dementia. Supervisors: Prof.dr. F.R.J. Verhey; Prof.dr. G.I.J.M. Kempen; Co-supervisor: dr. M.E. de Vugt.

Wouter Donders. Towards patient-specific (cerebro-) vascular model applications. Supervisors: Prof.dr. T. Delhaas; Prof.dr.ir. F.N. van de Vosse, TUE; Co-supervisor: dr.ir. W. Huberts.

Sizzle Vanterpool. The implications of intrauterine invasion by microbes for placental Pathology and the occurrence of adverse pregnancy outcomes. Supervisor: Prof.dr. B.W. Kramer. Co-supervisors: dr. J.V. Been, Erasmus MC Rotterdam, dr. U von Rango.

Manuela Heins. The Relationship between Social Adversity, Psychosis, and Depression across an Individual's Life Span. Supervisor: Prof.dr. I. Myin-Germeys.

Christianus van Ganzewinkel. NEONATAL PAIN; Out of Sight, Out of Mind? Supervisor: Prof.dr. B.W.W. Kramer; Co-supervisor: dr. P. Andriessen, MMC Veldhoven.

Anne-Hilde Muris. Hype or hope? Vitamin D in multiple sclerosis; A clinical and immunological perspective. Supervisor: Prof.dr. R.M.M. Hupperts; Co-supervisor: dr. J.G.M.C. Damoiseaux.

Gerard Bode. The link between ceramide transporters, innate Immunity and Alzheimer's disease. Supervisor: Prof.dr. M.H.V. de Baets; Co-supervisors: dr. P. Martinez, dr. M. Losen.

Jo Stevens. Advanced diagnostics and therapeutics for Alzheimer's disease. Supervisor: Prof.dr. M. de Baets; Co-supervisors: dr. M. Losen, dr. P. Martinez-Martinez.

Rosan Luijcks. Stress and pain in muscles and brain; developing psychophysiological paradigms to examine stress and pain interactions. Supervisors: Prof.dr. J.J. van Os; Prof.dr.ir. H.J. Hermens, UT; Cosupervisor: dr. R. Lousberg.

M.C. Haanschoten. Towards efficient cardiac surgery - the integrating role of anesthesiology and intensive care. Supervisors: Prof. dr. W. Buhre; Prof. dr. A. van Zundert (Queensland); Co-supervisors: Dr. M.A. Soliman Hamad; Dr. A. van Straten (Catharina zkhs.)

Harmen Jan van de Haar. Microvascular and blood-brain barrier dysfunction in Alzheimer's disease. Supervisor: Prof.dr.ir. W. Backes; Prof.dr. F. Verhey; Co-supervisor: Dr. J. Jansen; Dr.ir. M. v. Osch, LUMC.

Coenraad Itz. Chronic low back pain, considerations about: Natural Course, Diagnosis, Interventional Treatment and Costs. Supervisor: Prof.dr. M. van Kleef; Prof.dr. F. Huygen, EUR; Co- supervisor: Dr. B. Ramaekers.

Willemijn Jansen. The Path of Alzheimer's disease: from neuropathology to clinic. Supervisor: Prof.dr. F. Verhey; Co-supervisors: Dr. P.J. Visser; Dr. I. Ramakers.

Ligia dos Santos Mendes Lemes Soares. Phosphodiesterase inhibitors: a potential therapeutic approach for ischemic cerebral injury. Supervisor: Prof.dr. H.W.M. Steinbusch; Co-supervisors: Dr. R.M. Weffort de Oliveira, Brazil; Dr. J. Prickaerts

Martijn Broen. Anxiety and depression in Parkinson's disease. Supervisor: Prof.dr. R.J. van Oostenbrugge; Co-supervisors: Dr. A.F.G. Leentjens; Dr. M.L. Kuijf. 
Sandra Schipper. Extrasynaptic receptors as a treatment target in epilepsy. Supervisor: Prof.dr. J.H.S. Vles; Co-supervisors: Dr. G. Hoogland; Dr. S. Klinkenberg; Dr. M.W. Aalbers, RUG.

João Casaca Carreira. Making sense of Antisense Oligonucleotides Therapy in Experimental Huntington's disease. Supervisor: Prof.dr. Y. Temel; Co-supervisors: Dr. A. Jahanshahi; Dr. W. van Roon-Mom, LUMC.

Dominique IJff. Trick or Treat? Cognitive side-effects of antiepileptic treatment. Supervisors: Prof.dr. A.P. Aldenkamp; Prof.dr. M. Majoie; Co-supervisors: Dr. J. Jansen; Dr. R. Lazeron, Kempenhaeghe.

Alfredo Ramirez. Neurogenetic approach in neurodegenerative disorders. Supervisors: Prof.dr. B.P.F. Rutten; Prof.dr. H.W.M. Steinbusch; Prof.dr. M.M. Nöthen, University of Bonn.

Nienke Visser. Toric Intraocular lenses in cataract surgery. Supervisor: Prof.dr. R.M.M.A. Nuijts; Cosupervisor: Dr. N.J.C. Bauer.

Jakob Burgstaller. Prognostic indicators for patients with degenerative lumbar spinal stenosis. Supervisor: Prof.dr. M. van Kleef; Co-supervisors: Dr. M.M. Wertli, University of Zurich; Dr. H.F. Gramke.

Mark van den Hurk. Neuronal Identity and Maturation: Insights from the Single-Cell Transcriptome. Supervisors: Prof.dr. H.W.M. Steinbusch; Prof.dr. B.P.F. Rutten; Co- supervisors: Dr. G. Kenis; Dr. C. Bardy, Adelaide.

Maria Nikiforou. Prenatal stress and the fetal gut. Potential interventions to prevent adverse outcomes. Supervisors: Prof.dr. B.W. Kramer; Prof.dr. H.W. Steinbusch; Co- supervisor: Dr. T.G. Wolfs.

Janneke Peijnenborgh. Assessment of cognition, time perception, and motivation in children. Supervisors: Prof.dr. J.S.H. Vles; Prof.dr. A.P. Aldenkamp; Co-supervisors: Dr. J. Hendriksen; Dr. P. Hurks.

Joany Millenaar. Young onset dementia; towards a better understanding of care needs and experiences. Supervisors: Prof.dr. F. Verhey; Prof.dr. R. Koopmans, RUN; Co- supervisors: Dr. M. de Vugt; Dr. C. Bakker, RUN.

2017

Adriana Smits. Perinatal factors and hearing outcome. Supervisors: Prof.dr. R.J. Stokroos; Prof.dr. B.W. Kramer; Prof.dr. B. Kremer.

Angela Bouwmans. Transcranial sonography in parkinsonian disorders: clear window or blurred vision. Supervisor: Prof.dr. W.H. Mess; Co-promotores: Dr. W.E.J. Weber; Dr. A.F.G. Leentjens.

Björn K. Stessel. Patient centred care after day surgery: scope for improvement. Supervisors: Prof.dr. W. Buhre; Prof.dr. B. Joosten. Co-supervisor: Dr. A.H. Gramke.

Jan Guy Bogaarts. Quantitative EEG and machine learning methods for the detection of epileptic seizures and cerebral asymmetry. Supervisor: Prof.dr. W.M. Mess; Co-supervisor: Dr.ir. J.P.H. Reulen; Dr.ir. E.D. Gommer. 
Martin M. Müller. Pregnancy derived products for treatment of perinatal brain injuries. Supervisors: Prof.dr. B.W.W. Kramer; Prof.dr. D. Surbek, Bern; Co-supervisors: Dr. T. Wolfs; Dr. G. Gavilanes.

Daan Ophelders. Novel treatment strategies for the protection of the preterm brain; Re- balancing inflammation and regeneration. Supervisor: Prof.dr. B. Kramer; Co-supervisor: Dr. T. Wolfs; Dr. R. Jellema.

Rosalie van Knippenberg. Experience sampling in dementia care; an innovative intervention to support caregivers in daily life. Supervisors: Prof.dr. F. Verhey; Prof.dr. R. Ponds; Prof.dr. I. Myin-Germeys, KU Leuven; Co-supervisor: Dr. M. de Vugt.

Claudia Vingerhoets. Investigating neurobiological mechanisms underlying comorbid cognitive symptoms in psychosis and substance use. Supervisors: Prof.dr. T. van Amelsvoort; Prof.dr. J. Booij, UvA; Co-supervisor: Dr. O. Bloemen

Dennis Oerlemans. Evolution of Neuromodulation for Lower Urinary Tract Dysfunction; Past, Present and Future. Supervisors: Prof.dr. Ph. van Kerrebroeck; Prof.dr. G. van Koeveringe. Co-supervisors: Dr. E. Weil; Dr. T. Marcelissen.

Marion Levy. Evaluation of BDNF/TrkB signaling as a common target in the treatment of major depression and Alzheimer's disease. Supervisors: Prof.dr. H. Steinbusch; Prof. L. Lanfumey, Université Paris Descartes, France. Co-supervisors: Dr. G. Kenis; Dr. D. van den Hove.

Patrick Domen. Stay connected: a family-based diffusion imaging study in psychotic disorder. Supervisor: Prof.dr. J. van Os. Co-supervisor: Dr. M. Marcelis

Geor Bakker. Innovative Approaches to Understanding the Neurobiology of Psychosis. Supervisors: Prof.dr. T. van Amelsfoort; Prof.dr. J. Booij, UvA. Co-supervisor: dr. M. Caan, UvA; dr. O. Bloemen.

Wilma Boevink. HEE! Over Herstel, Empowerment en Ervaringsdeskundigheid in de psychiatrie. Supervisors: Prof.dr. J. van Os; Prof.dr. Ph. Delespaul. Co-supervisor: dr. H. Kroon.

Nataliia Markova. Modified swim test as a mouse depression paradigm of enhanced Cognitive processing: the role of GSK3ß. Supervisor: Prof.dr. H. Steinbusch; Prof.dr. K-P. Lesch, University of Wuerzburg. Co-supervisor: Dr. T. Strekalova.

Merijn van de Laar. Individual differences in insomnia; implications of Psychological factors for diagnosis and treatment. Supervisor: Prof.dr. A. Aldenkamp; Prof.dr. D. Pevernagie, Universiteit Gent. Co-supervisor: Dr. S. Overeem, TUE.

Willem Buskermolen. If only I could tell ...; Measuring predictors for challenging behaviour in people with both intellectual disability and hearing impairment. Supervisor: Prof.dr. A. Aldenkamp. Cosupervisor: Dr. J. Hoekman, UL.

Kay Deckers. The role of lifestyle factors in primary prevention of dementia; an epidemiological perspective. Supervisor: Prof.dr. F. Verhey. Co-supervisor: Dr. M. van Boxtel; Dr. S. Köhler.

Brechje Dandachi-FitzGerald. Symptom validity in clinical assessments. Supervisors: Prof.dr. R. Ponds; Prof.dr. F. Verhey.

Maurice Theunissen. Understanding factors affecting postoperative Quality of Life. Supervisors: Prof.dr. M. Peters, Prof.dr. M. Marcus. Co-supervisor: Dr. H. Gramke. 
Anna Cleutjens. COgnitive-Pulmonary Disease? Neuropsychological functioning in patients with COPD. Supervisors: Prof.dr. E. Wouters, Prof.dr. R. Ponds. Co-supervisors: Dr. D. Janssen, Horn, Dr. J. Dijkstra. Laura Serpero. Next Generaton Biomarkers in Perinatal Medicine: S100B Protein. Supervisors: Prof.dr. D. Gazzalo, Alessandria, Italy; Prof.dr. B..W.W. Kramer. Co-supervisor: Dr. A.W.D. Gavilanes.

Alessandro Varrica. S100B Protein and Congential Heart Diseases: Brain Aspects. Supervisors: Prof.dr. D. Gazzalo, Alessandria, Italy; Prof.dr. J.S.H. Vles; Prof.dr. L.J.I. Zimmermann. Co-supervisor: Dr. A.W.D. Gavilanes.

Pim R.A. Heckman. Targeting phosphodiesterase type 4 for improving cognitive fronto- striatal function: a translational approach. Supervisor: Prof.dr. J.G. Ramaekers. Co- supervisors: Dr. J.H.H.J.. Prickaerts; Dr. A. Blokland.

Sven van Poucke. Platelets, form sample to big data; exploring granularity in platelet research. Supervisors: Prof.dr. M.A.E. Marcus; Prof.dr. W. Buhre. Co-supervisor: Dr. M. Lancé.

Désirée M.J. Vrijens. Dysfunctions of the Lower Urinary Tract and Affective Symptoms. Supervisors: Prof.dr. Ph.E.V. van Kerrebroeck; Prof.dr. G.A. van Koeveringe. Co- supervisors: Dr. C. Leue.

Tamar van Veenendaal. Neurotransmitters \& Networks. An MR view on epilepsy and antiepileptic drugs. Supervisors: Prof.dr.ir. W.H. Backes; Prof.dr. A.P. Aldenkamp. Co- supervisor: Dr. J.F.A. Jansen.

Evelien M. Barendse. Autism Spectrum Disorders in High functioning Adolescents; Diagnostic considerations (AHA). Supervisors: Prof.dr. A.P. Aldenkamp; Prof.dr. R.P.C. Kessels, Radboud University.

Roy Lardenoije. A venture into the epigenetics of aging and Alzheimer's Disease. Supervisors: Prof.dr. B.P.F. Rutten; Prof.dr. H.W.M. Steinbusch. Co-supervisors: Dr. D. van den Hove; Dr. C.A. Lemere, USA.

Charlotte L. Mentzel. The course recognition and treatment of movement disorders in severe mental illness. Supervisors: Prof.dr. P.N. van Harten; Prof.dr. M.A.J. de Koning-Tijssen, UMCG. Co-supervisor: Dr. P.R. Bakker.

Tim Batink. Third Wave Behaviour Therapy: Process Measures and Contextual Interventions. Supervisors: Prof.dr. F.P.M.L. Peeters; Prof.dr. J.J. van Os; Prof.dr. M.C. Wichers, UMC Groningen.

Kevin L.J. Rademakers. Detrusor Underactivity: From Theory To Clinical Assessment. Supervisors: Prof.dr. G.A. van Koeveringe; Prof.dr. Ph.E.V. van Kerrebroeck. Co-supervisor: Dr. M. Oelke.

Iris M.J. Lange. Should I stay or should I go ? Brain mechanisms underlying fear and safety learning, and explosure therapy outcome. Supervisors: Prof.dr. K.R.J. Schruers; Prof.dr. T.A.M.J. van Amelsfoort. Co-supervisor: Dr. L. Goossens.

Ruben G.F. Hendriksen. Evidence for a dystrophin-associated encephalopathy in Duchenne Muscular Dystrophy. Supervisor: Prof.dr. J.S.H. Vles. Co-supervisors: Dr. G. Hoogland; Dr. M.W. Aalbers, UMC Groningen.

Michael Gofeld. Strengths and limitations of the lumbar spine ultrasound-guided interventions. Supervisor: Prof.dr. M. van Kleef. Co-supervisor: Dr. M. Sommer. 
Willem A.R. Zwaans. Strategies for chronic inguinal pain. Supervisor: Prof.dr. M. van Kleef. Cosupervisors: Dr. R.H.M. Roumen; Dr. M.R.M. Scheltinga, MMC Veldhoven.

Linda M. Rolf. Mapping the effects of vitamin D in multiple sclerosis A 3D Perspective. Supervisor: Prof.dr. R.M.M. Hupperts. Co-supervisors: Dr. J.G.M.C. Damoiseaux; Dr. J.J.F.M. Smolders, CWZ Nijmegen.

Maarten van Beek. Spinal Cord Stimulation in Clinical and Experimental Painful Diabetic Polyneuropathy. Supervisors: Prof.dr. E.A. Joosten; Prof.dr. M. van Kleef. Co- supervisor: Dr. S.M.J. van Kuijk.

Melina Barkhuizen. Genetic and perinatal risk factors for movement disorders. Supervisors: prof.dr. B.W.W. Kramer, prof.dr. H.W.M. Steinbusch, Prof.dr. A.F. Grobler. Co- supervisor: dr. A.W.D.Gavilanes-Jimenez.

Renske Uiterwijk. Cognitive function and cerebral small vessel disease in hypertension. Supervisor: prof.dr. R.J. van Oostenbrugge. Co-supervisor: Dr. J.E.A. Staals.

Elles Douven. Depression and apathy after stroke. Supervisor: prof.dr. F.R.J. Verhey. Co- supervisors: Dr. P. Aalten, dr. J. Staals.

Mauro Pessia. Brain K+ Channels: from molecular and physiological features to autism spectrum disorder and intellectual disability. Supervisors: prof.dr. H.W.M. Steinbusch, prof.dr. M.B. Donati, It.

Carsten Leue. Hyperarousal in the Hospital and what to do about it: the MED-PSYCH- NET - a transitional network approach fostering personalized care in psychosomatic medicine. Supervisors: Prof.dr. J. van Os, Prof.dr. A. Masclee. Co-supervisors: Dr. J. Strik, Dr. J. Kruimel

Andrea S. Herrera Soto. Aminochrome, an endotoxin for inducing a new rat model of Parkinson's Disease. Supervisor: prof.dr. H.W.M. Steinbusch. Co-supervisors: Prof.dr. Juan Segura-Aquilar; prof. G. Diaz-Veliz, Santiago of Chile

Eline E.B. de Clerck. Ocular neurodegenerative changes and macular cysts in prediabetes and type 2 diabetes. Supervisors: Prof.dr. C.A.B. Webers, Prof.dr. C.D.A. Stehouwer. Co-supervisor: Dr. J.S.A.G. Schouten

Steven T.H. Honings. Exploring psychosis and multidirectional violence: a prospective study in the general population. Supervisor: Prof.dr. J. van Os. Co-supervisor: Dr. M. Drukker

2018

Sau May Wong. Advances in Microvasculair MRI Techniques: Breaking the Pathophysiological Barriers in Cerebral Small Vessel Disease. Supervisor: Prof.drir. W.H. Backes, Porf.dr. R.J. van Oostenbrugge. Co-supervisor: Dr. J.F.A. Jansen

Mark B.N. van Winkel. Lonely at heart and stressed in company of Others; the influence of daily life social experiences and emotions on depression. Supervisors: prof.dr. F. Peeters; prof.dr. I. MyinGermeys, KU Leuven/UM; prof.dr. M. Wichers, UMC Groningen 
Harsha Birur Laxmana Rao. Revisiting the vascular theory of glaucoma using optical coherence tomography angiography. Supervisors: prof.dr. C.A.B. Webers; prof.dr. R.N. Weinreb, University of California, San Diego

Babette L.R. Reijs. Cognitive correlates of cerebrospinal fluid biomarkers for Alzheimer's disease. Supervisor: prof.dr. F.R.J. Verhey. Co-supervisors: Dr. P.J. Visser; dr. I.H.G.B. Ramakers

Rachel Slangen. Spinal cord stimulation in painful diabetic peripheral Neuropathy. Clinical- and costeffectiveness. Supervisors: prof.dr. M. van Kleef; Prof.dr. C. Dirksen; prof.dr. C. Faber

Ganne Chaitanya. Epilepsy: A network disorder. Supervisors: prof.dr. A.P. Aldenkamp; prof. P. Satishchandra, NIMHANS, Bangalore, India. Co-supervisors: Dr. J.F.A. Jansen; Dr. S. Zinger, TUE

Sumitha Rajendrarao. New Insight into the Multifaceted Pathogenic Mechanisms of Sporadic Amyotrophic Lateral Sclerosis. Supervisors: prof.dr. B.W. Kamer; prof.dr. H.W. Steinbusch. Cosupervisor: prof. T.R. Raju, NIMHANS, Bangalore, India

Suzanne Roggeveen. Interference of mobile phone with electrophysiology and emotions; results from short-term experimental studies. Supervisor: Prof.dr. J. van Os. Co-supervisor: Dr. R. Lousberg.

Matthias Walter. Multi-methodological approaches to investigate lower urinary tract function in health and disease. Supervisors: Prof.dr. Ph.E.V.A. van Kerrebroek; Prof.dr. G.A. van Koeveringe; Prof.dr. A. Curt, Zürich, $\mathrm{CH}$.

Lalit Gupta. Inhomogeneities in spontaneous brain fluctuations. Supervisors: Prof.dr.ir. WH. Backes; Prof.dr. P.A.M. Hofman. Co-supervisor: Dr. J.F.A. Jansen.

Chaitra Jayadev. Impact of imaging the pediatric retina. Supervisor: Prof.dr. C.A.B. Webers. Cosupervisor: Dr. N.J.C. Bauer; Dr. A. Vinekar.

Annelie Klippel. Navigating through complexity; processes and mechanisms underlying the development of psychosis. Supervisors: Prof.dr. I. Myin-Germeys, KU-Leuven; Prof.dr. M.C. Wichers, UMC Groningen. Co-supervisor: Dr. U. Reininghaus.

Kürşat Altinbaş. Reconstructing The Diagnostic Framework of Bipolarity. Supervisor: Prof.dr. J. van Os. Co-supervisor: Dr. I.S. Gülöksüz.

Andrea J.R. Balthasar. Eyes of the needle; Spectral tissue sensing, an innovative technology for detecting various tissue types during percutaneous needle-based procedures in locoregional anesthesia and pain medicine. Supervisor: Prof.dr. M. van Kleef. Co-supervisor: Dr. G-J. van Geffen, Radboud UMC Nijmegen.

Walmari Pilz. Shedding light on oropharyngeal dysphagia in myotonic dystrophy type 1. Supervisor: Prof.dr. B. Kremer. Co-supervisors: Dr. L.W.J. Baijens; Dr. V. Lima Passos.

Nynke J. van den Hoogen. Repetitive painful procedures in the neonate: Treatment and adult pain sensitivity. Supervisors: Prof.dr. E.A.J. Joosten, Prof.dr. D. Tibboel, Erasmus MC-Sophia, Rotterdam. Co-supervisor: Dr. J. Patijn.

Carlota Mestres Gonzalvo. Medication optimisation; Methodological aspects and new strategies. Supervisors: Prof.dr. F.R.J. Verhey, Prof.dr. P.H.M. van der Kuy, Erasmus MC Rotterdam. Cosupervisors: Dr. R. Janknegt, Zuyderland MC. 
Carolin Hoffmann. The Brain under Attack: Autoantibodies in Psychotic Disorders. Supervisors: Prof.dr. P. Martinez, Prof.dr. B. Rutten, Prof.dr. J. van Os, UU/UM.

Jindra M. Bakker. On the bumpy road of happiness: Mechanisms of daily life reward processing and how it can be changed. Supervisors: Prof.dr. M. Wichers, UMC Groningen, Prof.dr. I. Myin-Germeys, KU Leuven/UM. Co-supervisor: Dr. L. Goossens.

Marasha-Fiona de Jong. Between mood and matter; studies on the interface between mood disorders and physical conditions. Supervisor: Prof.dr. F.P.M.L. Peeters. Co- supervisors: Prof.dr. Mischoulon.

Anouk Smeets. New insights in deep brain stimulation for Tourette syndrome. Supervisor: Prof.dr. Y. Temel. Co-supervisors: Dr. L. Ackermans, Dr. A.A. Duits, de. A.F.G. Leentjens.

Margaretha Skowron. Cisplatin resistance in urothelial carcinoma; Understanding and targeting inherent and acquired mechanisms. Supervisors: Prof.dr. G.A. van Koeveringe, Prof.dr. P. Albers, Heinrich-Heine Univ. Düsseldorf. Co-supervisors: Dr. J.G.H. van Roermund, Dr. A. Romano.

Thierry Mentzel. Capturing the cacophony of movement. Supervisors: Prof.dr. P.N. van Harten, Prof.dr. H.A.M. Daanen, VUA. Co-supervisor: Dr.mr. O.J.N. Bloemen, GGZ Hilversum/UM.

Petronella de Meij. Quality indicators for the assessment of pain clinic care: A step forward? Quality from professionals and pain patients' perspective (QiPPP). Supervisors: Prof.dr. G.D.E.M. van der Weijden, Prof.dr. M. v. Kleef. Co-supervisor: Dr. A.J.A. Köke.

Thomas Vaessen. Stress sensitivity in psychosis: assessment, mechanism \& intervention. Supervisor: Prof.dr. I. Myin-Germeys, KU Leuven/UM.

Yori van der Steen. Dissecting the psychosis continuum; risk factors along the pathway from experiences to disorder. Supervisor: Prof.dr. I. Myin-Germeys, KU Leuven/UM, Prof.dr. R. van Winkel, KU Leuven.

Aryo Zare. Unveiling the sensory connections between the bladder and the brain that involve the periaqueductal gray matter. Supervisor: Prof.dr. G.A. van Koeveringe; Co- supervisor: Dr. A. Jahanshahi. Magdalena Weidner. Brain serotonin throughout development - for better and for worse. Supervisors: Prof.dr. H.W.M. Steinbusch, Prof.dr. K.P. Lesch, JM.Univ. Würzburg. Co- supervisor: Dr. D.L.A. van den Hove.

Catherine Vossen. Cortical processing of pain; the role of habituation. Supervisors: Prof.dr. E.A. Joosten, Prof.dr. J. van Os, UU/UM. Co-supervisor: Dr. R. Lousberg.

Whitney Freeze. Microvascular contributions to dementia; Exploring the role of blood- brain barrier leakage in cerebral small vessel disease and Alzheimer disease. Supervisors: Prof.dr. F.R.J. Verhey, Prof.dr.ir. W.H. Backes. Co-supervisor: Dr. H.I.L. Jacobs.

Simone Schüller. Characterization of Stem and Immune Cell Ontogeny to Inform Prevention and Treatment of Infections in Preterm Newborns. Supervisors: Prof.dr. B.W.W. Kramer, Prof.dr.med. A. Berger, Wien. Co-supervisor: Dr. E. Villamor.

Michael J. Kemna. Predicting relapses in ANCA associated vasculitis. Supervisor: Prof.dr. J.W. Cohen Tervaert. Co-supervisors: Dr. J. Damoiseaux, Dr. P. van Paassen. 
Artemis latrou. Epigenetics in mental and neurodegenerative disorders. Supervisor: Prof.dr. B.P.F. Rutten. Co-supervisors: Dr. D.L.A. van den Hove, Dr. G. Kenis.

Laura Wielders. Prevention \& Treatment of Cystoid Macular Edema after Cataract Surgery. Supervisor: Prof.dr. R.M.M. Nuijts. Co-supervisors: Dr. J.S.A.G. Schouten, CWZ Nijmegen, Dr. B. Winkens.

Daisy Hoofwijk. The way to understanding Chronic Postsurgical Pain; From clinical and psychological predictors to incorporating genetics. Supervisor: Prof.dr. W.F.F.A. Buhre; Prof.dr. E.A.J. Joosten; CoSupervisor: dr. H.-F. Gramke; dr. A.A.A. Fiddelers.

Loes Leenen. Self-management in Epilepsy; The Goal is: "Live with a Z(s)mile. Supervisors: Prof.dr. H.J.M. Majoie; Prof.dr.mr. S.M.A.A. Evers; Prof.dr. C.M. van Heugten.

Chiara Peila. 'Effects of Pasteurization and Refrigerated Storage on Human Milk Neurobiomarkers Concentrations. Supervisors: Prof.dr. D. Gazzallo, Alessandria, It./MUMC+; Prof.dr. G. Visser, UU; Prof.dr. E. Bertino, Alessandria, It.

Raymond van de Berg. The Vestibular Implant: Feasibility in humans. Supervisor: Prof.dr. H. Kingma; Co-supervisor: dr. J.-P. Guyot, Université de Genève, $\mathrm{CH}$.

Nils Guinand. The Vestibular Implant: a more stable horizon for patients with a bilateral vestibular deficit? Supervisors: prof.dr. H. Kingma; Prof.dr. J.-P. Guyot, Université de Genève, $\mathrm{CH}$.

Jasper Smit. Exploring deep brain stimulation as a treatment for tinnitus. Supervisors: Prof.dr. R.J. Stokroos; Prof.dr. Y. Temel; Co-supervisor: dr. Jahanshahianvar.

Bindu Paravil Sankaran. Brain MRI in Mitochondrial Disorders: Correlating the Phenotype with Genotype. Supervisor: Prof.dr. H. Smeets; Prof.dr. A. Taly, NIMHANS, Bangalore, India.

Syenna Schievink. Vascular cognitive impairment; at the heart of the matter. Supervisor: Prof.dr. F.R.J. Verhey; Prof.dr. R.J. van Oostenbrugge; Co-supervisor: dr. S. Köhler.

Isabelle Bos. Biomarkers of Alzheimer's disease; relations with vascular factors and cognition in the pre-dementia stages. Supervisor: Dr. P.J. Visser; Prof.dr. F.R.J. Verhey; Co-supervisor: dr. S.J.B. Vos.

Stijn Michielse. Road work ahead; cerebral pathways mediating Psychological mechanisms underlying the psychosis spectrum. Supervisor: Prof.dr. J.J. van Os; Co- supervisor: dr. M.C. Marcelis.

Georgios Schoretsanitis. Risperidone-based therapeutic regimens; Drug interactions and adverse drug reactions. Supervisor: prof.dr. K.R.J. Schruers; Co-supervisor: dr. M. Bak .

Alieske Dam. INLIFE; An innovative online social support intervention for caregivers of persons with dementia. Supervisor: Prof.dr. M.E. de Vugt; Prof.dr. F.R.J. Verhey; Co- supervisor: Dr. M.P.J. van Boxtel.

Roel Haeren. Vascular ventures; Analysis of vascular structures and function in epilepsy. Supervisor: Prof.dr. Y Temel; Co-supervisor: dr. K. Rijkers; Dr. G. Hoogland.

Chiara Fabbri. Pharmacogenomics of antidepressant drugs: perspectives for the personalization of treatment in depression. Supervisors: Prof.dr. K. Schruers; Prof.dr. A. Serretti, Bologna. 
Esther van Duin. Dancing in the (B)rain'; neurobiology of reward, stress \& Information processing in 22q11.2 deletion syndrome. Supervisors: Prof.dr. T. van Amelsvoort; Prof.dr. J. Booij, UvA. Cosupervisor: dr. D. Hernaus.

Rob Verdonschot. Oropharyngeal dysphagia and its psychiatric Comorbidities; The prevalence of affective symptoms and the unmet clinical need for integrated care in medically unexplained symptoms. Supervisor: Prof.dr. B. Kremer; Co-supervisors; Dr. L. Baijens; dr. S. Vanbelle.

Lisanne Breuer. Accelerated Cognitive Ageing in Epilepsy' Does it Exists? Supervisors: Prof.dr. A. Aldenkamp; Prof.dr. P. Boon, UZ Gent; Co-supervisors: dr. A. de Louw, Kempenhaeghe, Heeze; dr.ir. S. Zinger, TUE.

Liselot Kerpershoek. Access to formal dementia care; A European perspective. Supervisors: Prof.dr. F. Verhey; Prof.dr. M. de Vugt; Prof. B. Woods, Bangor University, UK Co-supervisor: Dr. C. Wolfs.

Henrietta Steinhart. Same Same but Different; Psychological Interventions and how to Mind the Knowledge Practice Gap. Supervisor: Prof.dr. I. Myin-Germeys. Co-supervisor: Dr. U. Reininghaus.

Ulrich Mehnert. The management of urine storage dysfunction in the neurological patient. Supervisors: Prof.dr. G. van Koeveringe; Prof.dr. Ph.van Kerrebroeck; Prof.dr. S. Wachter, Antwerpen; Prof.dr E. Chartier-Kastler, Sorbonne, Paris.

Giovanne B. Diniz. Weaning-induced alterations on neuropeptidergic populations of the rat hypothalamus. Supervisors: Prof.dr. H. Steinbusch; Prof.dr. J. Bittencourt, ICB/USP, Brasil.

Rajani Ravindra Battu. Inherited Retinal Diseases: New Imaging and Molecular Genetics. Supervisor: Prof.dr. C.A.B. Webers. Co-supervisors:Dr. J.S.A.G. Schouten, CWZ; dr. T.T.J.M. Berendschot.

2019

Jans van Ool. Diagnostic and neuropsychiatric considerations in epilepsy and intellectual disability; Psychological perspectives. Supervisor: Prof.dr. A. Aldenkamp. Co-supervisors: Dr. J. Hendriksen; Dr. H. Schelhaas, Kempenhaeghe.

Eveline Janssen. Depression in the elderly: focus on high risk groups. Supervisors: Prof.dr. F. Verhey; Prof.dr. M. de Vugt. Co-supervisor: Dr. M. Schram.

Cécile Kicken. Extreme blood coagulation; investigating the influence of physiological extremes on thrombin generation and platelet activation. Supervisor: Prof.dr. W. Buhre Co-supervisors; Dr. B. de Laat; Dr. M. Lancé, Qatar.

Martinus van Eerd. Diagnosis and Interventional Pain Treatment of Cervical Facet Joint Pain. Supervisor: Prof.dr. M. van Kleef. Co-supervisor; Dr. J. Patijn, Eindhoven; Dr. M. Sommer.

Chenxing E. Zhang. Novel insights in the pathophysiology of cerebralsmall vessel disease - a study using advanced imaging techniques. Supervisors: Prof.dr. R.J. van Oostenbrugge; Prof.dr.ir. W.H. Backes; Co-supervisor: dr. J. Staals.

Ivo Eijkenboom. A zebrafish model of small-fiber neuropathy. Supervisors: Prof.dr. H.J.M. Smeets; Prof.dr. C.G. Faber; Co-supervisor: dr. J. Vanoevelen. 
Bianca de Greef. Small fiber neuropathy: from underlying conditions to treatment. Supervisor: Prof.dr. C.A. Faber; Co-supervisor: Dr. I.S.J. Merkies; Dr. J.G.J. Hoeijmakers.

Lotte Berk. MINDFULNESS AND AGING: Exploring Mechanisms and Interventions. Supervisors: Prof.dr. J. van Os; Prof.dr. M.W. de Vugt; Co-supervisor: dr. M.P.J. van Boxtel.

Mor Dickman. Practice patterns and outcomes of corneal transplantation. Supervisor: Prof.dr. R.M.M.A. Nuijts; Co-supervisors: Dr. T.J.M. Berendschot; dr. F.J.H.M. van den Biggelaar.

Thyagi Ponnamperuma. Mental Health Problems in Sri Lankan Adolescents Exposed to the Tsunami and Other Traumatic Events. Supervisor: Prof.dr. M.W. De Vries; Co-supervisor: Dr. N.A. Nicolson.

Robbert C. Maatman. Anterior cutaneous nerve entrapment syndrome (acnes): an analysis of various subtypes and alternative treatment modalities. Supervisor: Prof.dr. M. van Kleef; Co-supervisors: Dr. R.M.H. Roumen, dr. M.R.M. Scheltinga.

Mari Elshout. Neovascular Age-Related Macular Degeneration in the Era of Value-Based Health Care. Supervisor: Prof.dr. C.A.B. Webers; Co-supervisor: Dr. J.S.A.G. Schouten.

Jeroen Deenik. Thinking inside the box; Changing lifestyle to improve the health status of inpatients with severe mental illness. Supervisor: Prof.dr. P.N. Harten; Co-supervisors: Dr. D.E. Tenback; dr. I.J.M. Hendriksen.

Thomas Draak. Peripheral Neuropathy outcome measures Standardisation (PeriNomS) study part 3: Capturing the Patient's Voice. Supervisor: Prof.dr. C.G. Faber; Co-supervisor: Dr. I.S.J. Merkies.

Ana Luisa Gil Martínez. Neuroprotection in neurodegenerative processes associated with Parkinsonism and aging. Correlation between dopaminergic neuronal death and glial activation. Supervisor: Prof.dr. H.W.M. Steinbusch, Prof.dr. Maria-Trinidad Herrero Ezquerro, University of Murcia.

Bernice J.A. Gulpers. Anxiety in older adults; Correlates, comorbidities and prognosis with lifespan perspectives. Supervisor: Prof.dr. F.R.J. Verhey, Prof.dr. R.C. Oude Voshaar; Co-supervisor: Dr. S. Köhler.

Elke Devocht. Combining a cochlear implant and a hearing aid in opposite ears: The best of both worlds. Supervisor: prof.dr. H. Kingma; co- supervisor: dr. E.I.J. George.

Gillian Townend. Rett Syndrome: Recognising the Communication Challenges, Needs and Potential of Individuals Living with a Rare Disease. Supervisor: Prof.dr. L.M.G. Curfs; co- supervisor: Dr. P.B. Marschik, Med. University of Graz, Austria.

Takashi Koizumi. Genetic and neuroinflammatory components of familial and sporadic cerebral Small Vessel Disease. Supervisor: Prof.dr. H. Steinbusch,Prof.dr. T. Mizuno,Japan; co-supervisor: Dr. S. Foulquier

Muhammad Ali. Integrative network-based approaches for modelling Human disease. Supervisor: Prof.dr. J. Kleinjans; co-supervisor: Dr. D. van den Hove; Dr. E. Pishva.

Guillaume Durand. The adaptive side of psychopathy. Investigating adaptive characteristics associated with the psychopathic personality. Supervisor: Prof.dr. B. Rutten; co-supervisor: Dr J. Lobbestael. 
Darius C. Henatsch. Honey: A Novel Treatment in Chronic Ear Infections. Supervisor: Prof.dr. R.J. Stokroos; UMC Utrecht/UM; co-supervisor: Dr. J.J. Briedé.

Reinhilde J. Melles. Vaginal penetration: pain or pleasure? The role of fear and sexual arousal. Supervisor: Prof.dr. M.L. Peters; co-supervisor: Dr. M. ter Kuile, LUMC, Dr. M. Dewitte.

Raul Felipe Abella Antón. Cardiac Surgery Biochemical Monitoring in Congenital Heart Diseases Infants. Supervisors: Prof. dr. D. Gazzolo, Prof. dr. L.J.I. Zimmermann, Prof. dr. J.S.H. Vles, co-supervisor; Dr. A.W.D. Gavilanes.

Francesca M. Snoeijen-Schouwenaars. Diagnostic, neuropsychiatric and therapeutic considerations in epilepsy and intellectual disability - medical perspectives -. Supervisor: prof.dr. A.P. Aldenkamp, cosupervisors: Dr. H.J. Schelhaas, SEIN Zwolle; dr. J.G.M. Hendriksen, Kempenhaeghe, Heeze

Mariëlle H.J. Pruppers. Peripheral Neuropathies: Standardizing Functional Assessment. Supervisors: prof.dr. C.G. Faber; prof.dr. N.C. Notermans, UU;Dr. I.S.J. Merkies, ius promovendi. 